UNITED STATES

DEPARTMENT OF THE INTERIOR

GEOLOGICAL SURVEY

WATER-QUALITY DATA FOR THE SOUTHERN UTE INDIAN RESERVATION, SOUTHWESTERN COLORADO

By E. Carter Hutchinson and Robert E. Brogden

U.S. GEOLOGICAL SURVEY

Open-File Report 76-16

Prepared in cooperation with the SOUTHERN UTE TRIBAL COUNCIL, the FOUR CORNERS REGIONAL PLANNING COMMISSION, and the

U.S. BUREAU OF INDIAN AFFAIRS

Lakewood, Colorado

December 1976 
Metric conversion factor. . . . . . . . . . . . . . . . . . . . . IV

Mandatory and recommended limits for dissolved constituents in

drinking water. . . . . . . . . . . . . . . . . . . IV

Abstract. . . . . . . . . . . . . . . . . . . . . . 1

Introduction. . . . . . . . . . . . . . . . . . . . . . . 1

Purpose. . . . . . . . . . . . . . . . . . . . . . 1

Scope. . . . . . . . . . . . . . . . . . . . . 3

Acknowledgments. . . . . . . . . . . . . . . . . 3

Relation of data to drinking-water standards. . . . . . . . . . . . . . . 3

System of well numbering. . . . . . . . . . . . . . . . . . . . . 4 4

Selected references......................... 6

\section{ILLUSTRATIONS}

[Plates are in pocket]

Plate 1. Map showing locations of ground-water and surface-water sampling sites, eastern one-half of the Southern Ute Indian Reservation, southwestern Colorado.

2. Map showing locations of ground-water and surface-water sampling sites, western one-half of the Southern Ute Indian Reservation, southwestern Colorado.

Figure 1. Map showing location of Southern Ute Indian Reservation, southwestern Colorado. . . . . . . . . . . . . . . . . . 2

2. Diagram showing system of numbering wells. . . . . . . . . 5

\section{TABLES}

Table 1. Chemical analyses of ground-water samples. . . . . . . . . . 7

2. Chemical analyses of surface-water samples . . . . . . . . . 31 
For the use of those readers who may prefer to use metric units rather than English units, the conversion factor for the term used in this report is given below:

$\begin{array}{ccc}\text { Multiply English unit } & \text { By } & \text { To obtain metric unit } \\ \text { miles } & 1.609 & \text { kilometers }\end{array}$

MANDATORY AND RECOMMENDED LIMITS FOR DISSOLVED CONSTITUENTS IN DRINKING WATER

[Adapted from the Colorado Department of Health, 1971, and the U.S. Public Health Service, 1962]

\begin{tabular}{|c|c|c|c|c|c|c|c|}
\hline \multirow{2}{*}{\multicolumn{6}{|c|}{ Constituent }} & \multicolumn{2}{|c|}{ Concentration, in } \\
\hline & & & & & & $\begin{array}{c}\text { milligrams } \\
\text { per liter }\end{array}$ & $\begin{array}{r}\text { micrograms } \\
\text { per liter }\end{array}$ \\
\hline \multicolumn{8}{|l|}{ Recommended limits: } \\
\hline 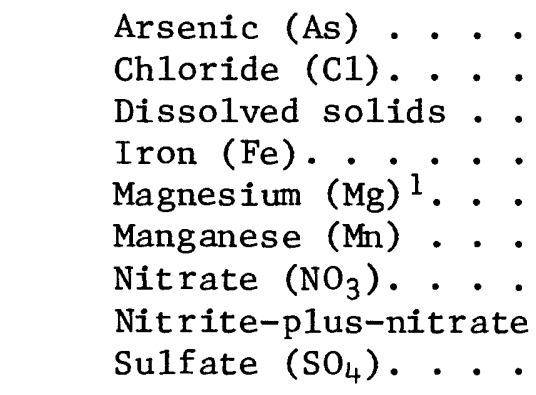 & $\begin{array}{l}\dot{\cdot} \\
\dot{\cdot} \\
\dot{\cdot} \\
\dot{\cdot} \\
\text { as } \\
\text {. }\end{array}$ & 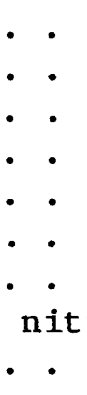 & 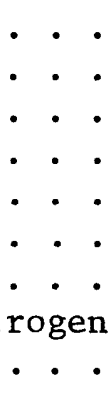 & 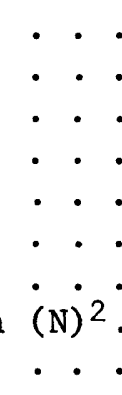 & 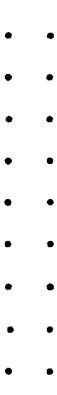 & $\begin{array}{l}0.01 \\
250 \\
500 \\
125^{.30} \\
45^{.05} \\
10 \\
250\end{array}$ & 300 \\
\hline \multicolumn{8}{|l|}{ Mandatory 1imits: } \\
\hline $\begin{array}{l}\text { Arsenic (As).... } \\
\text { Fluoride (F1). } . . \cdot \\
\text { Selenium (Se). } . .\end{array}$ & $\begin{array}{l}\dot{\cdot} \\
\dot{\cdot}\end{array}$ & $\begin{array}{l}\cdot \cdot \\
\cdot \dot{ } \\
\cdot\end{array}$ & 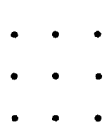 & $\begin{array}{l}\cdot \cdot \cdot \\
\cdot \dot{\cdot} \\
\cdot \\
\cdot\end{array}$ & $\begin{array}{l}\cdot \cdot \\
\cdot \cdot \\
\cdot\end{array}$ & $\begin{array}{l}.05 \\
1.3 \\
.01\end{array}$ & 50 \\
\hline
\end{tabular}

${ }^{1}$ Colorado Department of Health only.

${ }^{2}$ U.S. Public Health Service only. 


\title{
WATER-QUALITY DATA FOR THE SOUTHERN UTE INDIAN RESERVATION, SOUTHWESTERN COLORADO
}

By E. Carter Hutchinson and Robert E. Brogden

\begin{abstract}
This report contains basic water-quality data from a study by the U.S. Geological Survey on the Southern Ute Indian Reservation in southwestern Colorado. Data collected during 1973-76 from 338 ground-water and surface-water samples are presented in two tables. All of the samples were analyzed for major cations and anions, and selenium and arsenic. Data presented in the tables are keyed by numbers to maps showing the locations of the sampling sites. Many of the samples contained arsenic, chloride, dissolved solids, fluoride, iron, magnesium, manganese, nitrate, nitrite-plus-nitrate as nitrogen, selenium, and sulfate in concentrations exceeding recommended or mandatory standards for drinking water established by the Colorado Department of Health and the U.S. Public Health Service.
\end{abstract}

\section{INTRODUCTION}

Information on the chemical quality of ground water and surface water on the Southern Ute Indian Reservation (fig. 1) is presented in this report. The basic data were collected by the U.S. Geological Survey from 1973 through 1976. The investigation was conducted in cooperation with the Southern Ute Tribal Council, the Four Corners Regional Planning Commission, and the U.S. Bureau of Indian Affairs.

\section{Purpose}

The purpose of the investigation was to inventory the chemical characteristics of shallow ground water and surface water on the reservation. Information presented in the water-quality tables can provide present well owners and future water users with data on the chemical characteristics of shallow ground water and streams on the reservation. The information will allow the Tribal Council to better plan their future land use and will assist in determining the suitability of the resource for developing water supplies for municipa1, domestic, and agricultura1 uses. 


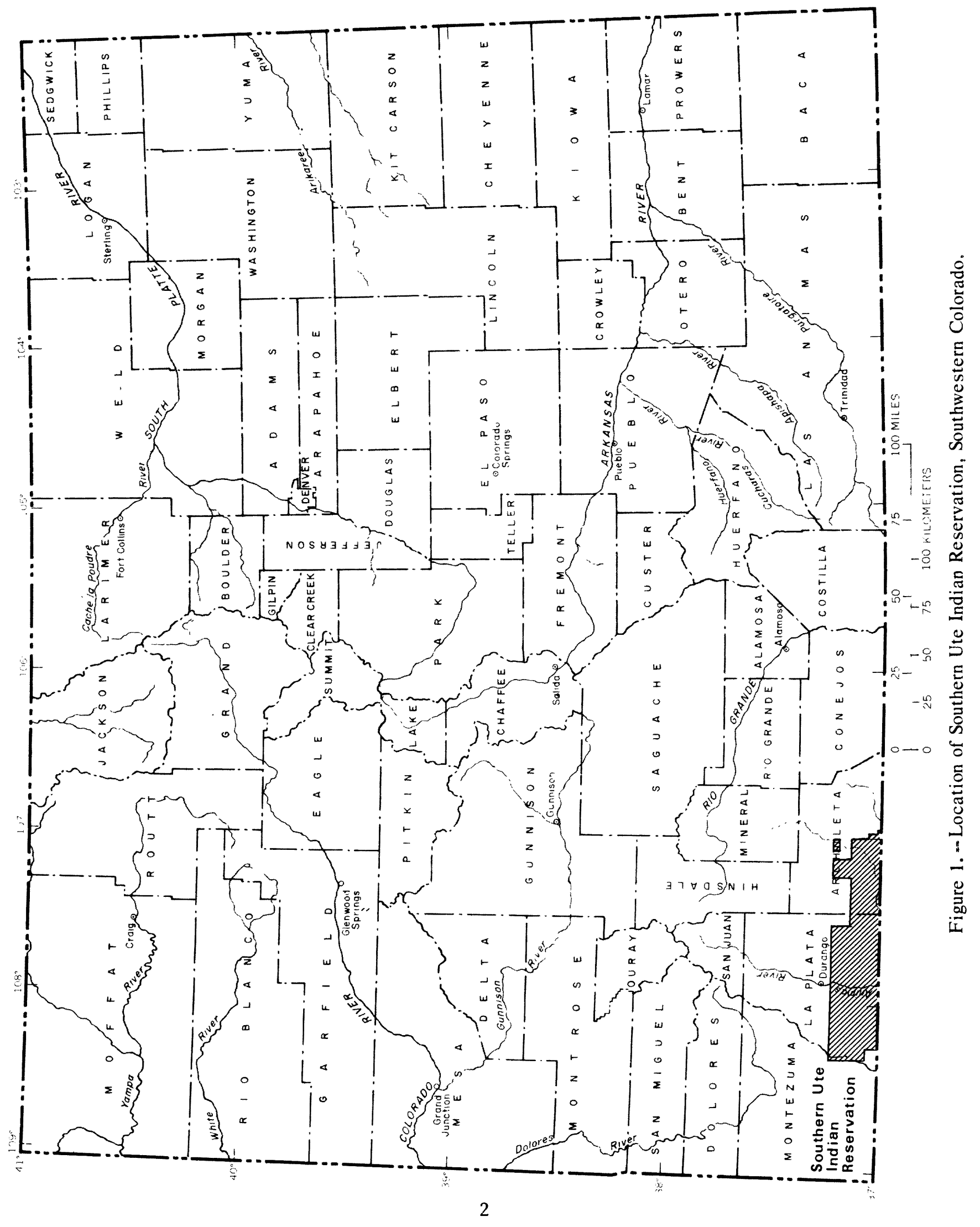




\section{Scope}

A11 338 samples collected during the 4-year study were analyzed for major anions, major cations, selenium, and arsenic. Water-quality data in this report are presented in two tables, and are keyed by numbers to site locations on plates 1 and 2. Analyses of ground-water samples, including springs, are summarized in table 1 at the back of the report. Analyses of surface-water samples collected from streams on the reservation are summarized in table 2 at the back of the report.

\section{Acknowledgments}

The authors express their appreciation to Mr. Leonard Burch, chairman of the Southern Ute Tribal Council, and to Mr. Chris A. Baker, vice chairman, for providing hydrologic field assistants who aided U.S. Geological Survey personnel in the collection of basic data. Throughout the 4-year investigation, under the general guidance and assistance of $\mathrm{Mr}$. John Williams, who represented the Southern Ute Tribal Council, Messrs. Everett Burch, Roderick Williams, Ivan Red, Elliott Cloud, and Raymond Frost helped obtain well data and sample wells. Their linguistic abilities in English, Ute, and Spanish proved to be of great assistance in discussing the investigation with the many land owners. Messrs. Raymond DeKay, Robert Tsiosdia, and officials and employees of the U.S. Bureau of Indian Affairs at Ignacio, Colo., and Albuquerque, N. Mex., provided administrative support during the investigation; laboratory support was provided by personnel at Gallup, N. Mex.

\section{RELATION OF DATA TO DRINKING-WATER STANDARDS}

The potability of ground water and surface water on the reservation can be determined by comparing the chemical data in tables 1 and 2 with the recommended drinking-water-quality standards of the Colorado Department of Health (1971) and the U.S. Public Health Service (1962) presented on page IV at the front of the report and immediately below the column headings in tables 1 and 2. Many of the analyses indicated that some chemical constituents occur in excess of the standards. Although the concentrations of some constituents exceed the standards, they do not necessarily indicate a health hazard. For example, high dissolved-solids concentrations may impart a noticeable taste to the water supply. High iron and manganese concentrations may cause coloring of utensils and fixtures and impart a disagreeable taste to water. High fluoride concentrations can cause permanent discoloration and mottling of children's teeth. However, in proper concentrations, fluoride can prevent tooth decay. Magnesium and sulfate concentrations in excess of the standards may have a laxative effect on people.

Concentrations of selenium, arsenic, nitrate, and nitrite-plus-nitrate as nitrogen in excess of the standards can constitute a health hazard (Colorado Department of Health, 1971, and U.S. Public Health Service, 1962). Selenium 
was determined to occur as much as 1,300 times the recommended 1imit, and arsenic was observed to occur as much as 6 times the recommended 1imit. Indications of selenium poisoning include nervousness, vomiting, loss of hair and fingernails, and hypertension. High selenium concentrations in plants and water have reportedly caused poisoning of humans and livestock on the reservation (Beath, 1962). Symptoms of arsenic poisoning include fatigue and loss of energy. Standard treatment processes of public water supplies have little or no effect on removing selenium and arsenic. The locations of water samples that contain selenium and arsenic in excess of recommended standards are shown on plates 1 and 2 .

Nitrate and nitrite-plus-nitrate as nitrogen in excess of the standards has been determined locally throughout the reservation. Newborn infants can be affected by high nitrate or nitrite-plus-nitrate as nitrogen concentrations in drinking water and milk, resulting in a condition known as "blue babies." older children and adults are usually not affected by high nitrate or nitriteplus-nitrate as nitrogen concentrations. Standard treatment processes of public water supplies have no effect on the removal of nitrate and nitrite-plusnitrate as nitrogen from drinking water.

Individuals with water supplies that contain selenium, arsenic, nitrate, and nitrite-plus-nitrate as nitrogen in excess of health limits need to consider another source of drinking water. Sampling water from newly drilled wells and analyzing the water will indicate whether or not the water is suitable for drinking. If the constituents mentioned above are found to occur in excess of the recommended concentrations, an alternative source of water needs to be considered.

\section{SYSTEM OF WELL NUMBERING}

The we11 numbers in tables 1 and 2 indicate the we11 locations as shown on plates 1 and 2. The numbers are based on the U.S. Bureau of Land Management system of land subdivision, and show the location of the well by quadrant, township, range, section, and position within the section. A graphic illustration of this method of well location is shown in figure 2 . The first letter " $N$ " preceding the location number means that the site is located in the area governed by the New Mexico principal meridian. The second letter indicates that quadrant in which the well is located. Four quadrants are formed by the intersection of the base line and the principal meridian--A indicates the northeast quadrant, $B$ the northwest, $C$ the southwest, and $D$ the southeast. The first three-digit numeral indicates the township, the second three-digit numeral the range, and the third two-digit numeral the section in which the we11 is located. The letters following the section number locate the well within the section. The first letter denotes the quarter section, the second the quarter-quarter section, and the third the quarter-quarter-quarter section. The letters are assigned within the section in a counter-clockwise direction, beginning with (A) in the northeast quarter. Letters are assigned within each quarter section and within each quarter-quarter section in the 


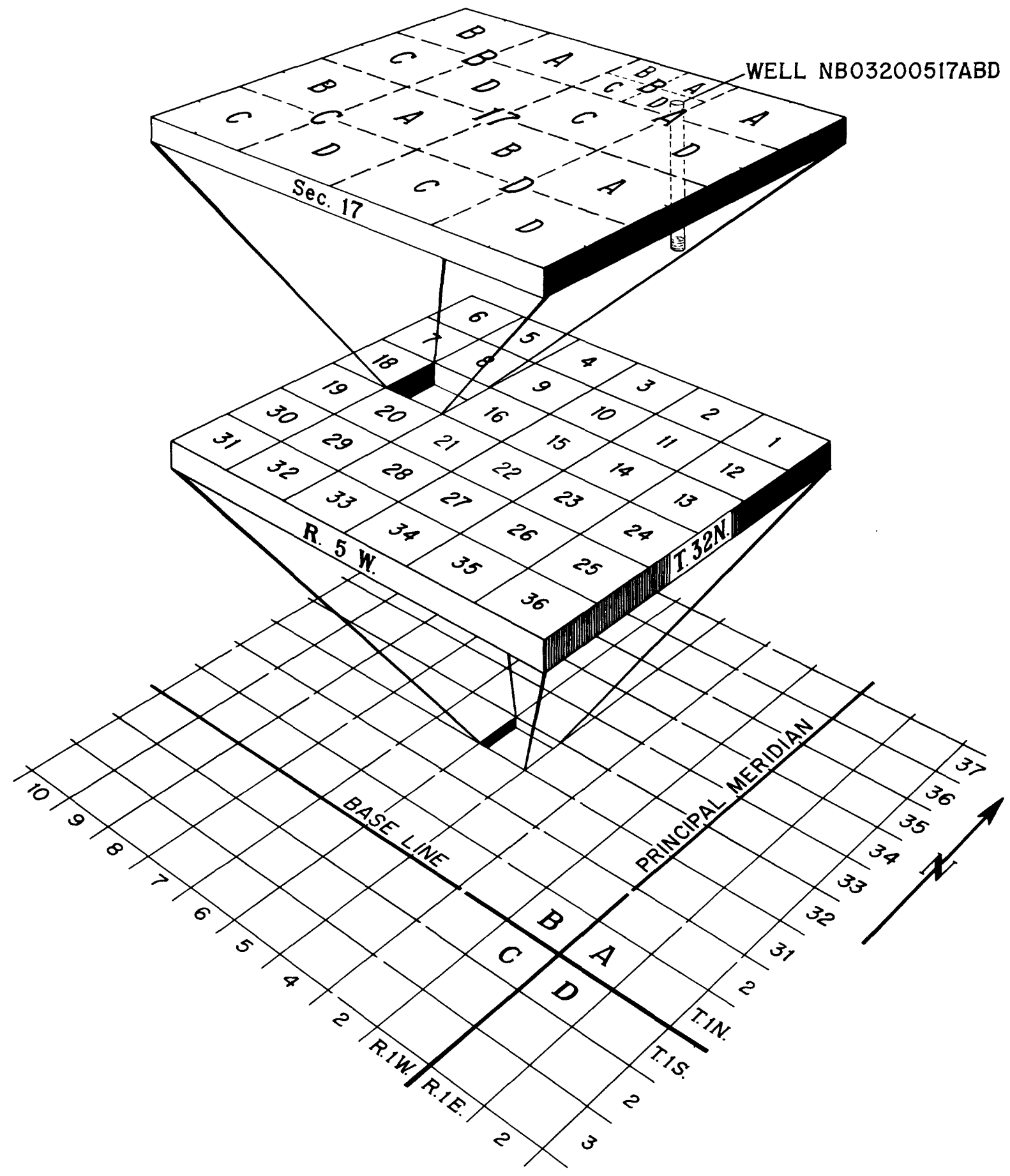

Figure 2. --System of numbering wells. 
same manner. Where two or more locations are within the smallest subdivision, consecutive numbers beginning with 1 are added to the order in which the wells were inventoried. For example, NB03200517ABD indicates a well in the southeast quarter of the northwest quarter of the northeast quarter of sec. 17, T. 32 N., R. 5 W.; the "B" indicates the township is north of the baseline and that the range is west of the New Mexico principal meridian.

\section{SELECTED REFERENCES}

Beath, 0. A., 1962, Selenium poisons Indians: Sci. News Letter, no. 81, p. 254 .

Colorado Department of Hea1th, 1971, Colorado drinking water supplies, February 1971--Chemical quality: Denver, $42 \mathrm{p}$.

Haynes, D. D., Voge1, J. D., and Wyant, D. G., 1972, Geology, structure, and uranium deposits of the Cortez quadrangle, Colorado: U.S. Geo1. Survey Misc. Geol. Inv. Map I-629.

Shoemaker, J. W., and Holt, R. D., 1973, Coal resources of Southern Ute and Ute Mountain Ute Indian Reservations, Colorado and New Mexico: New Mexico Bur. Mines and Mineral Resources Circ. 134, 22 p.

Steven, T. A., Lipman, P. W., Hail, W. J., Jr., Barker, Fred, and Luedke, R. G., 1974, Geologic map of the Durango quadrangle, southwestern Colorado: U.S. Geo1. Survey Misc. Geol. Inv. Map I-764.

U.S. Environmental Protection Agency, 1973, Water quality criteria, 1972: Washington, U.S. Govt. Printing Office, 695 p.

U.S. Public Health Service, 1962, Drinking water standards, 1962: U.S. Pub1ic Health Service Pub. 956, 61 p. 

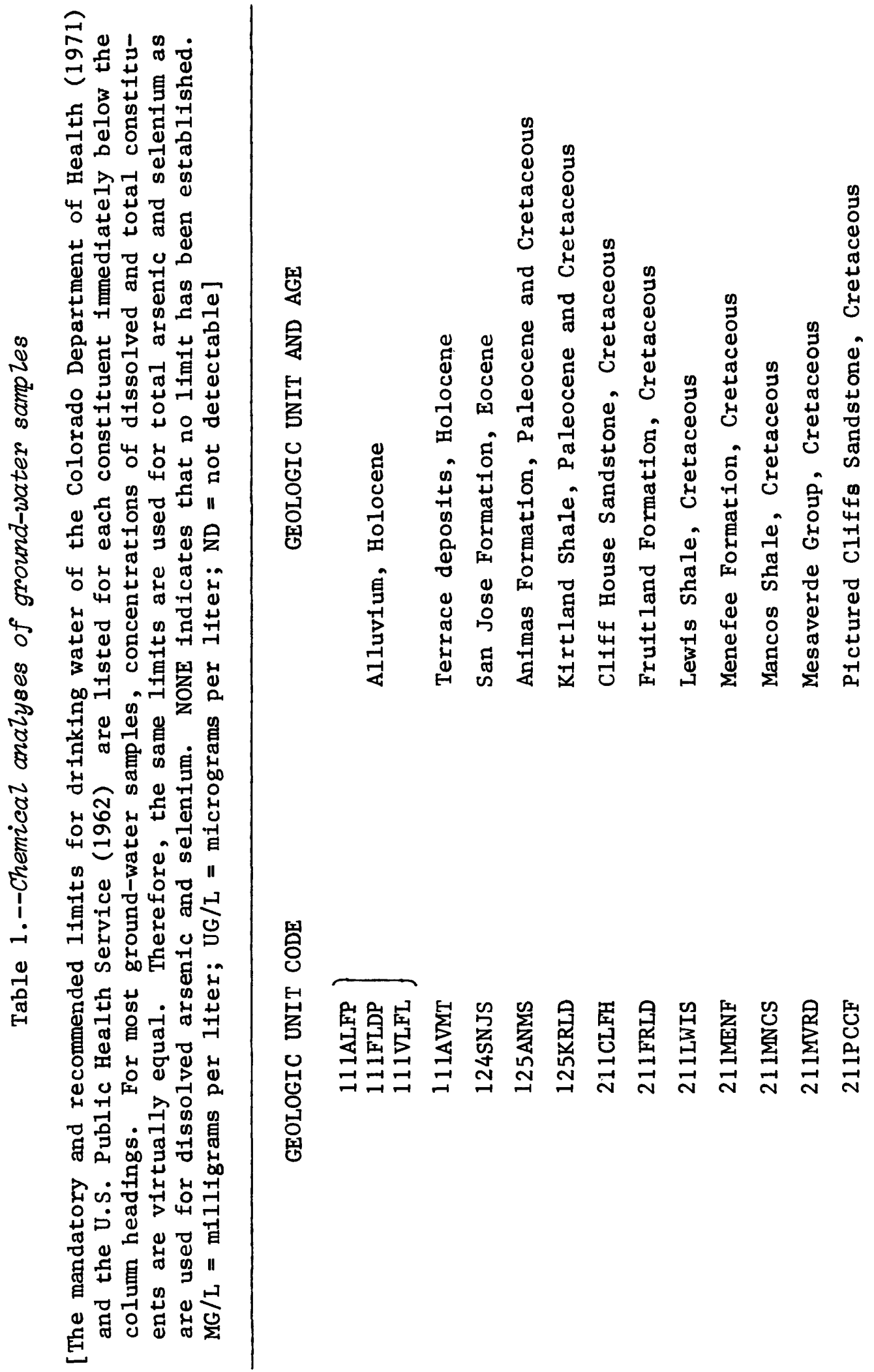

봉

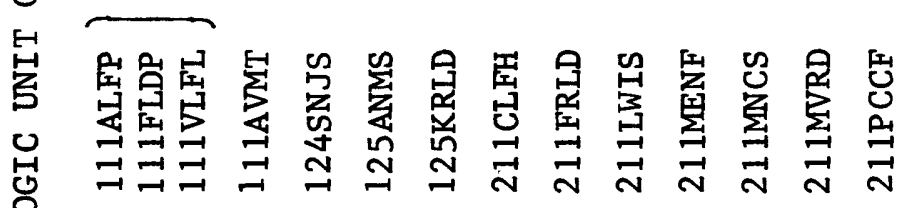
엉 


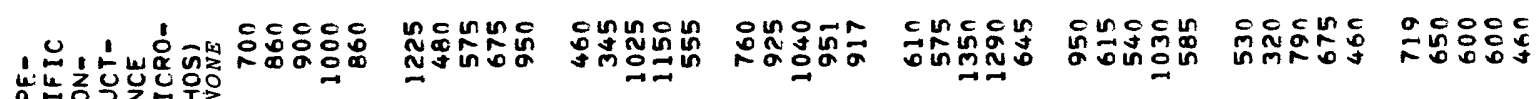

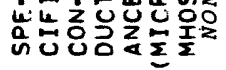

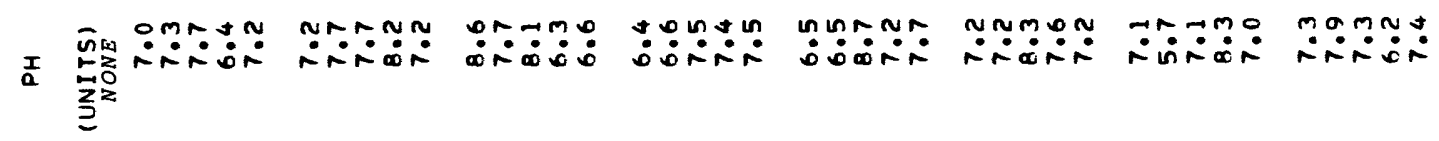

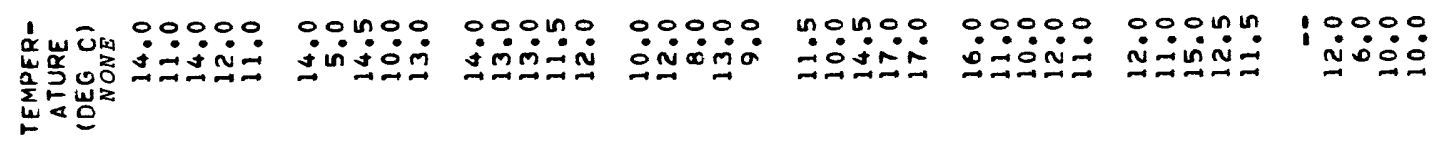

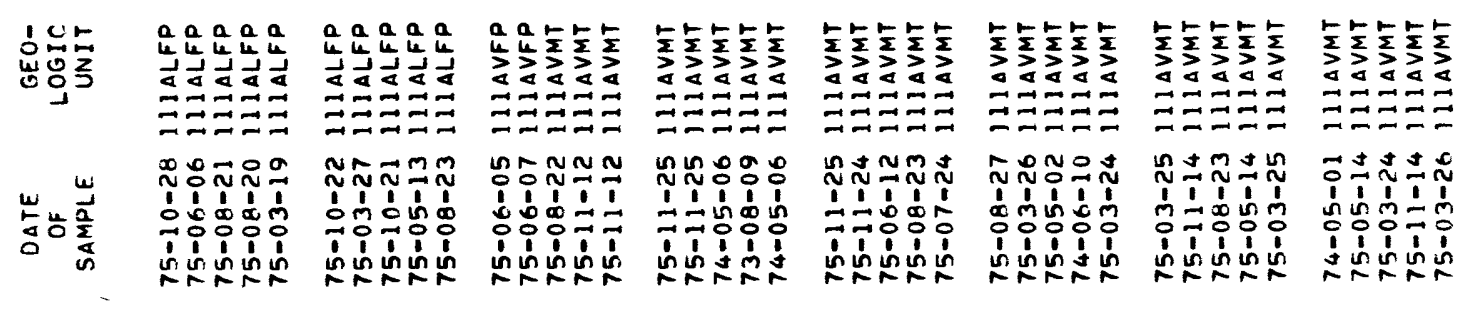

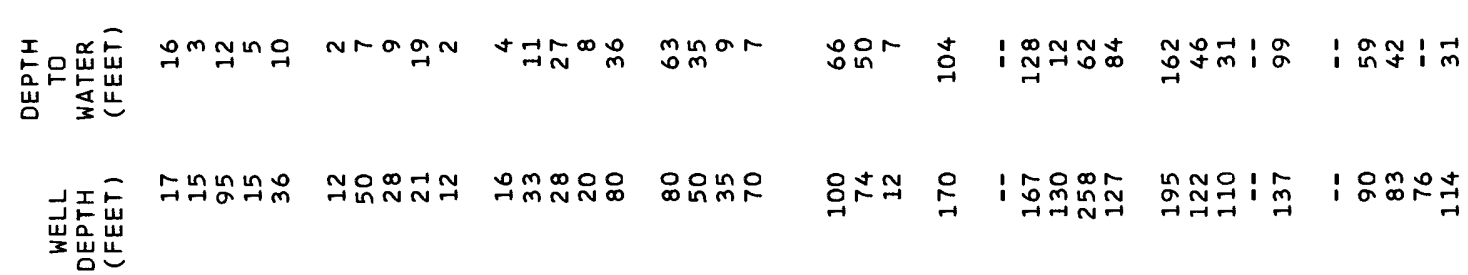

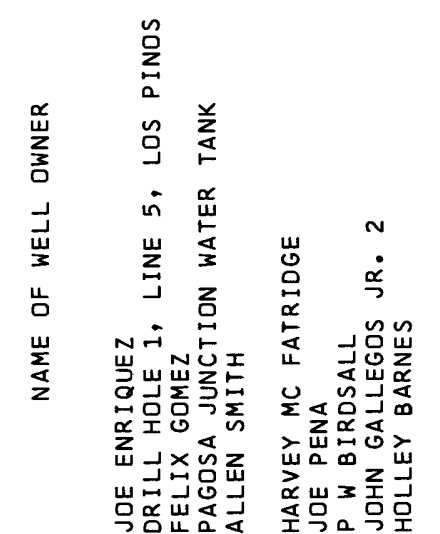

虽哭

Nar -1

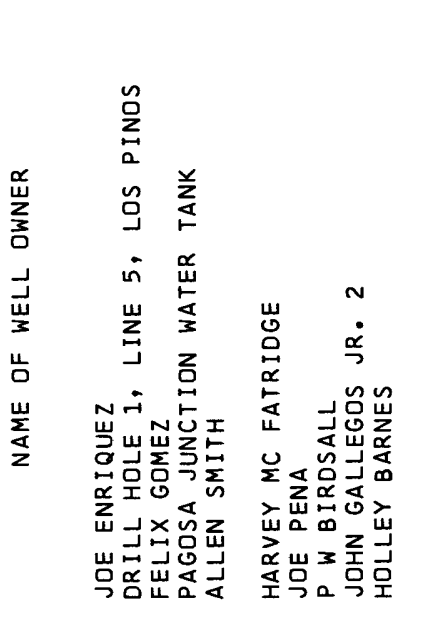

甹骂

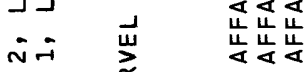

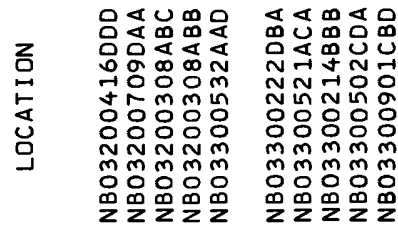

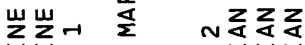

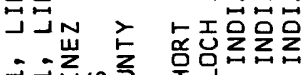

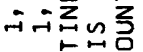

山w $\alpha$

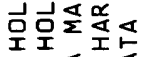

声势㟧

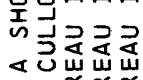

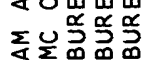

我吅㧧凹

Jxinin

話矛罢品

ज得方门

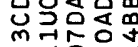

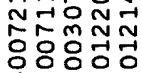

鱼选遇

pou

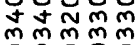

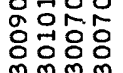

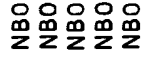

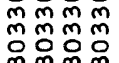

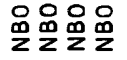

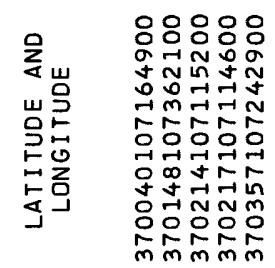

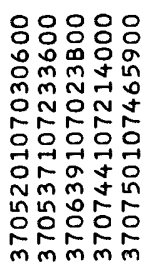

응융응

응응

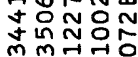

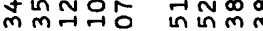

作

구요

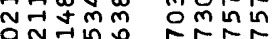

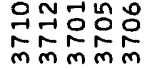

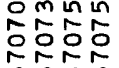

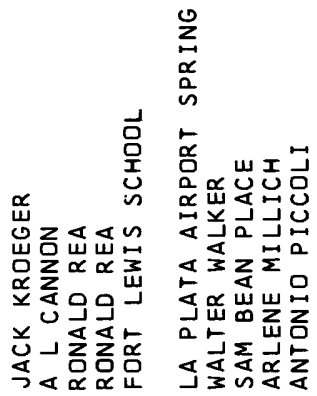

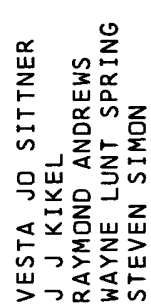

$\cong$

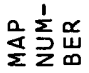

rnmon

or $\infty$ 욱

$\exists \approx \cong \pm 0$

어ㅁㅓㅕㅇㅝ

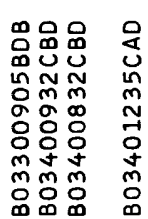

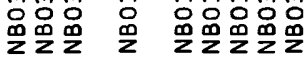

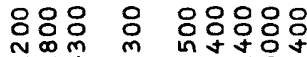

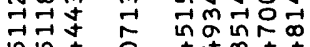

55

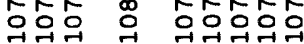

군

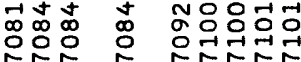

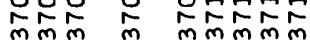

ํㅗNNำ Nํำกั

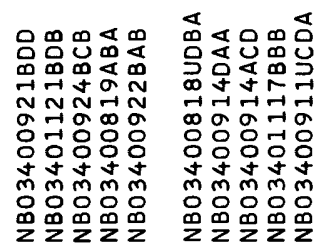

ㅇ๐ㅇㅇㅇ ㅇㅇㅇㅇ ñ

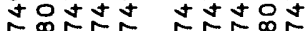
oooo o toooo ने 的少

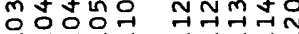

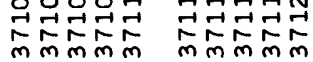

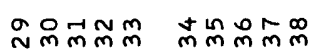




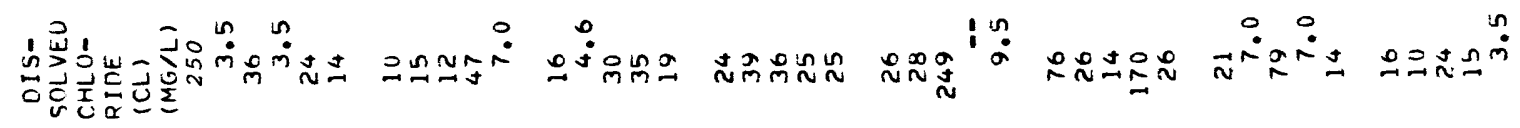

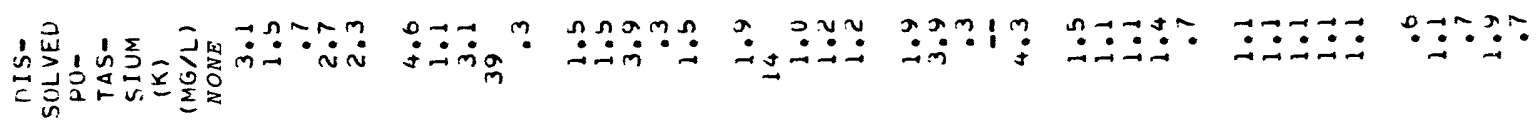

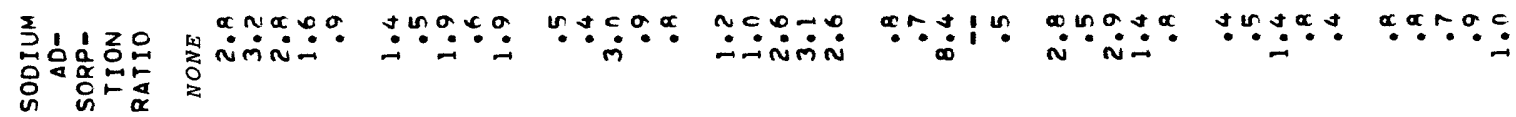

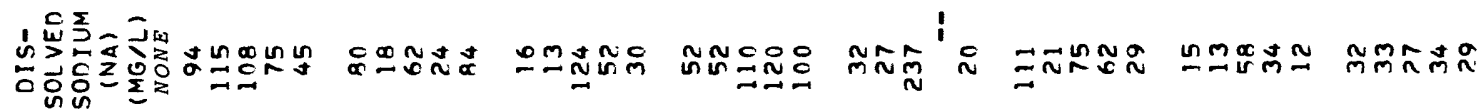

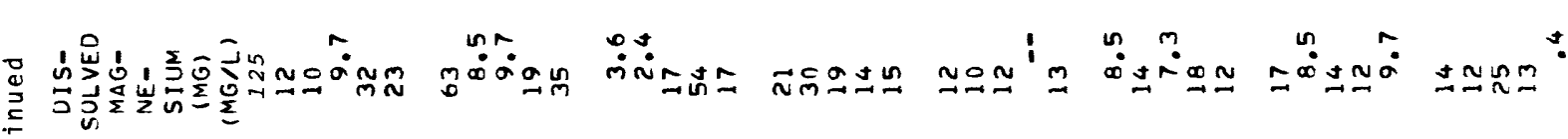

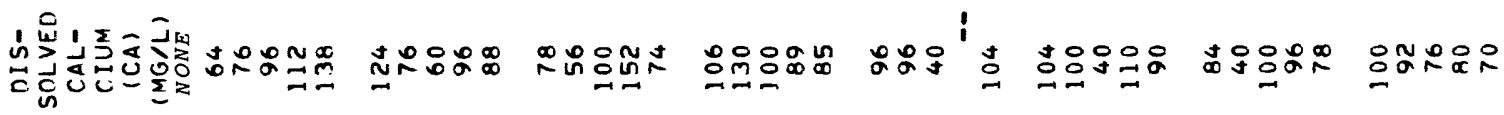

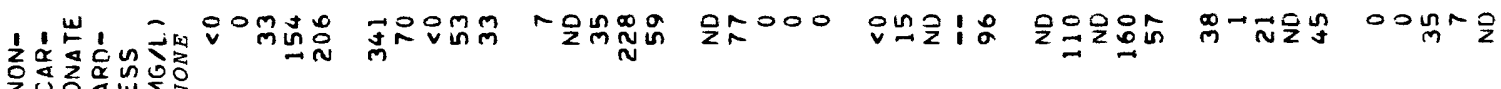

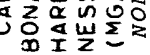

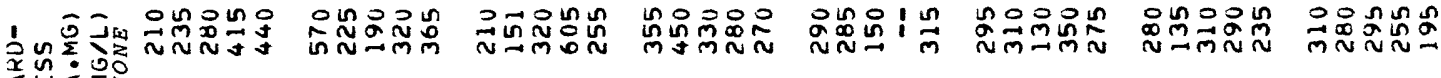

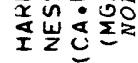

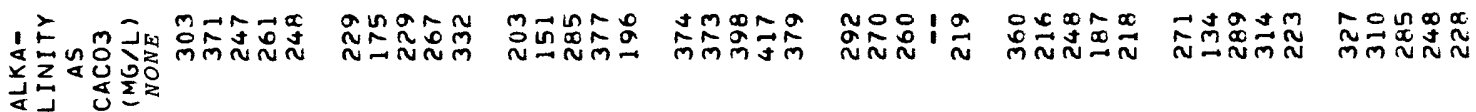

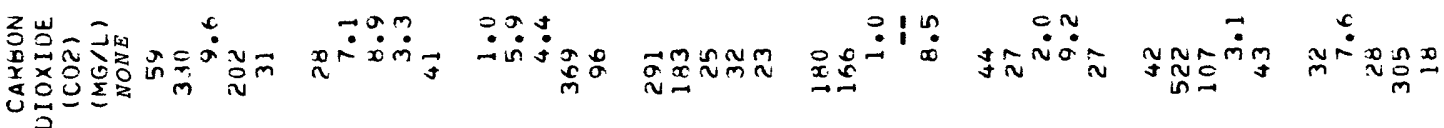

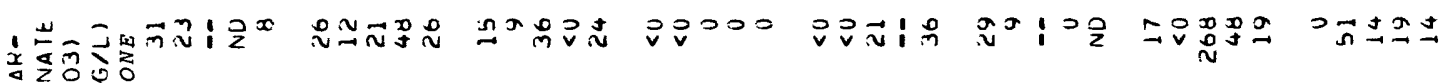
过是它是

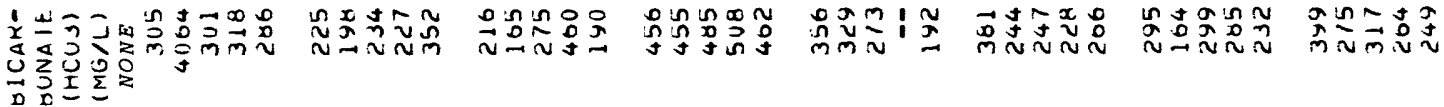

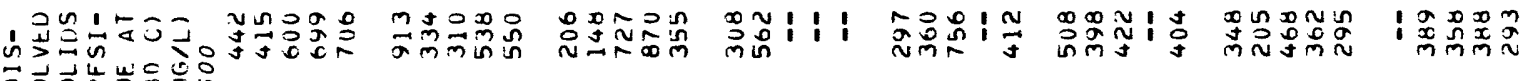

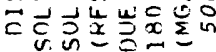

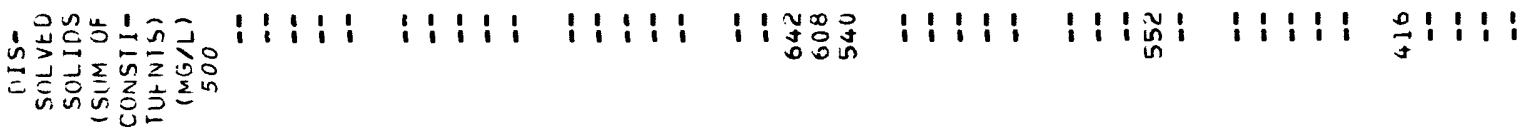

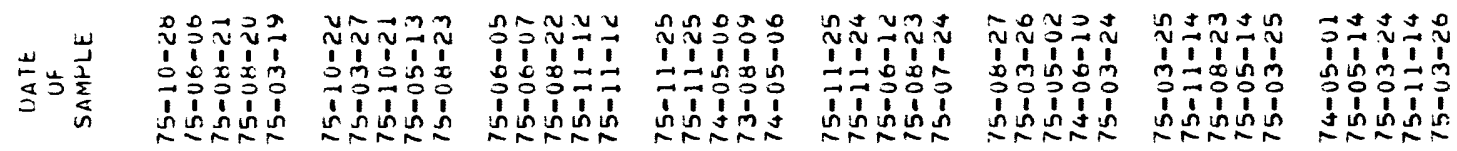




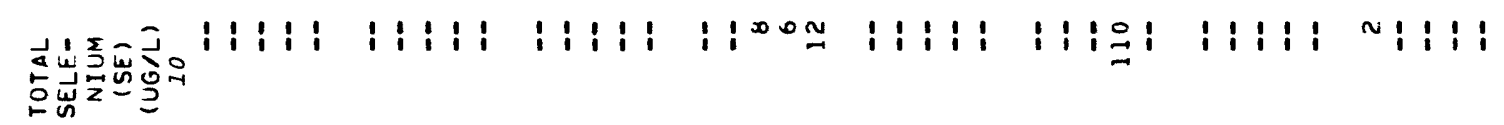

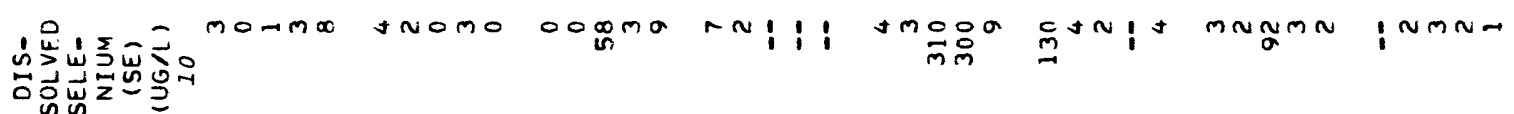

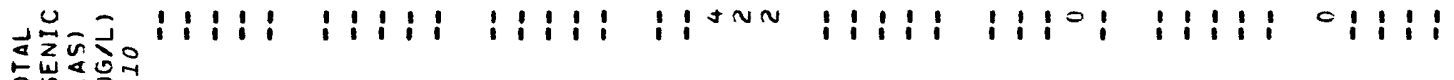

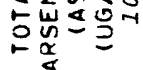

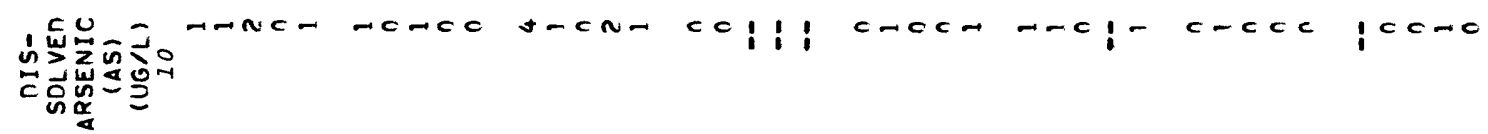

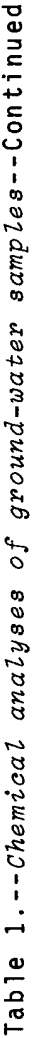

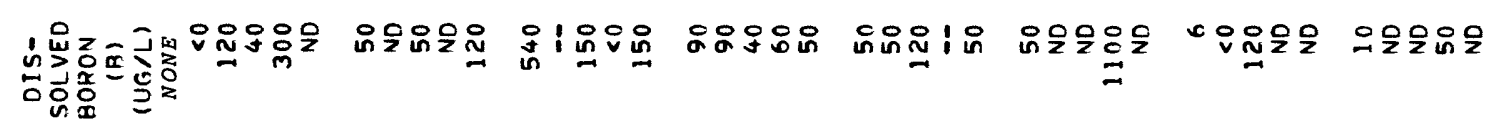

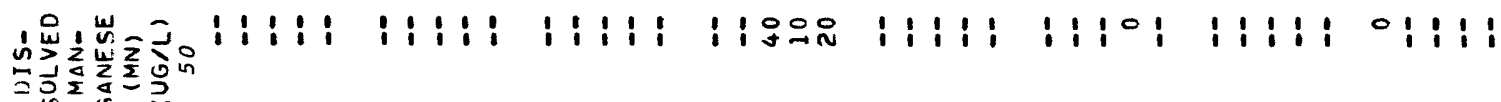

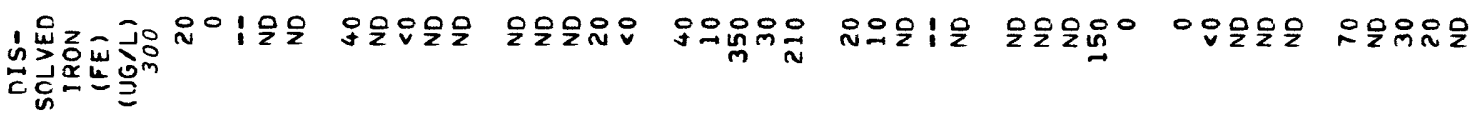

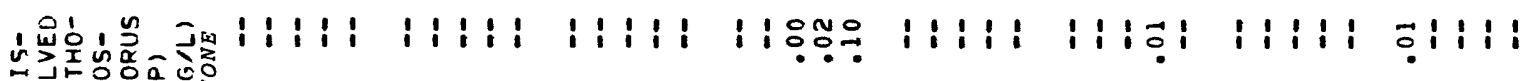
o

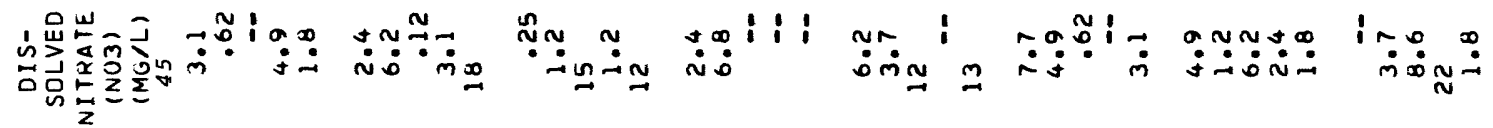

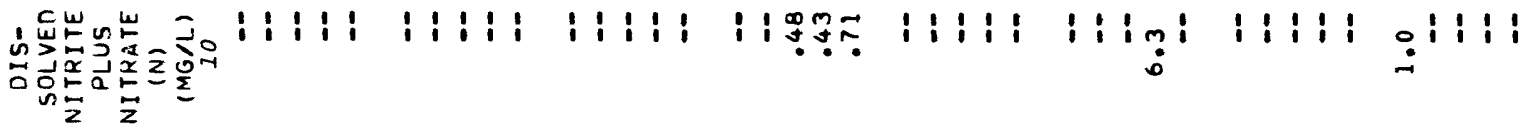

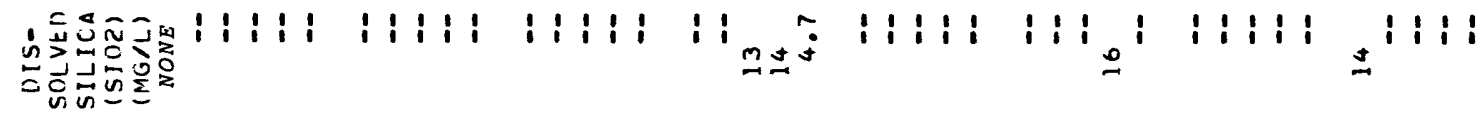

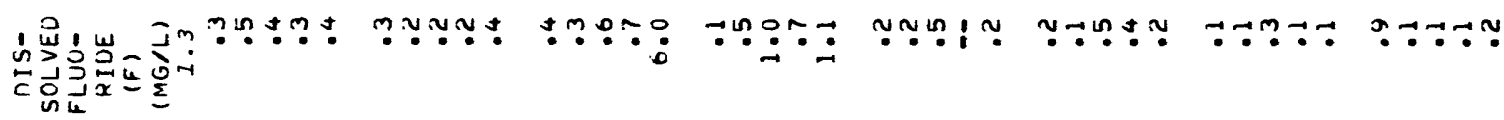

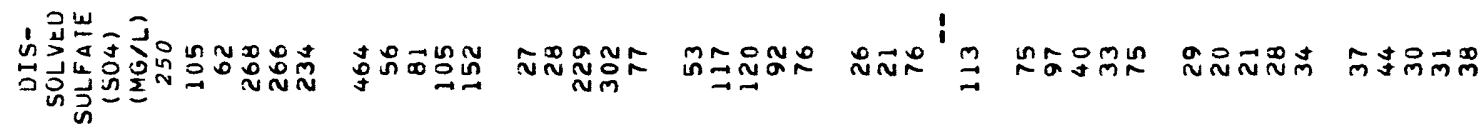

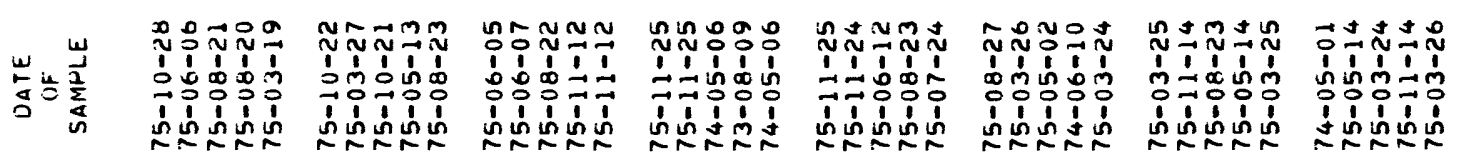




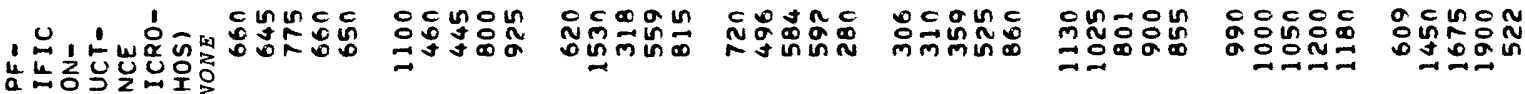

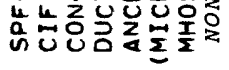

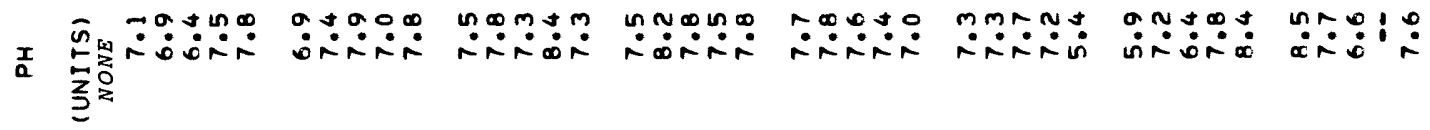

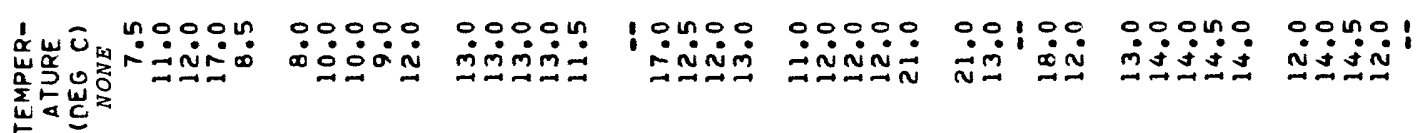

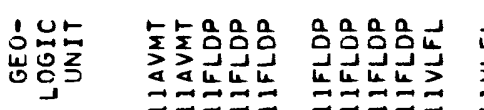

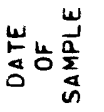

กํํํㅇํㅇ

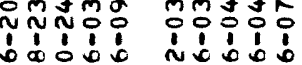

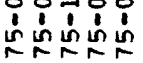

binisi

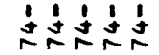

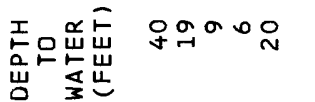

$\stackrel{\infty}{+}+m m N$

anm:

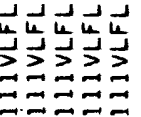

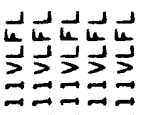

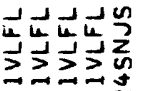

$\Xi \Xi \Xi \Xi さ$

츠ํํ오

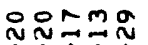

ํํำกำ

b’

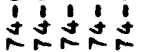

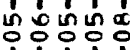

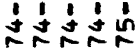

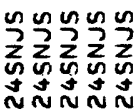

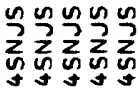

जัNNئ

I- - ․

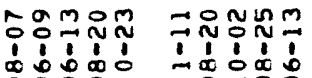

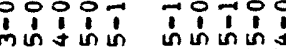

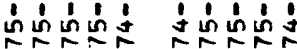

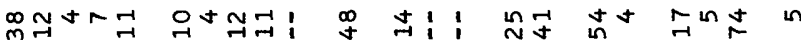

qำ엇

유ำ-

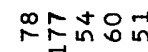

$\ln \sin \sin 8$

บำกำ

$\stackrel{ }{\sim}$ 욝 岂䍃出

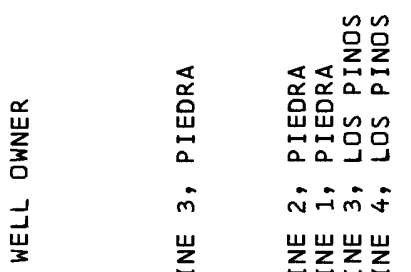

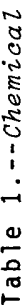

茄

$\frac{w}{2}$

㺼

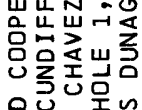

원돈

出出品䍃

$\infty\lrcorner$

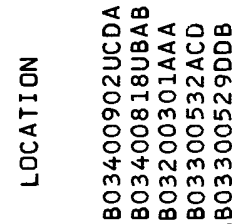

コココ

जテベ

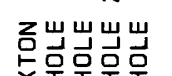

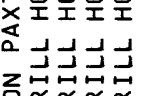

垎器器言产

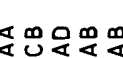

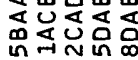

ํํํํํํำ

ㄷㅇㅇㅇㅇㅇ

minm

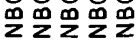

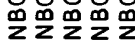

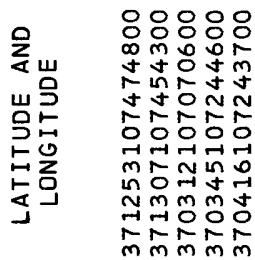

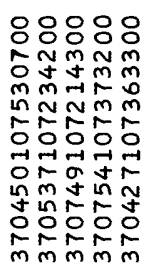

攵交紊出

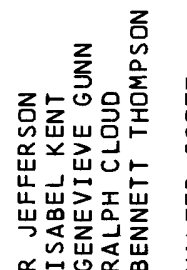

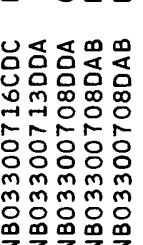

\section{৪৪৪৪০}

이요

min

ooㅇoㅇ

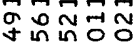

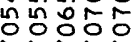

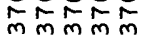

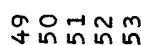

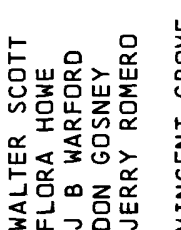

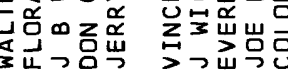

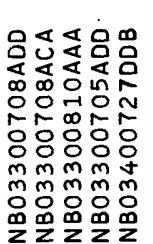

잉

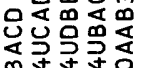

Nrin

88080

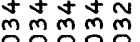

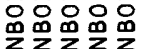

\section{ㅇㅇㅇㅇ}

NMNNN

mmam

우엄응

MNㅔ

웅ㅇoㅇㅇㅇ

花的向

88888

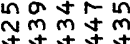

लिखि

óóónó

man

워겈겅ㅇㅇ

m̄mmm

o음ำ

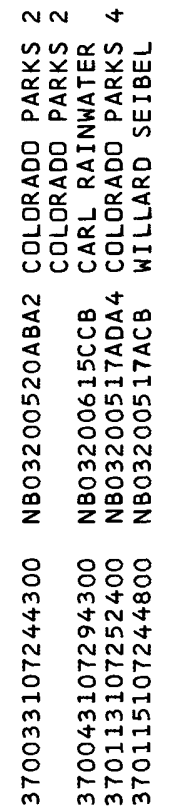

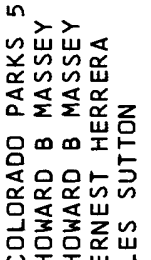

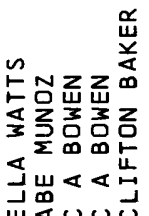

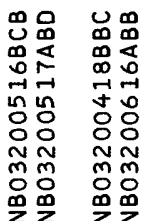

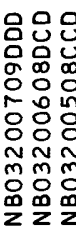

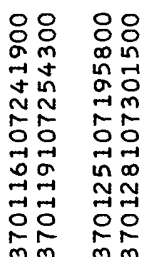

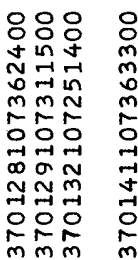

ț

magor NmatR 


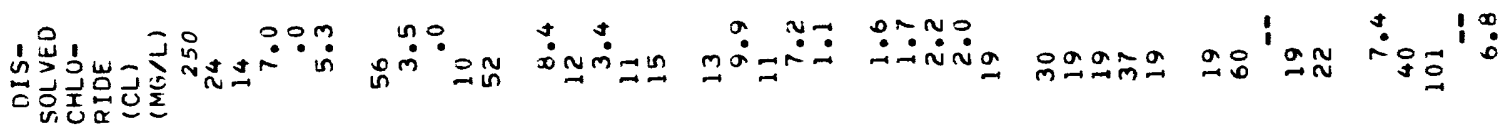

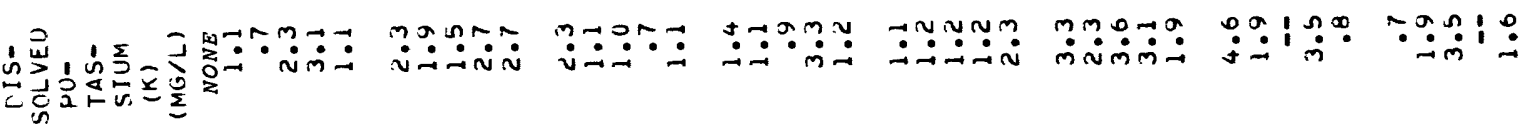

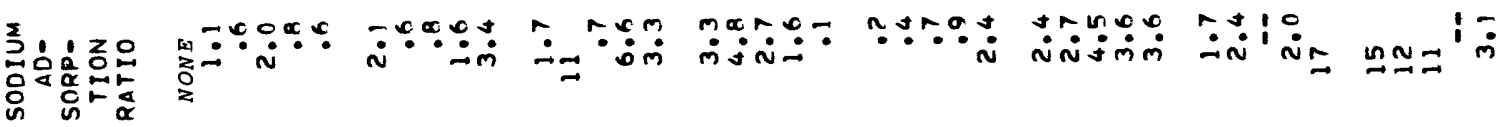

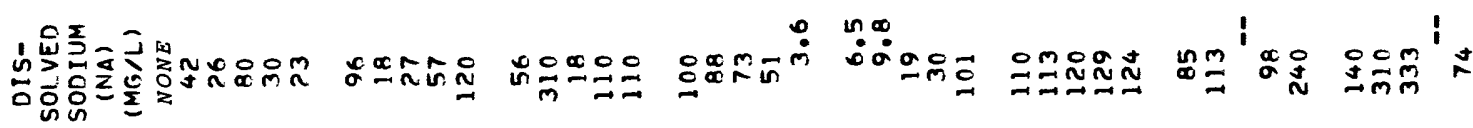

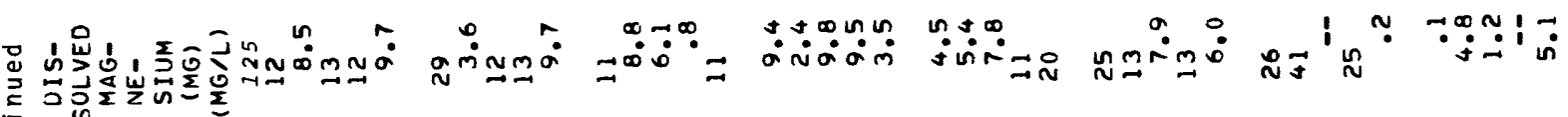

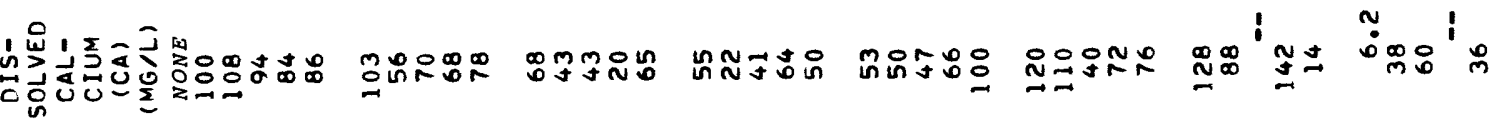

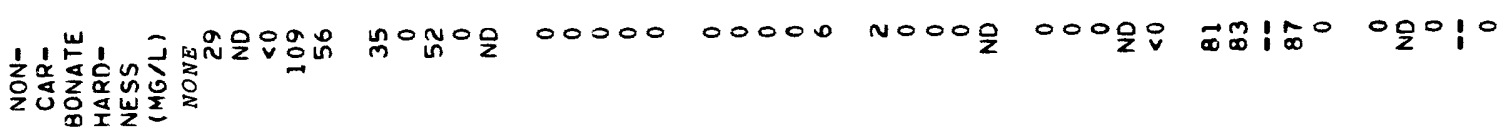

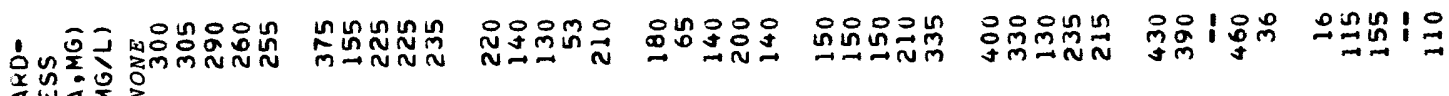

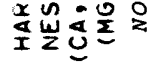

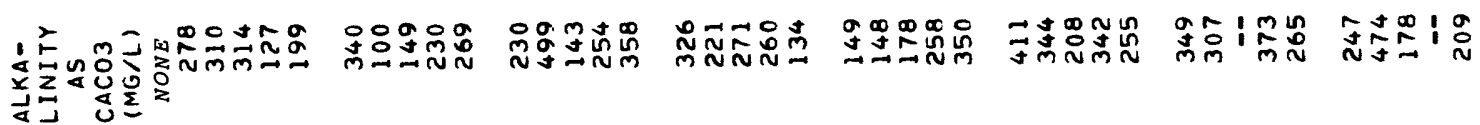

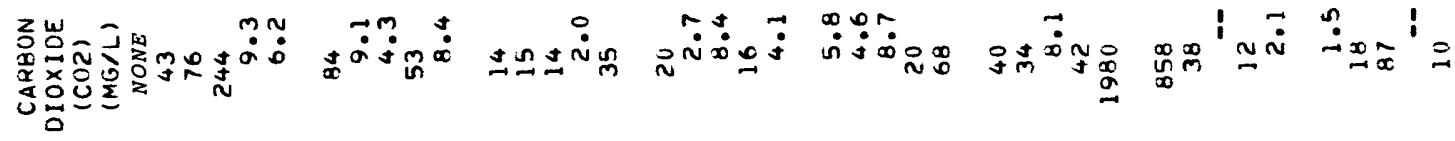

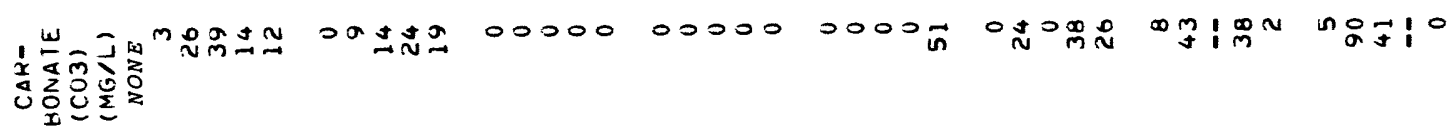

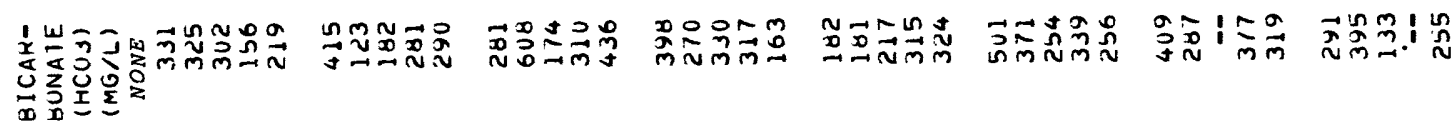

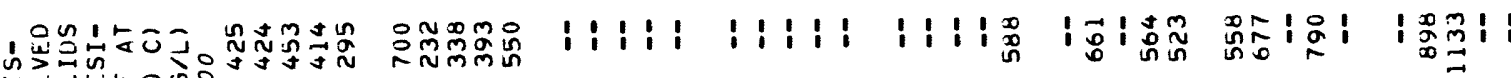

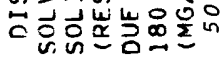

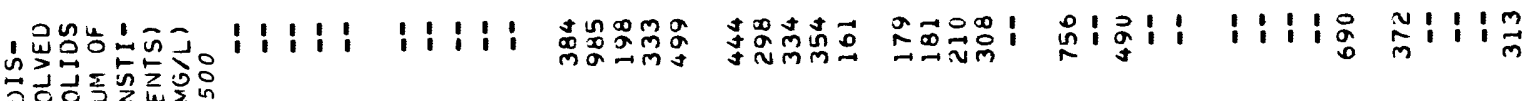

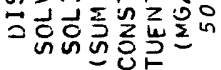

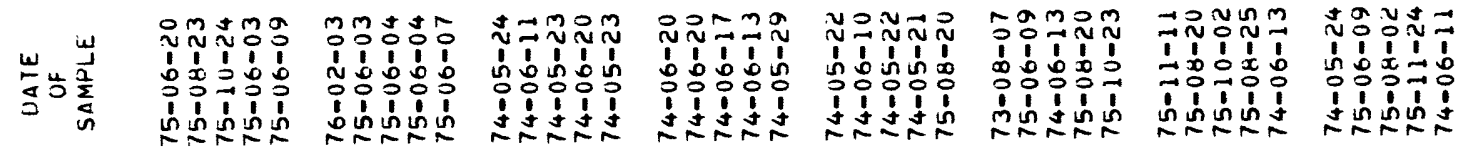




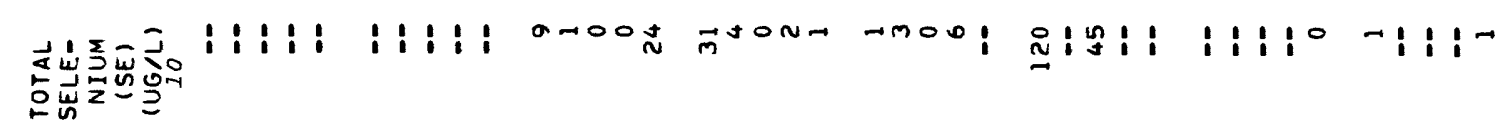

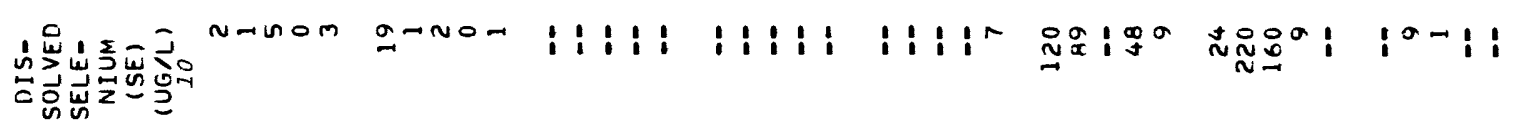

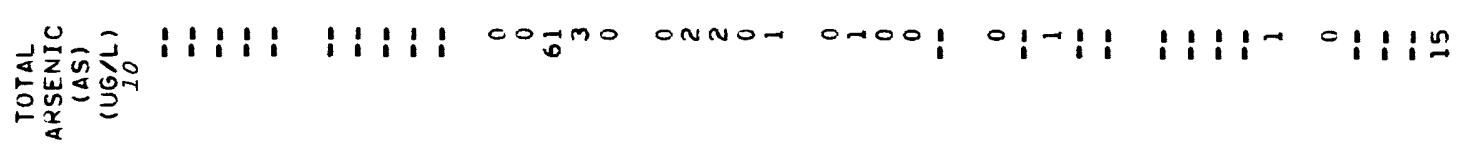

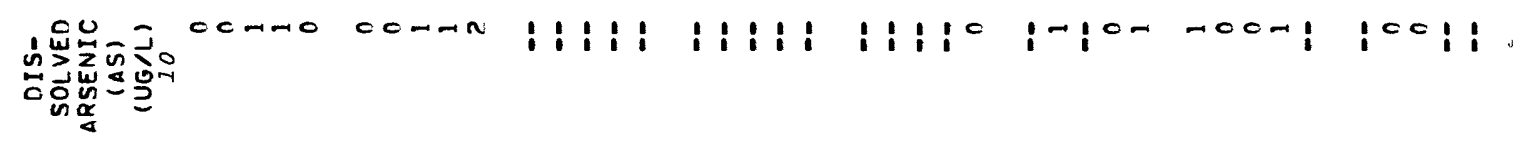

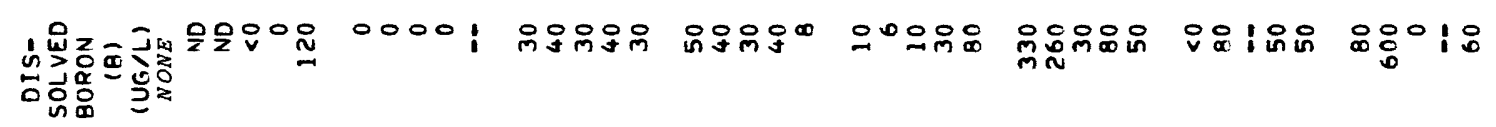

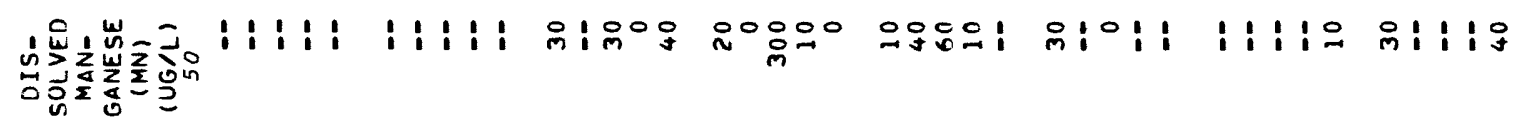

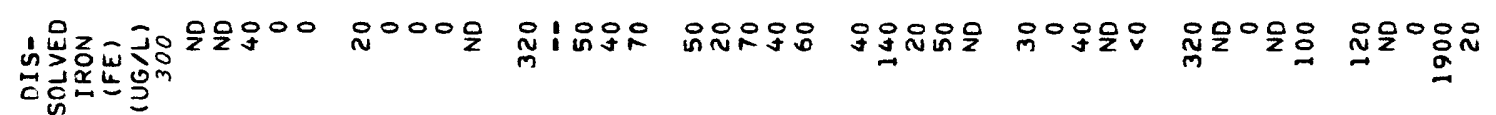

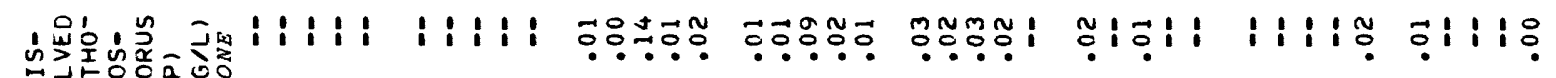

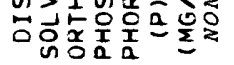

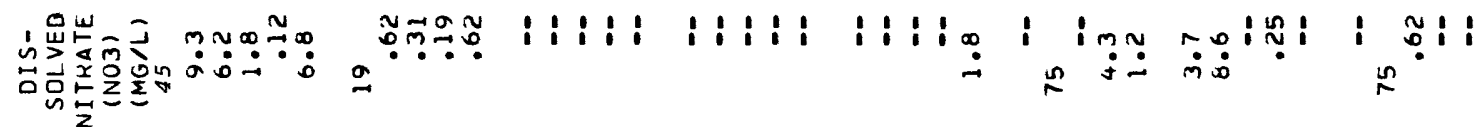

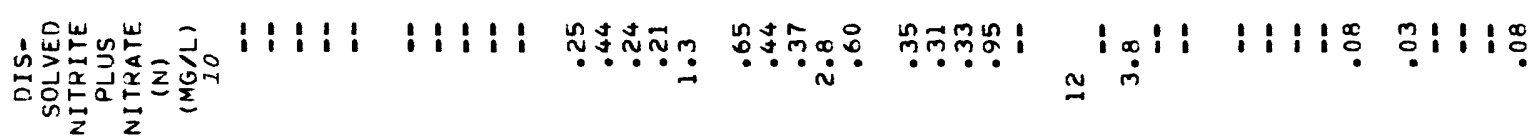

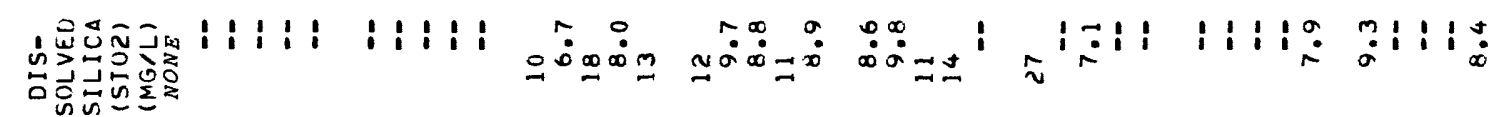

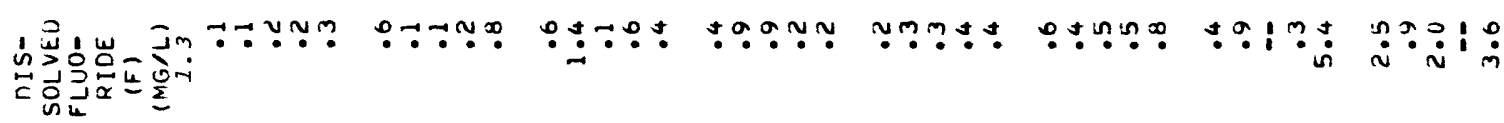

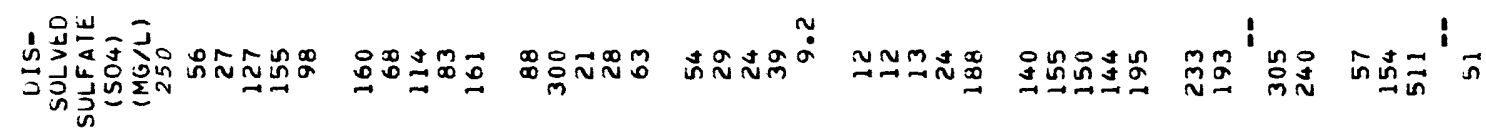

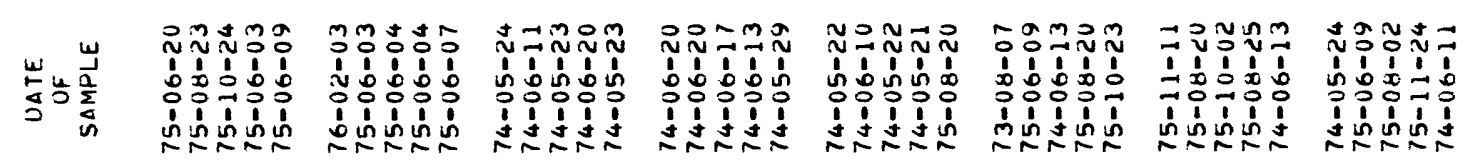




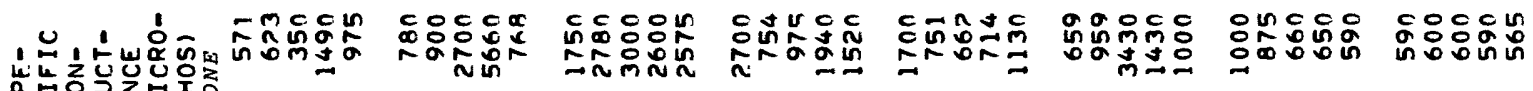

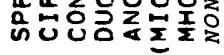

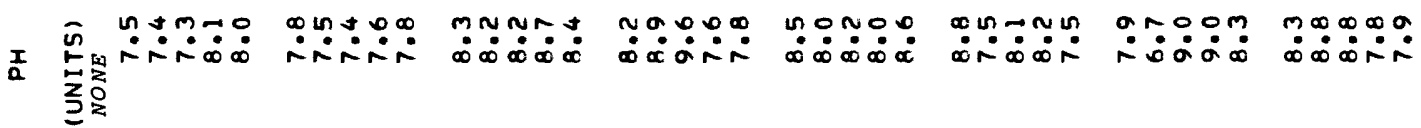
采山心

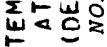

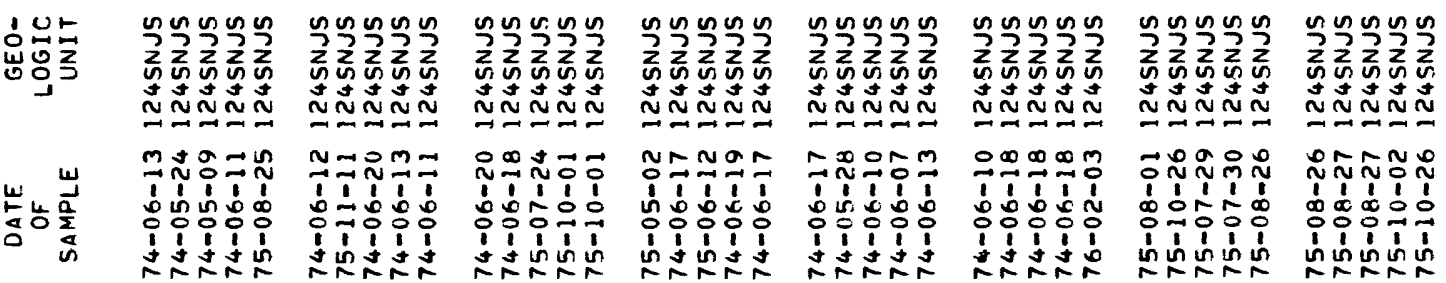

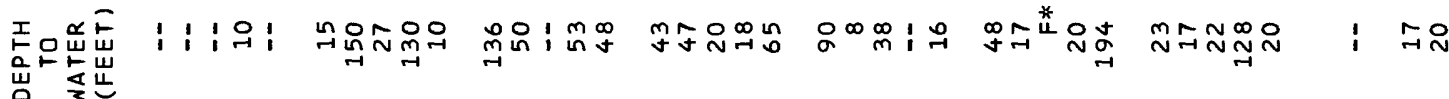
声点 똤씀는

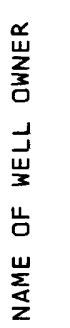
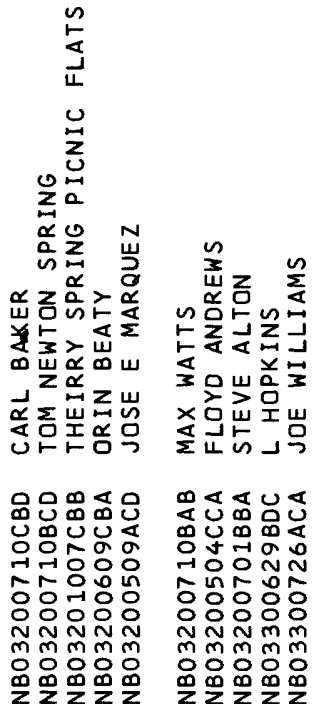

$+\infty$
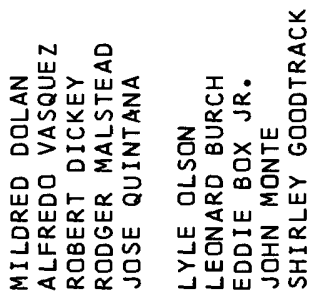

勇总点

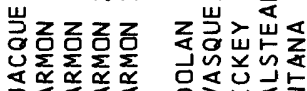

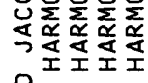

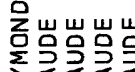
움모웜 文戈牙

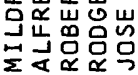
造造墕

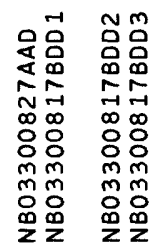

ํㅜㅁํ워

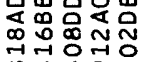
잉ㅇㅇㅇㅇㅇ mm m m m m 啹碞幒

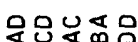
边 웅ㅎㅇㅇㅇㅇㅇ 등웅ㅇㅇㅇㅇㅇ 시륬m

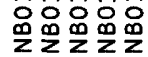

응ㅇㅇ

용ㅇㅇ

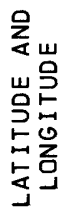

开年

5T5:

nntmat

oํㅇㅇㅇㅇㅇ

บ นกํำ

mmmm

ज为羊品

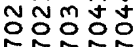

৪৪ :8 88:००

mmmm

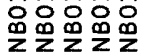

战鹃

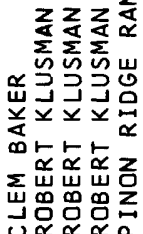

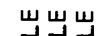

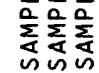

щщ山щ

Z芭小Nm motono

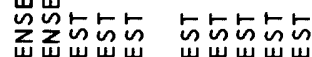

岂出出出 㟔出㟔㟔出

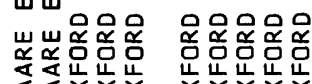

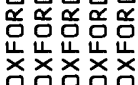

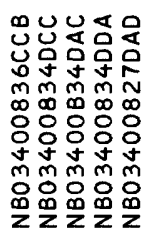

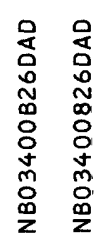

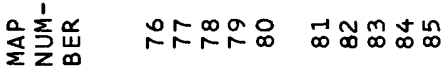

霌

:৪8:

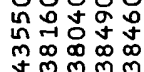

둥후웅우

동두웡음

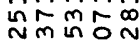

ํำ- -2 ก

웅웅우

음웅

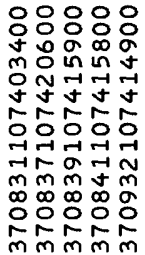

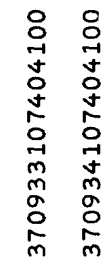

$\sum \sum \infty$

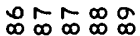

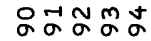

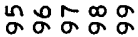

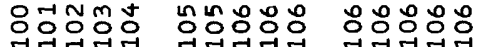




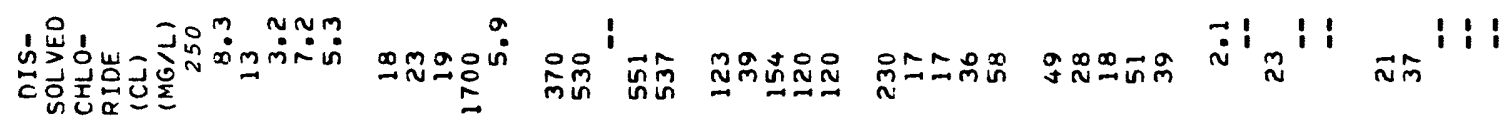

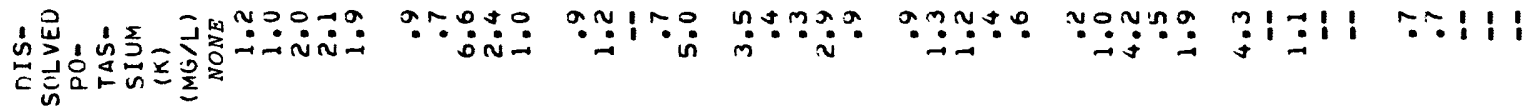

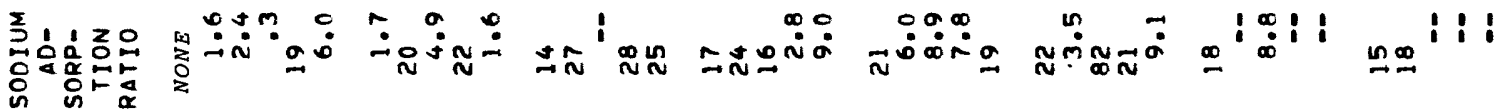

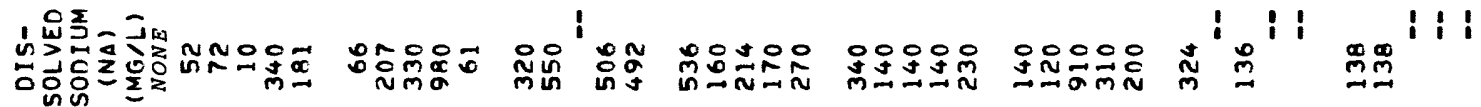

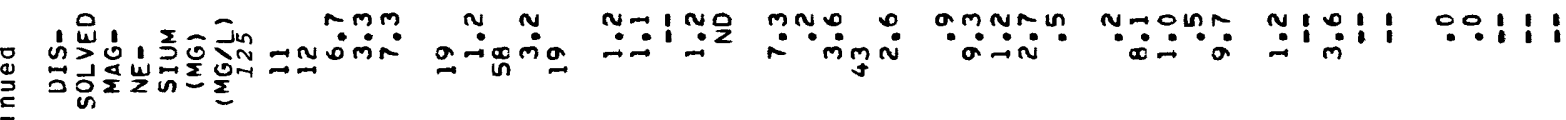

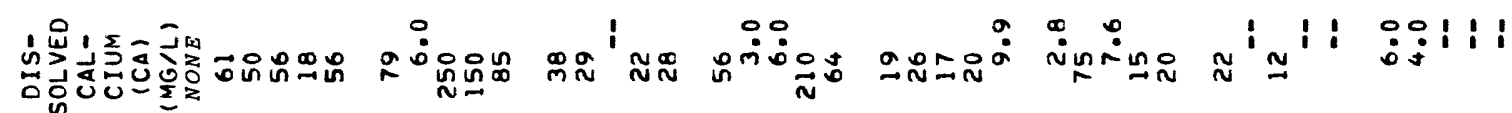

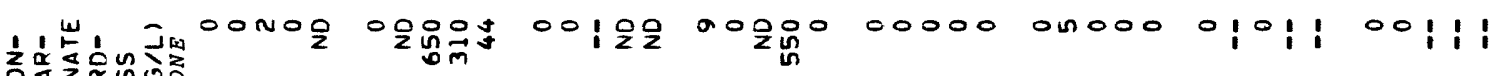

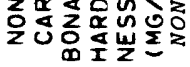

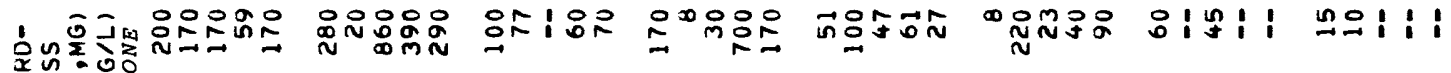

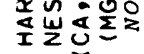

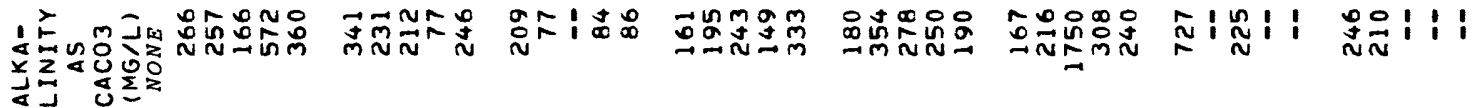

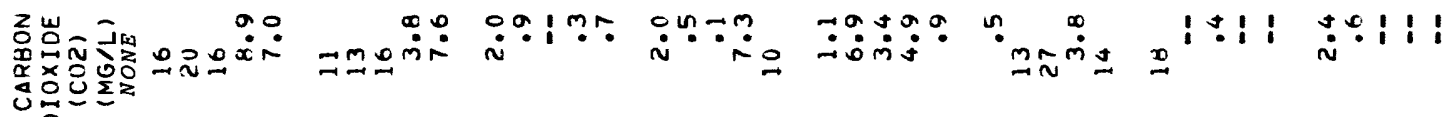

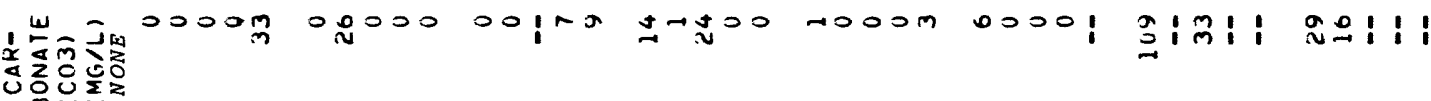

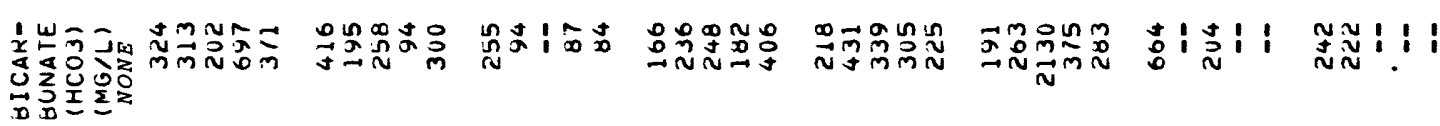

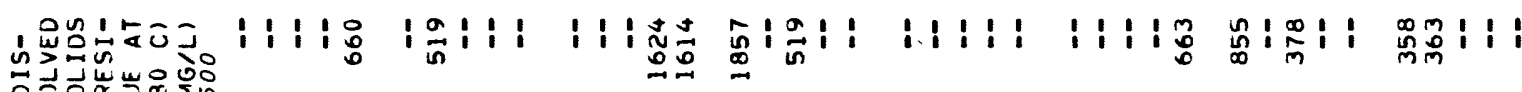

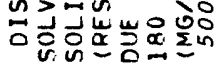

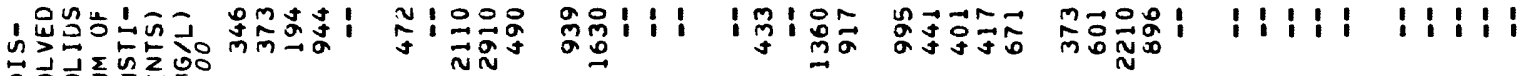

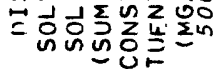

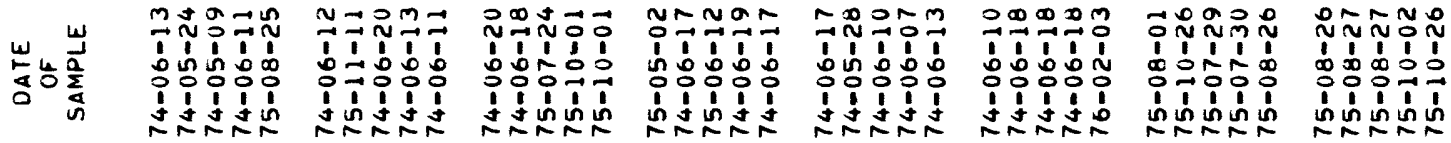




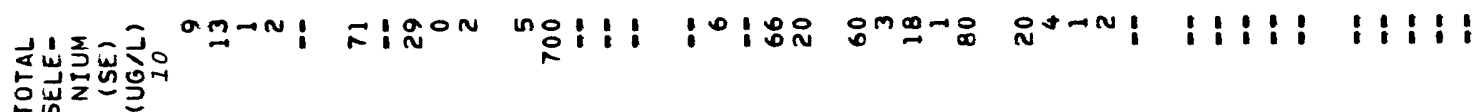

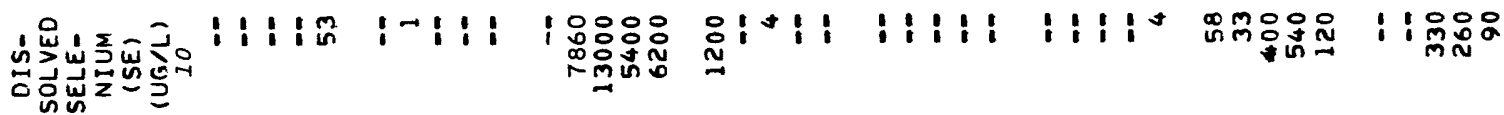

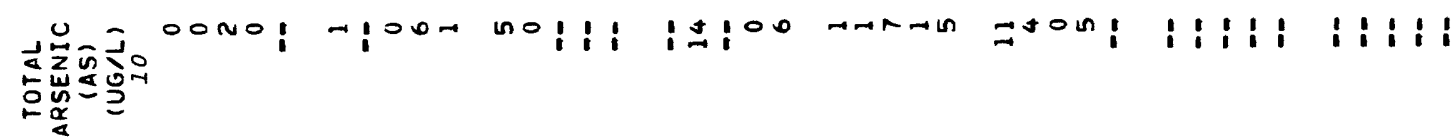

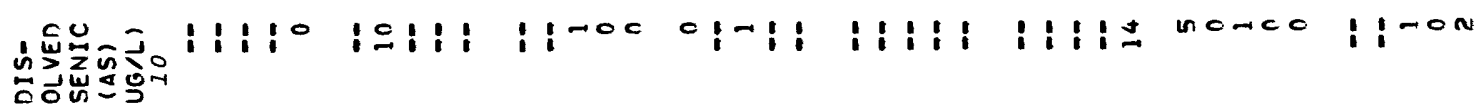

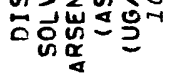

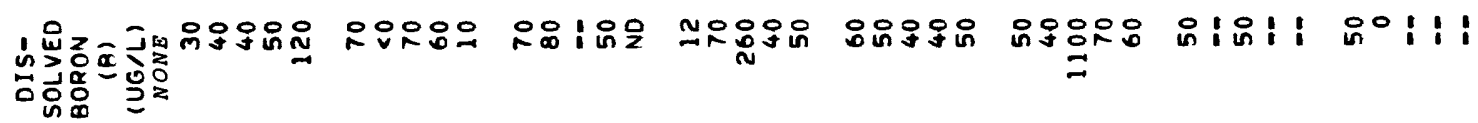

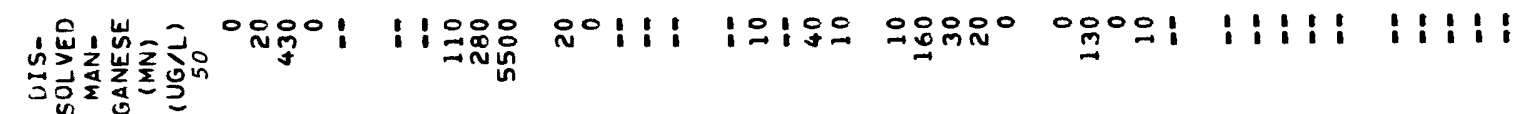

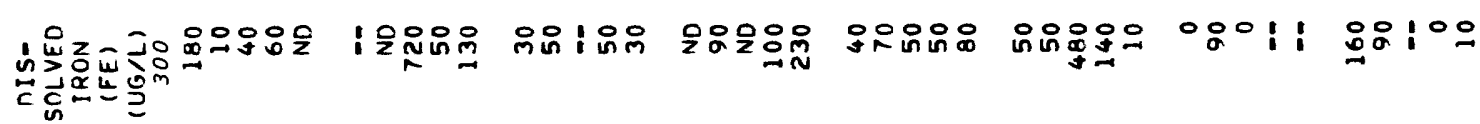

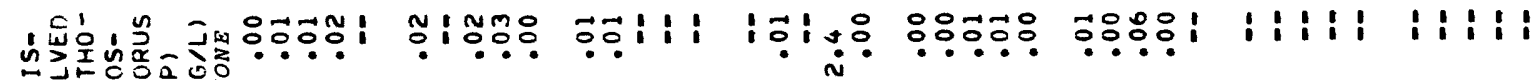

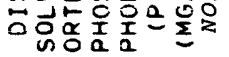

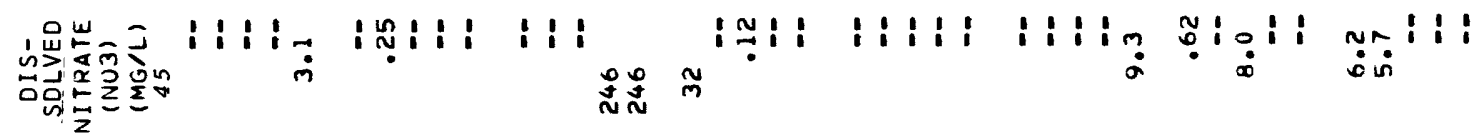

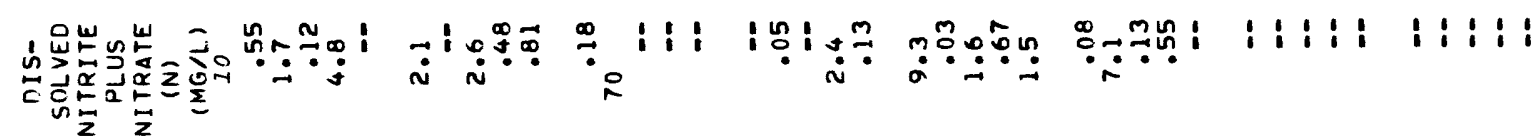
'.

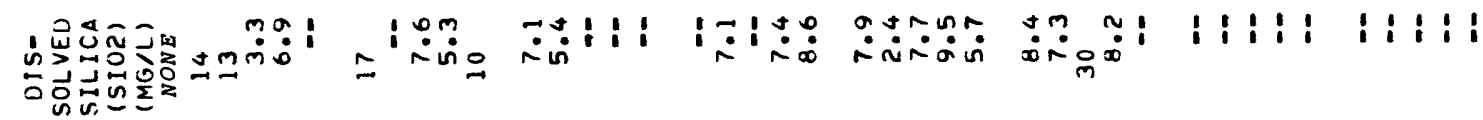

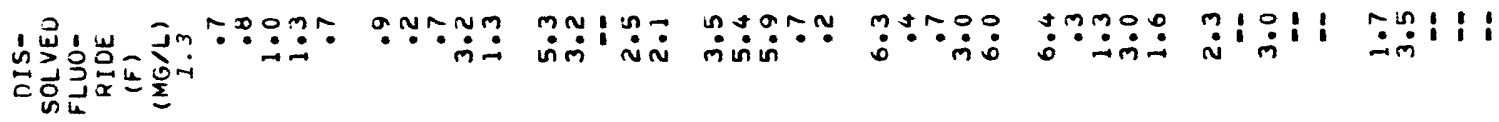

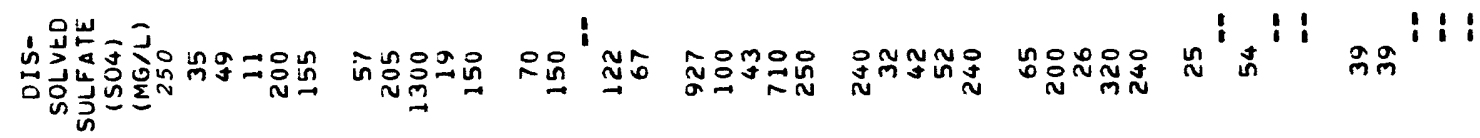

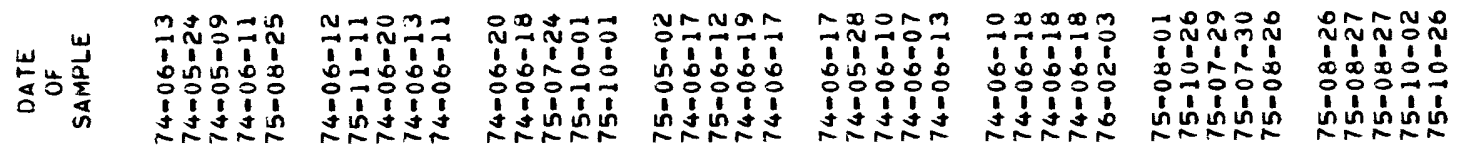




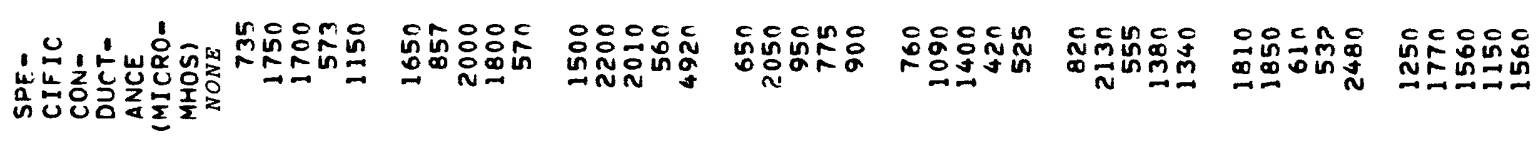

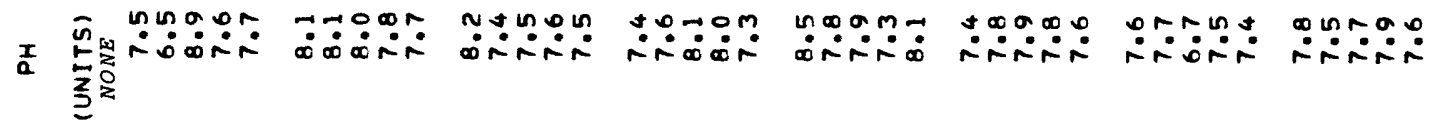

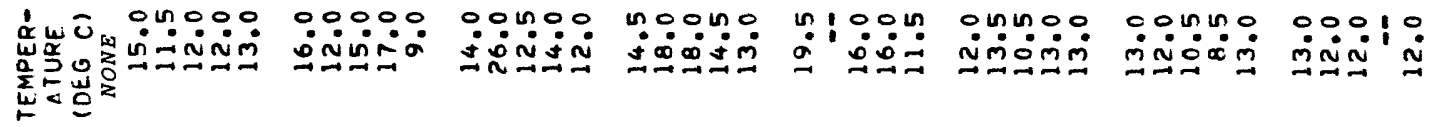

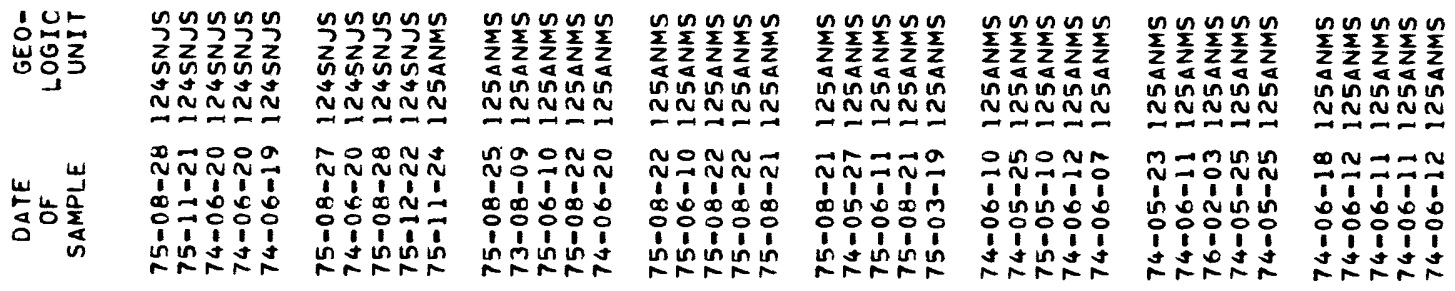

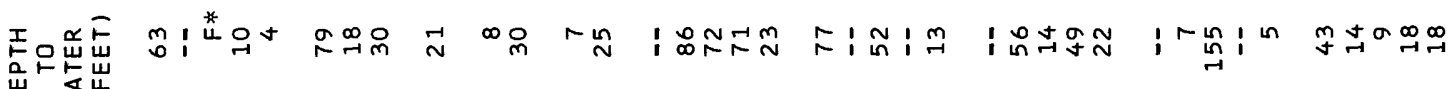

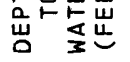

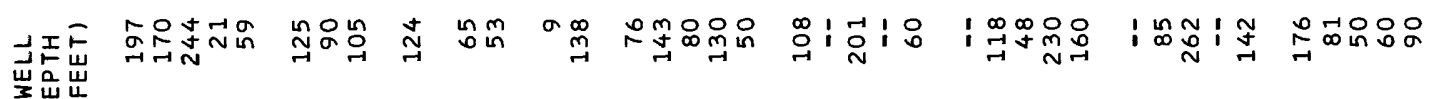
㟧岂

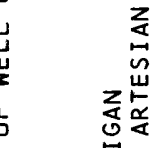

$\frac{\sum_{\Sigma}}{2}$

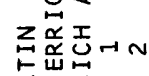

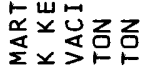

过方出

岁品落品

$\varangle \infty<<\infty$

过号这品

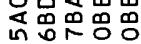

NNNNM NNNN

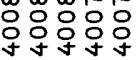

mm

之罗罗罗品

웅응ㅇㅇㅇ

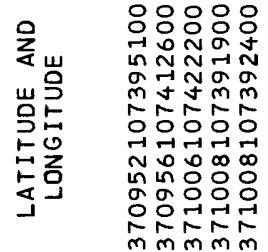

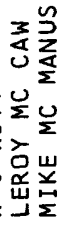

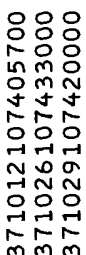

这这势

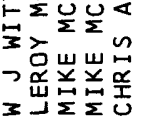

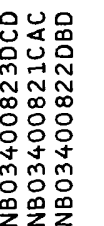

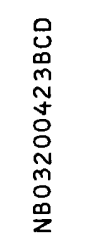

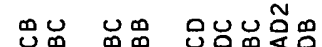

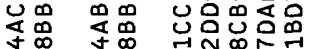

$\underset{\sim}{\infty} \stackrel{-1}{+\infty}$

잉 mo

Nim N N

品品 罚品

$\rightarrow-10$ 宛然

엉ㅇㅇㅇㅇㅇ

NiN N N

罗罗罡罗

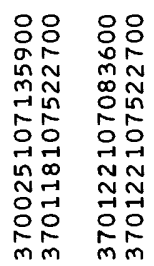

웅ㅇㅇㅇ

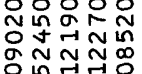

o농응

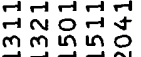

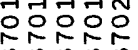

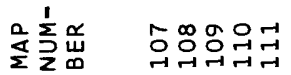

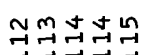

국요
워ำฟ

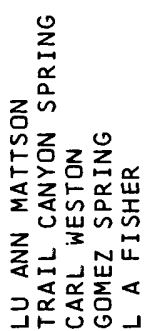

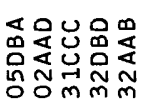

이의 $m$ m

응ㅇํㅇ

N $\mathrm{mm}$

罗罗品品

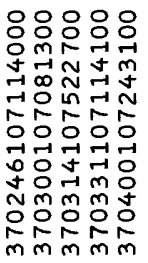

กิกับิ

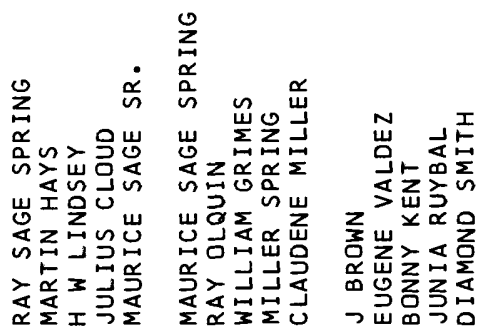

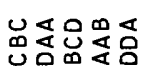

NNN

NNNNN

웅ㅇํㅇํำ

mmmmmmm mm

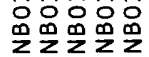

응웅웅유

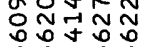

mîNㅗำ

o웅영

Nํํํํำ

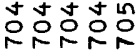

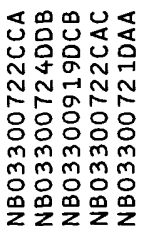

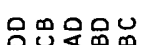

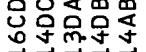

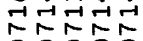

응요

mmm

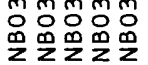

응ㅇㅇㅇ 웅융유

mon

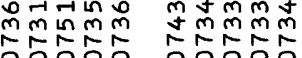

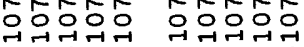

1.

tho잉

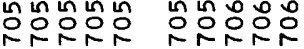

mm

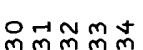

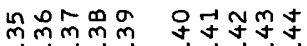




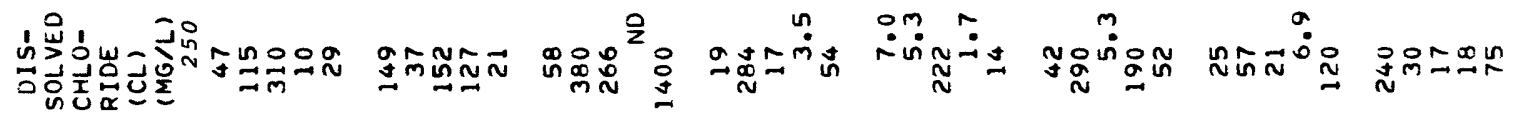

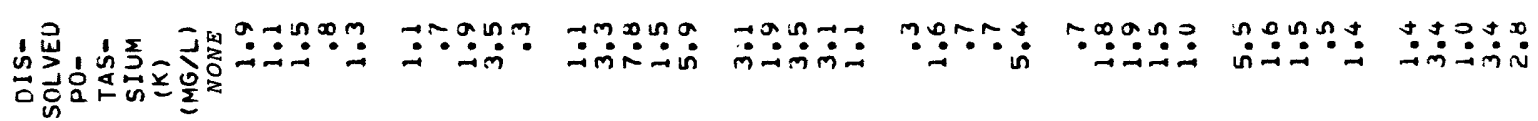

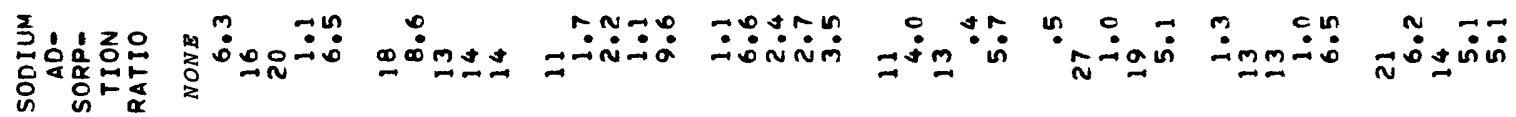

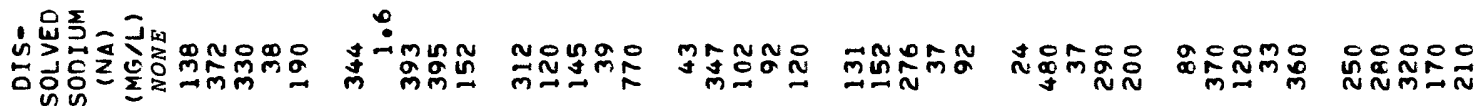

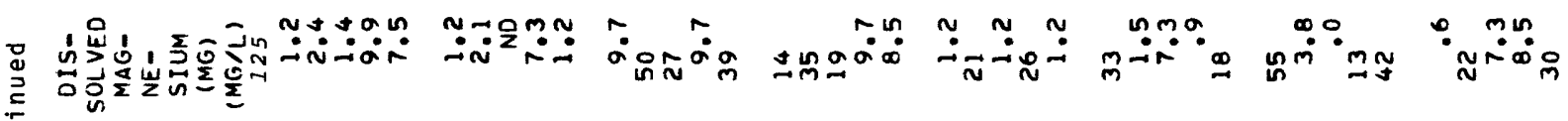

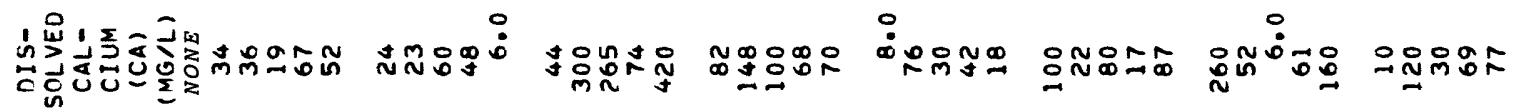

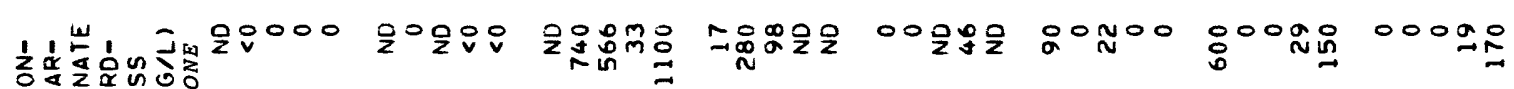
之ơ

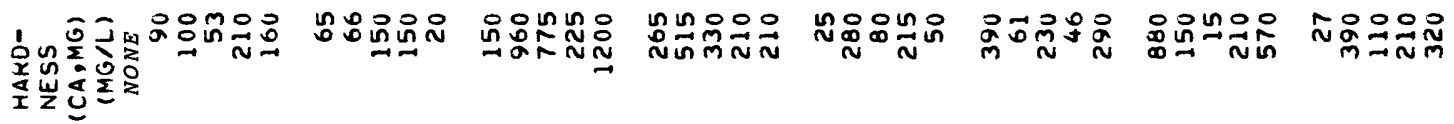

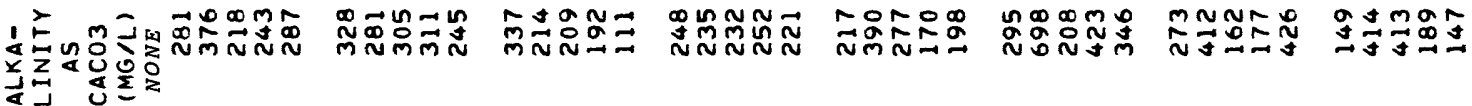

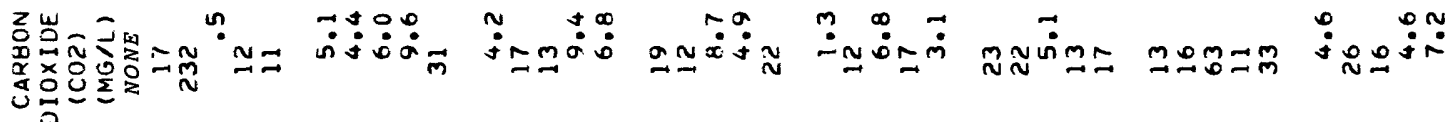

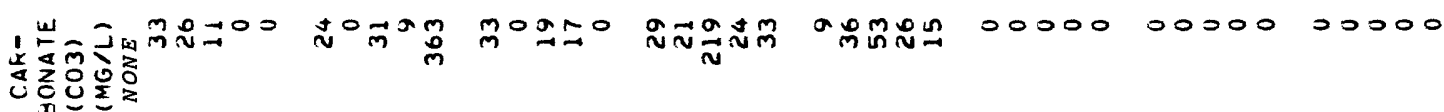

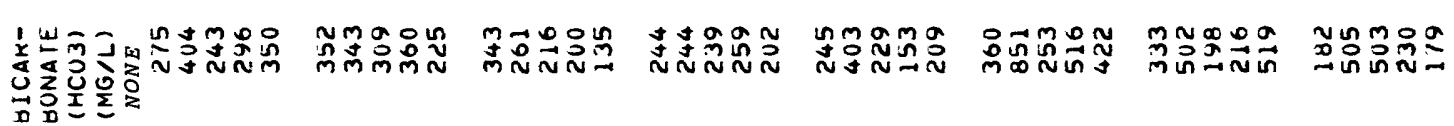

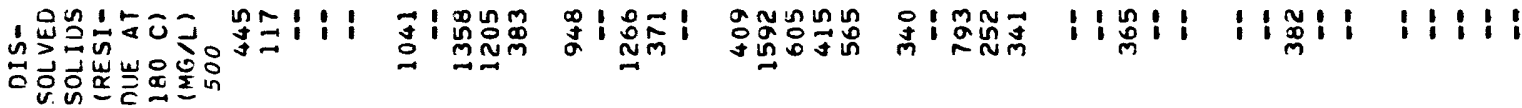

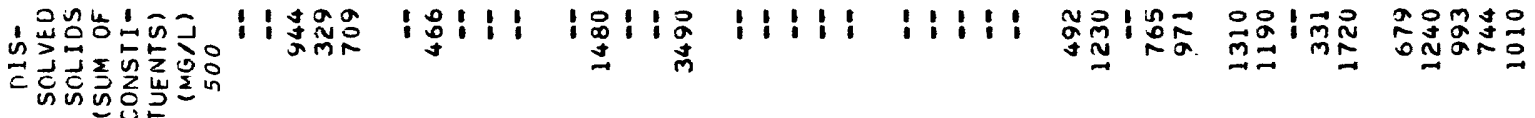

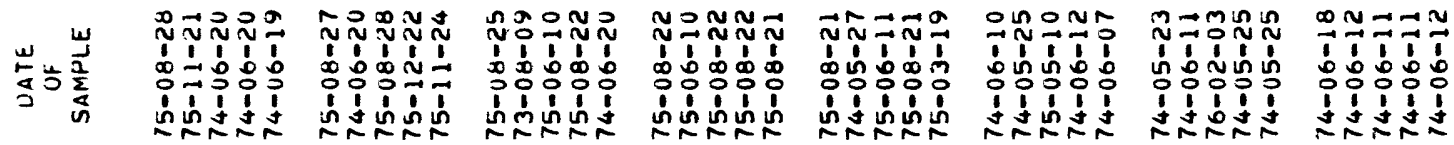




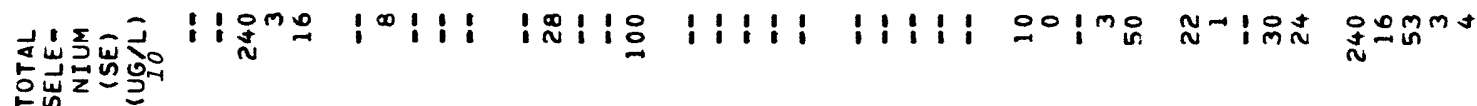

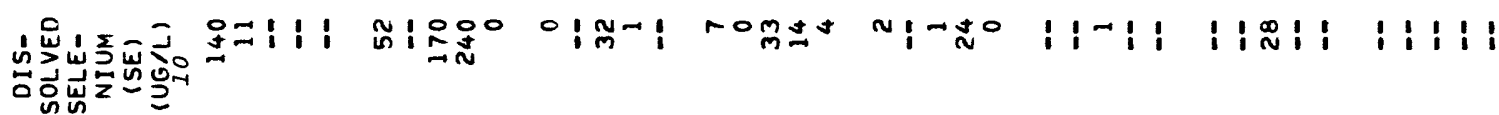

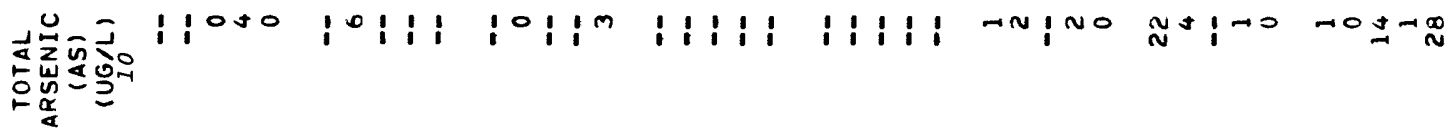

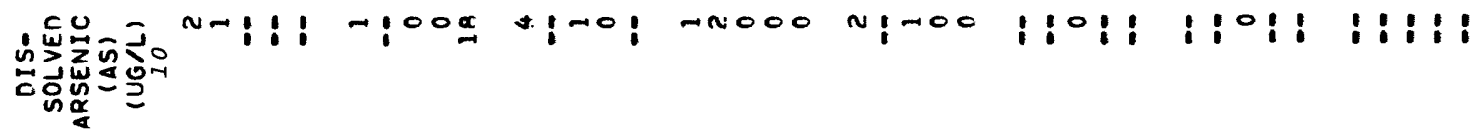

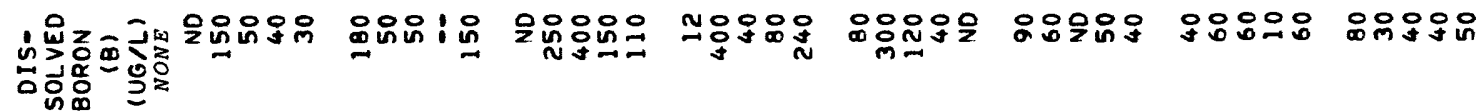

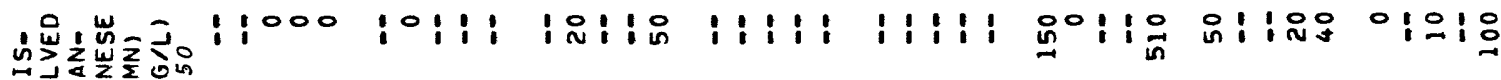

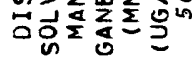

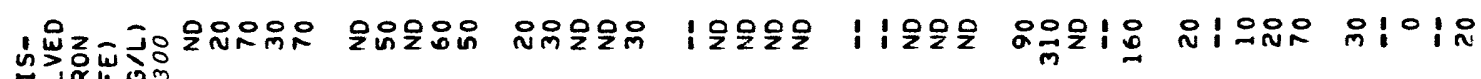

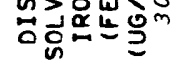

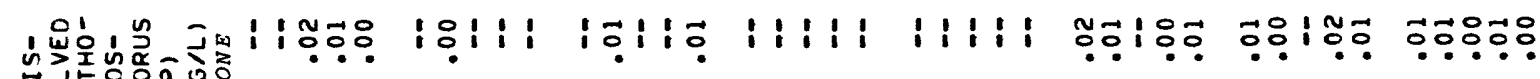

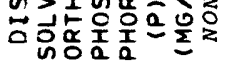

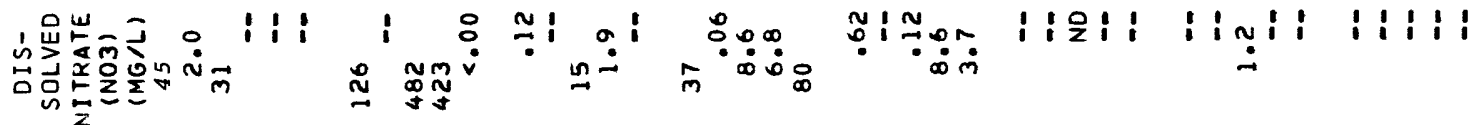

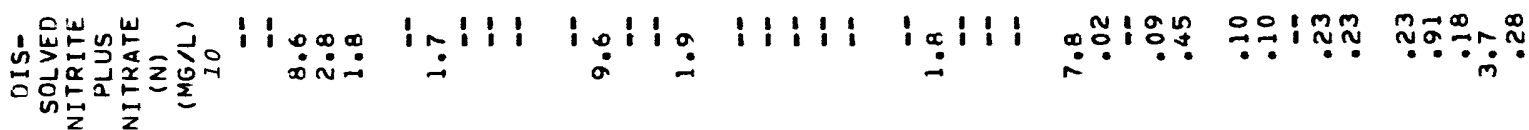

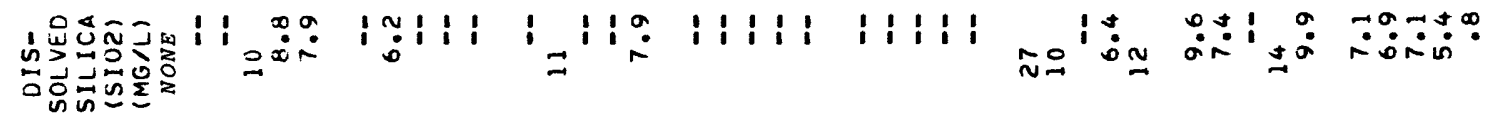

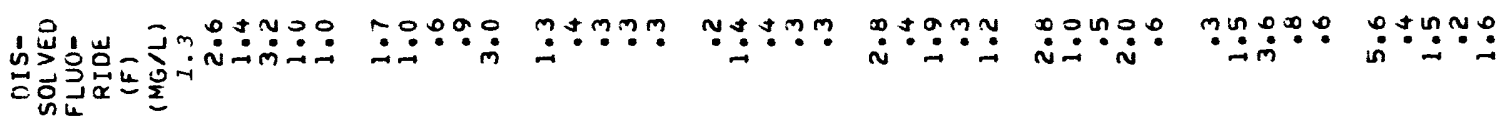

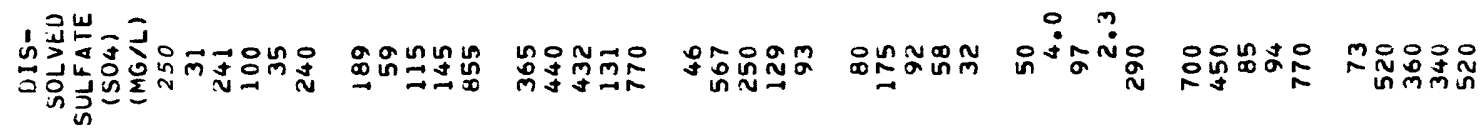

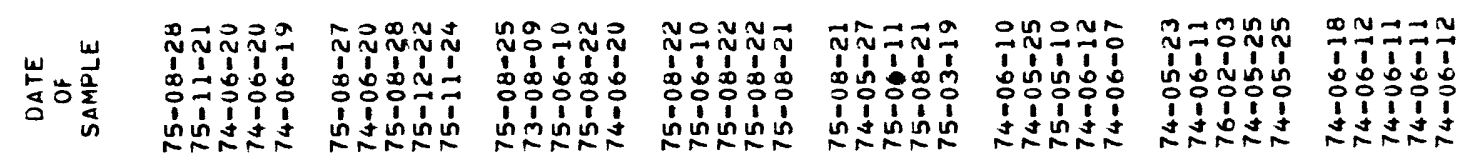




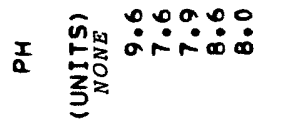

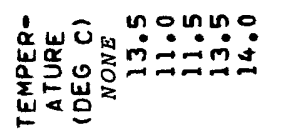

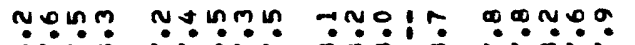

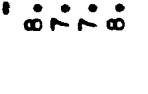

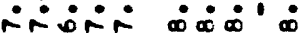

i:on:

$\because 00: 0$

눙ㅇㅇㅇ

แn:ㅇํำ

:ㅇํㅇํㅇำ

$0: 000$

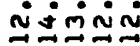

$0000:$

\section{岲号点
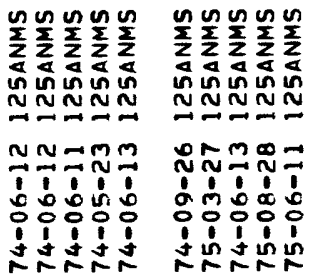

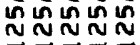 \\ กักตั

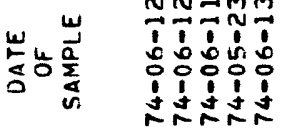 \\ 성ํำ \\ ingin

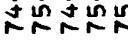

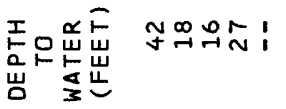

$m$ แก๊

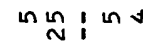

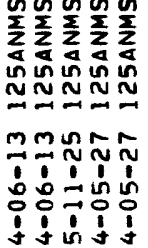

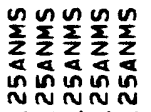

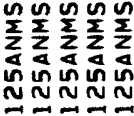

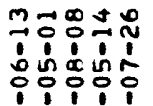

íníni

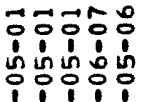

ininíg

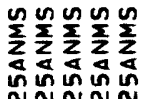

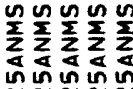

กำกำ

⿻ㅗㅇํํ융

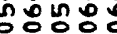

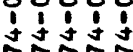

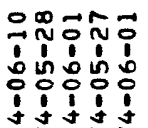

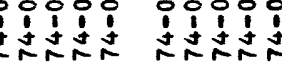

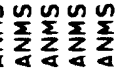

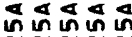

NNN等

ธกักกัก

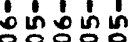

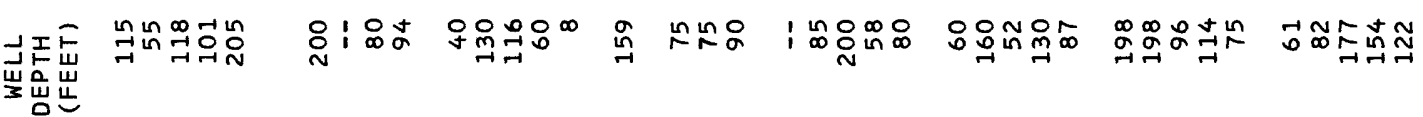

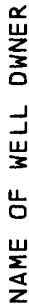
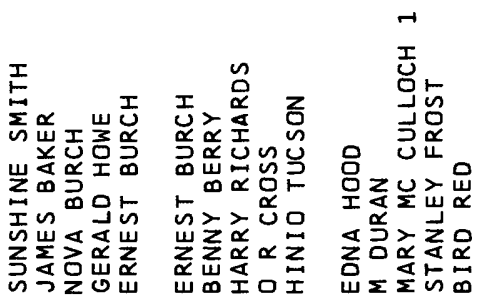

응이요

운응원

子约

숭옹ㄷㅇ옹

있

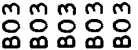

공요음

ㅇㅇㅇ음

ํํㅇํํำ

2222

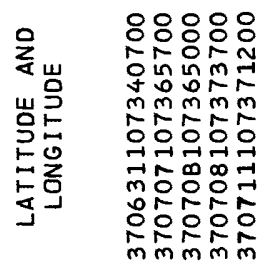

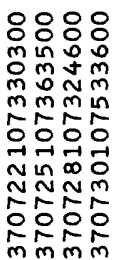

造交紊出

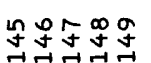

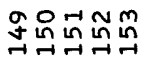

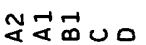

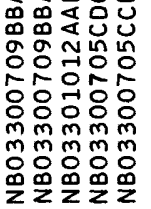

$\begin{array}{ll} & 0 \\ 0 & 0 \\ 0 & d \\ 0 & 0 \\ 0 & 0 \\ 0 & 0 \\ 0 & 0 \\ 0 & 0 \\ m & 0 \\ 0 & 0 \\ 0 & 0 \\ 0 & 0 \\ z & 0\end{array}$

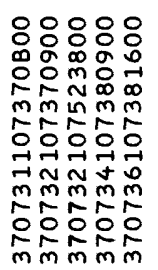

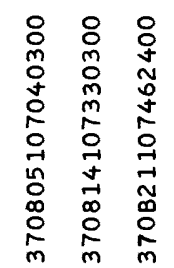

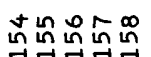

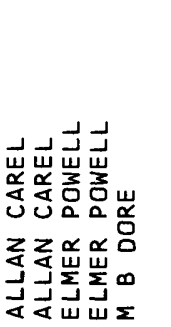

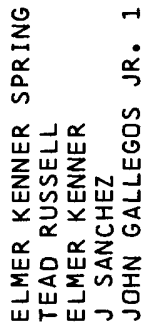

눙워워

约品垈

5.

유:웅

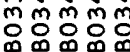

设罗罗罗

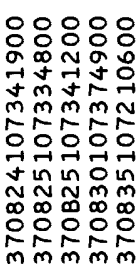

之之之之之

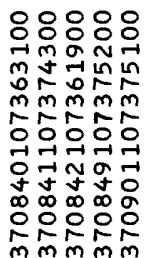

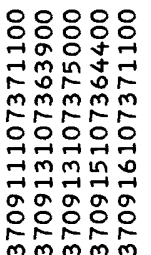

웅음응웅

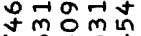

mpon

도옹응

ननन न

유NN

옹ㅇㅇㅇ

5웅요

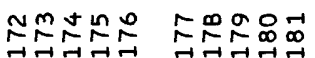




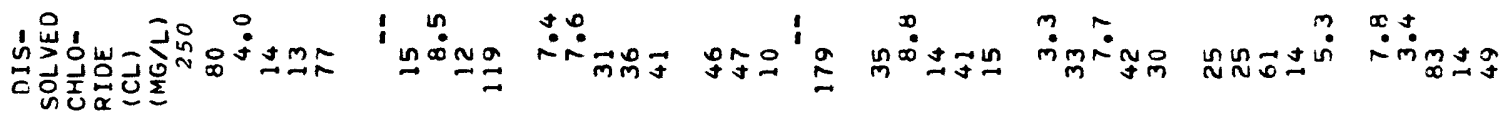

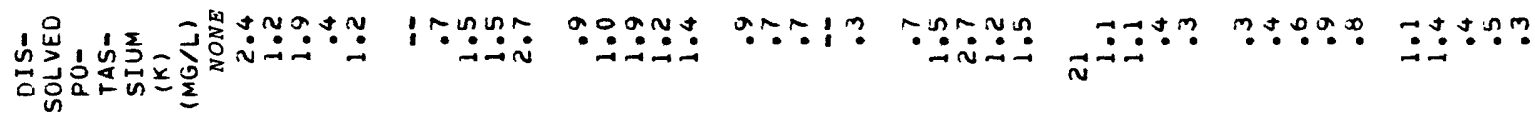

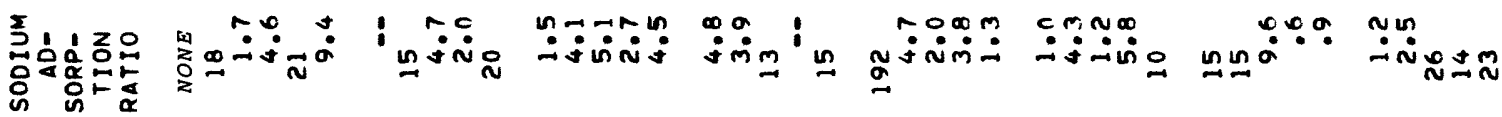

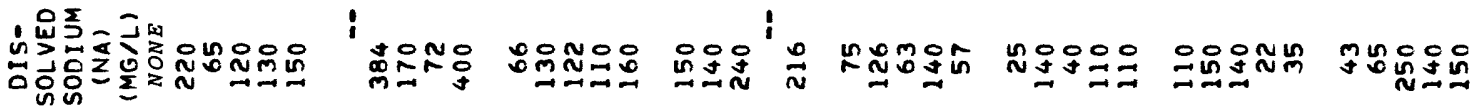

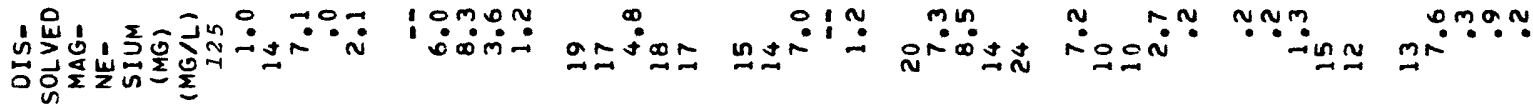

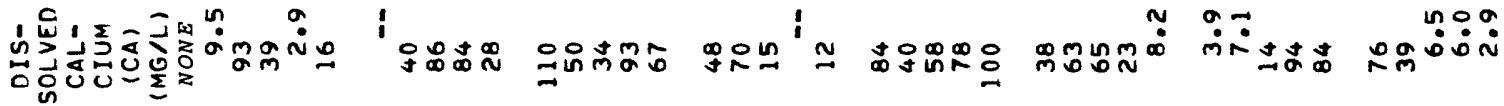

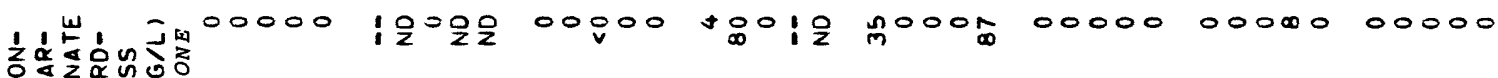

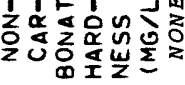

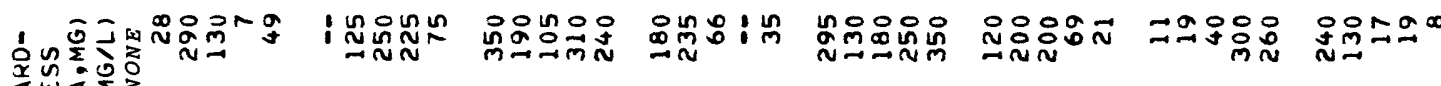

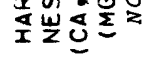

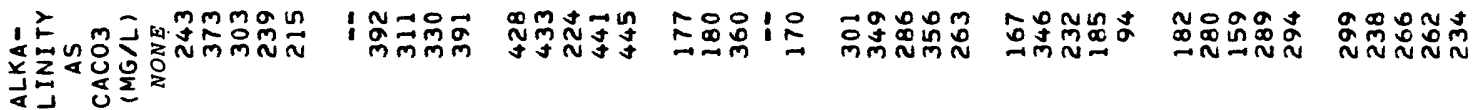

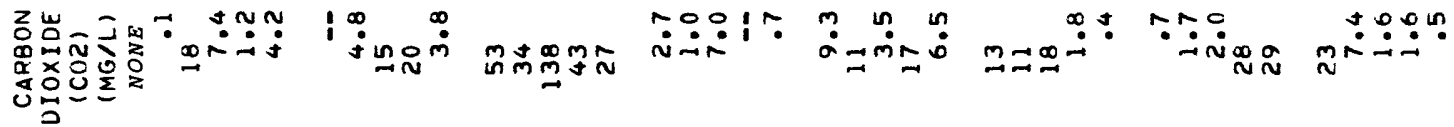

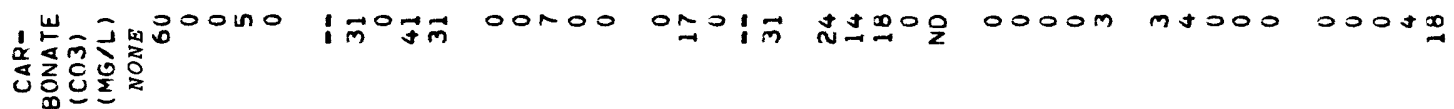

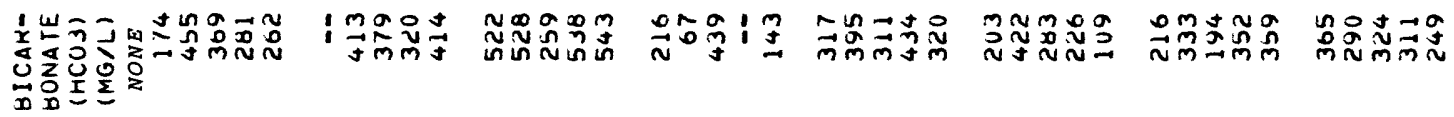

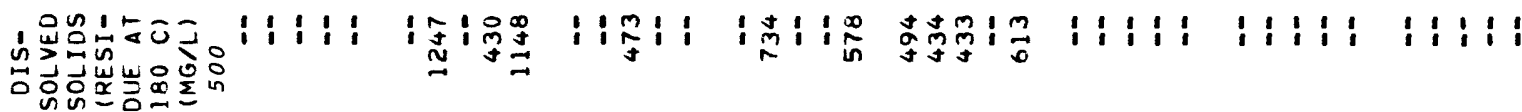

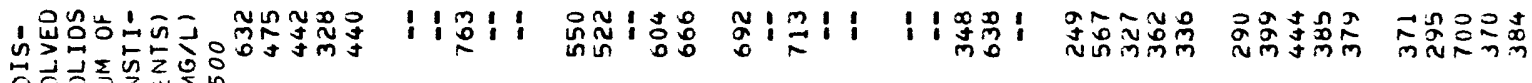

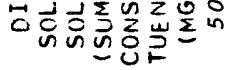

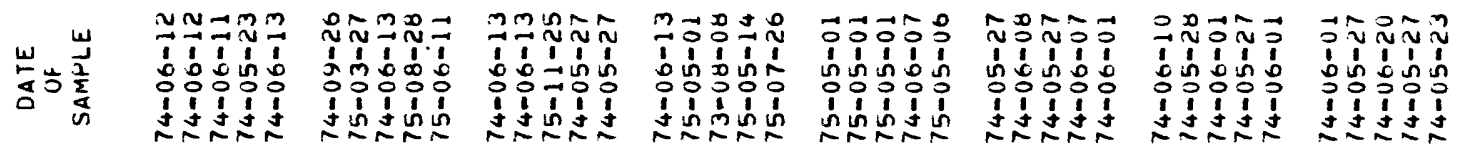




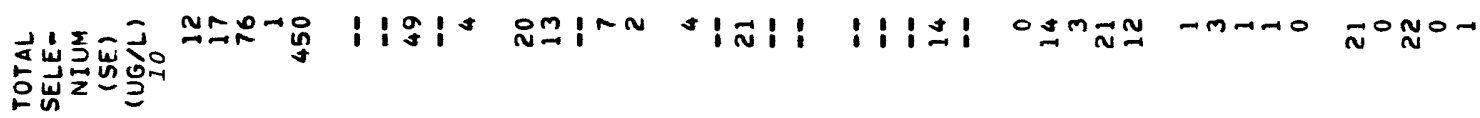

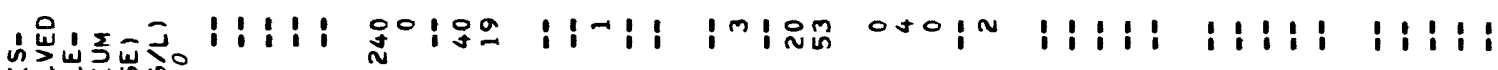

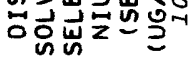

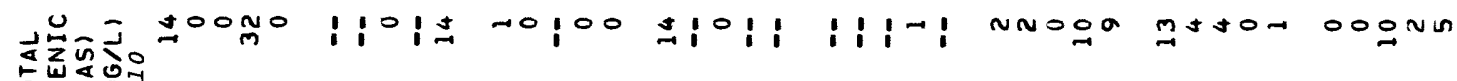

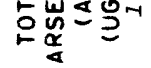

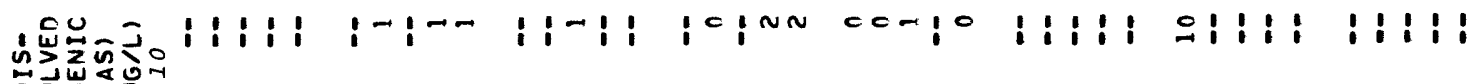

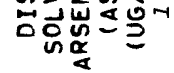

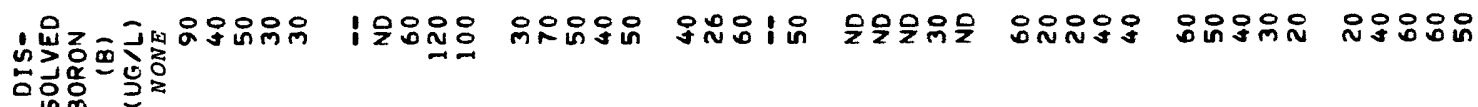

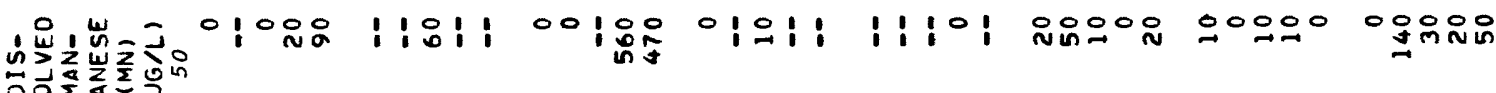

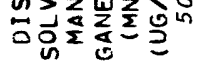

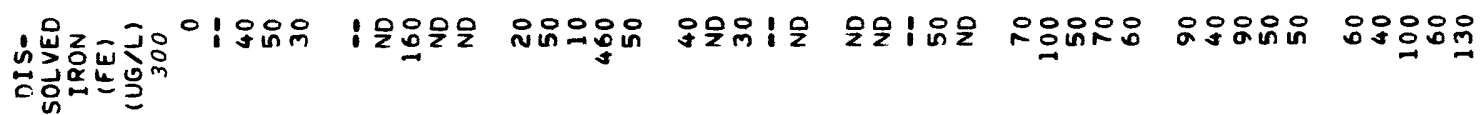

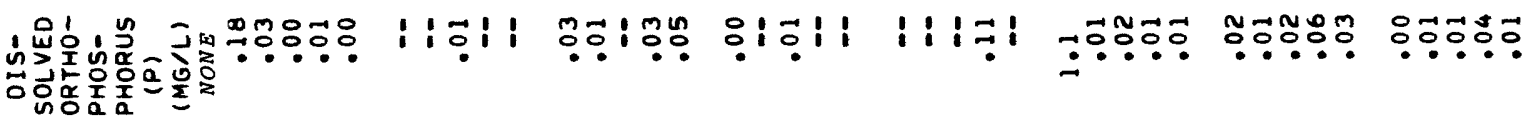

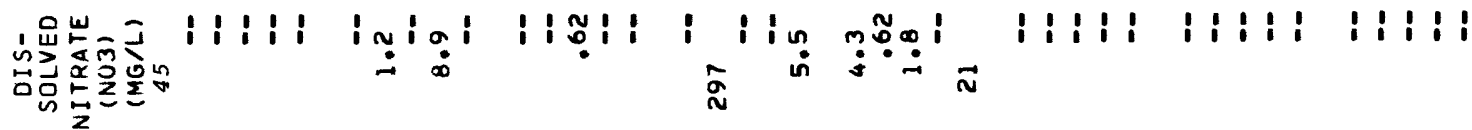

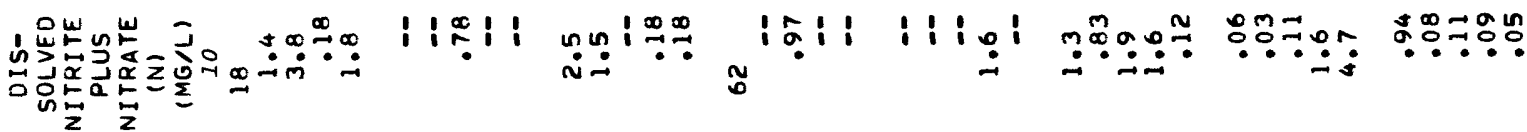

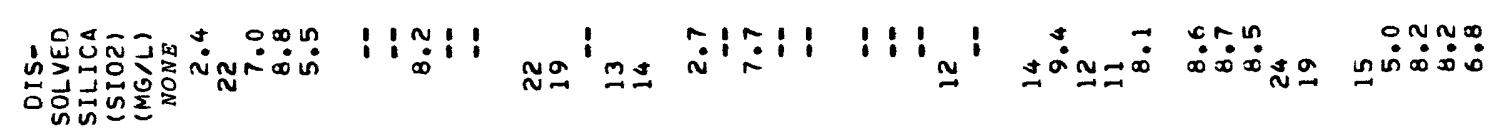

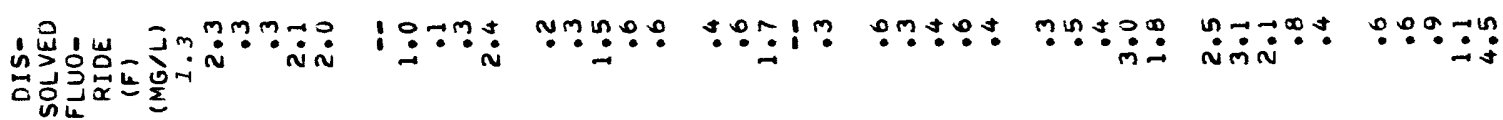

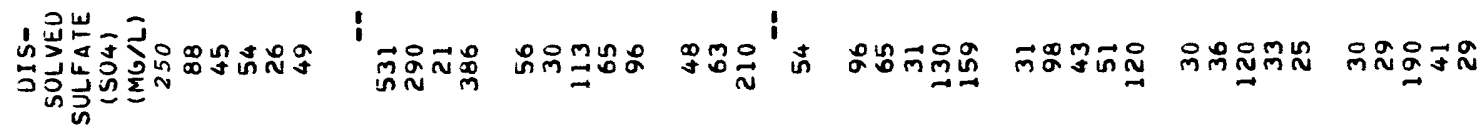

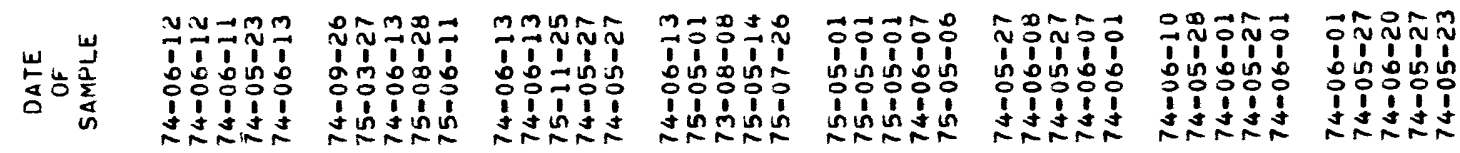




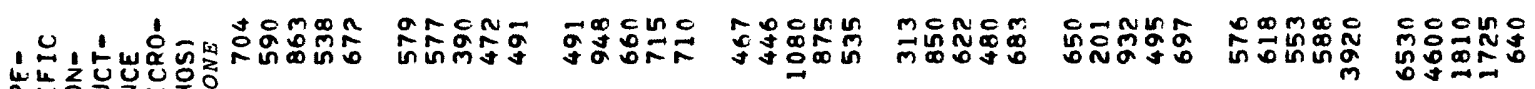

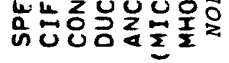

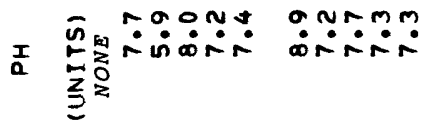

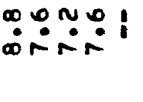
orimo:
isin:
$\cos$

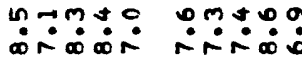

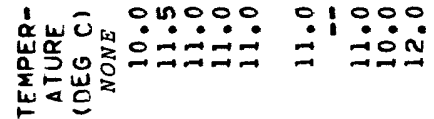

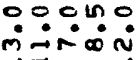
10000

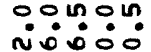
ทำ!!
01 un 0

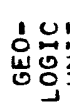

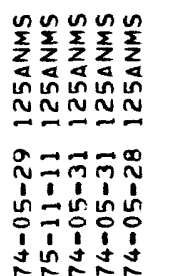

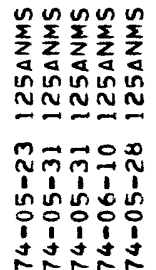

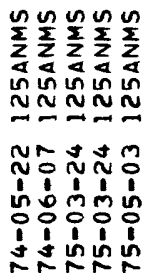

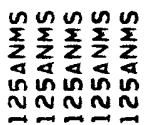

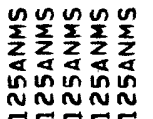

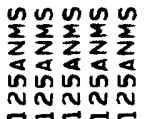

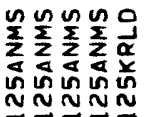

으요

우ำำ

유유 $\vec{N}$

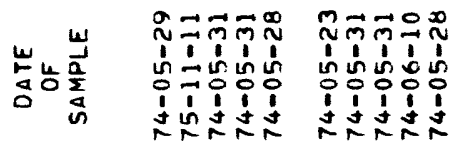

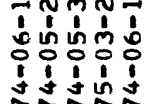

ำî́n

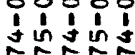

Nㅡ요무음

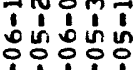

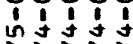

ลึํㅇㅇㅇ

1111

i i ipio

जी

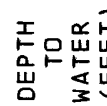

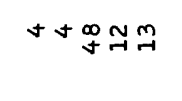

$0 \underset{-1+\infty}{+\infty} \sigma$

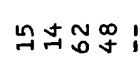

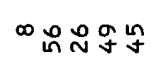

mơnton

$\underset{-1}{ \pm}$ ปั่

さ嵒卡芭

艺芭!

\section{次点 3 岩出}

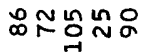

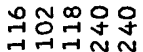

머웜ㅇㅇㅇㅇㅛ

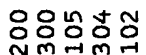

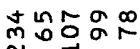

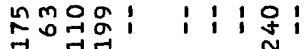

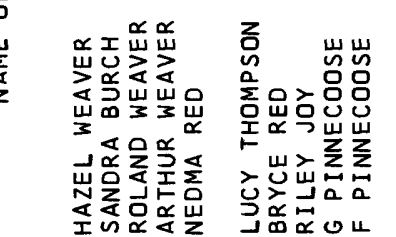

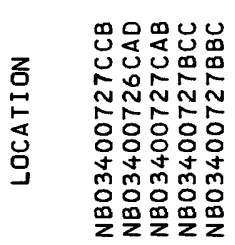

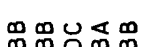

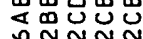

กNNำ

웅유유

mimm

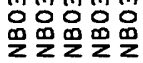

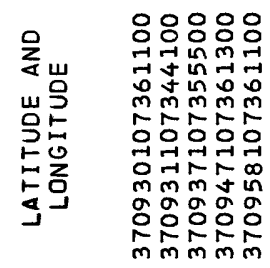

웅ㅇㅇㅇ

लำ

둥둥ㄷㅇ

त्रुजन्न ज्ञ

웅ํํㅇํㅇ

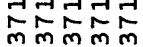

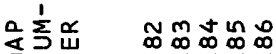

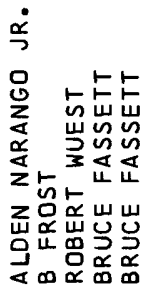

ي๊u

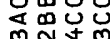

N N

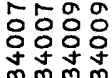

ก๊ำ

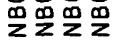

ㅇ:응

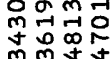

둥ㄷㅇㅇ

ㄸํㅇㅇㅝ

o궁

mmm

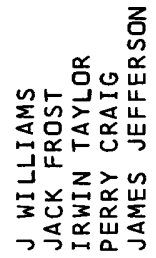

कư

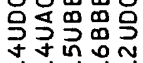

송등요

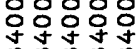

mo

응ㅇㅇ 둥ㅇㅇㅇㅇㅇ

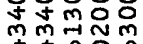

mํำ

응응웅으

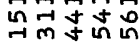

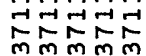

농요

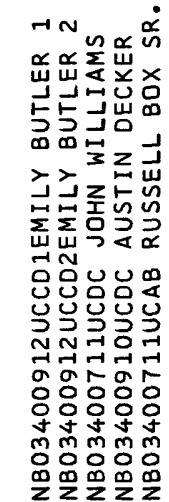

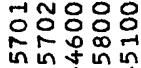

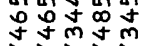

동등으웅

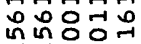

코촉

败紫占

동ํํํํำ

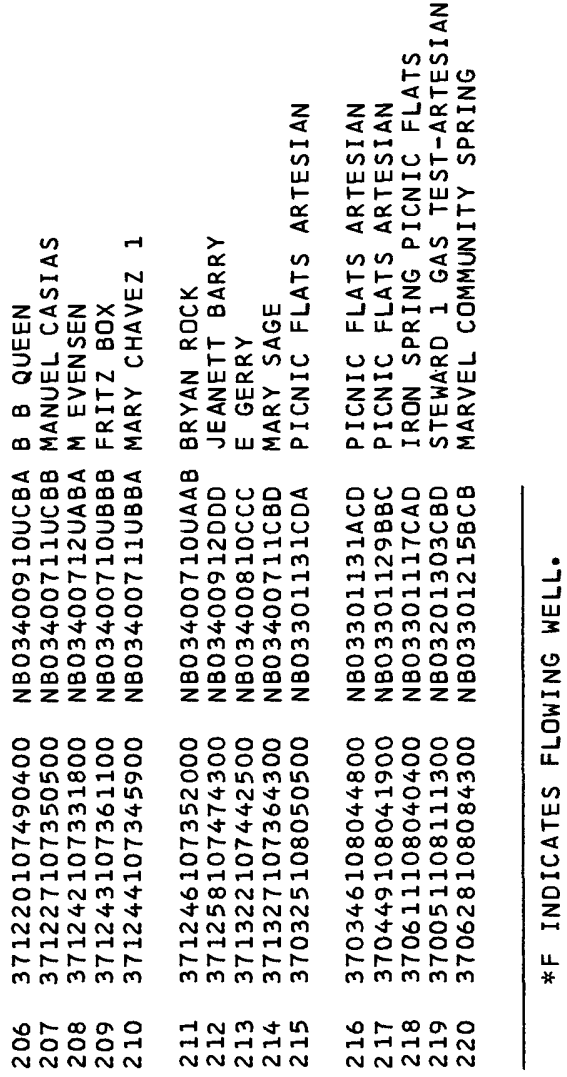




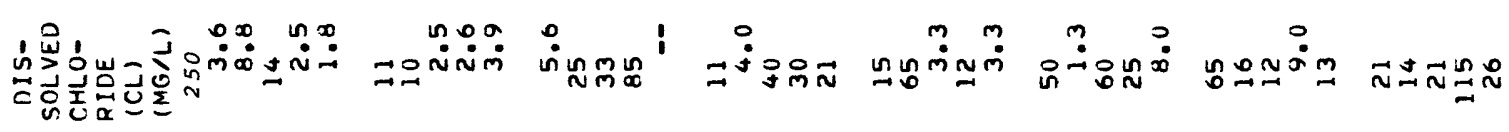

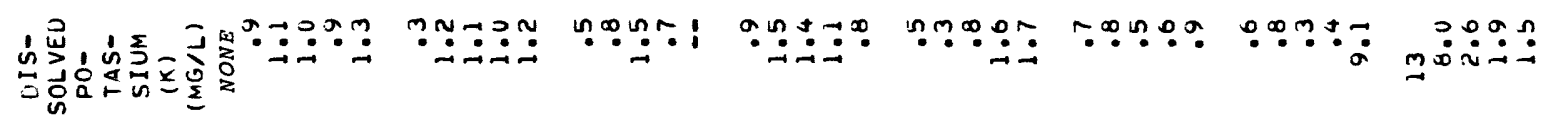

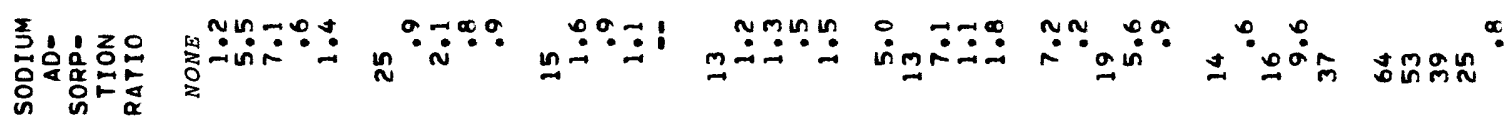

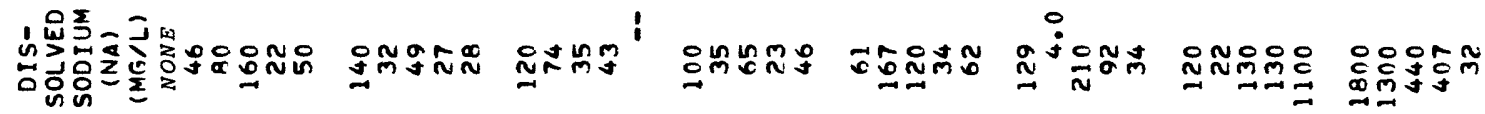

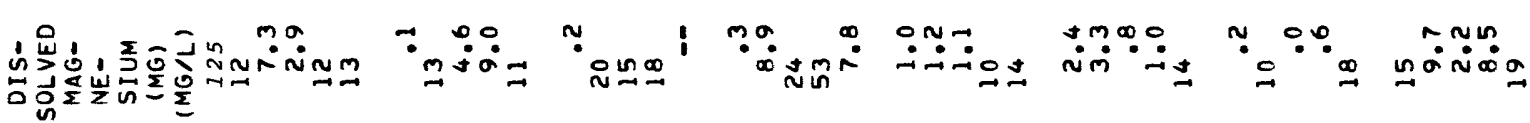

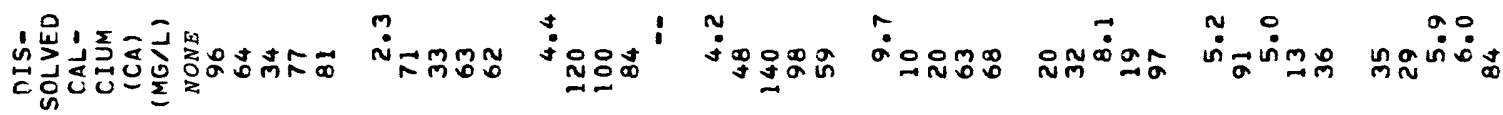

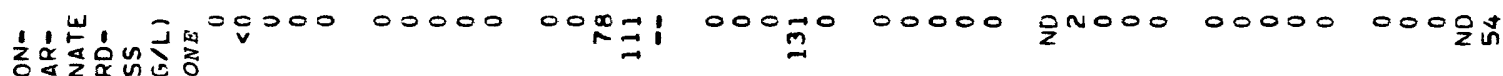

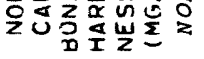

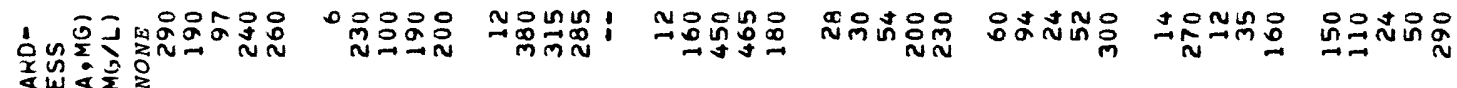

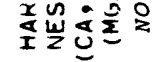

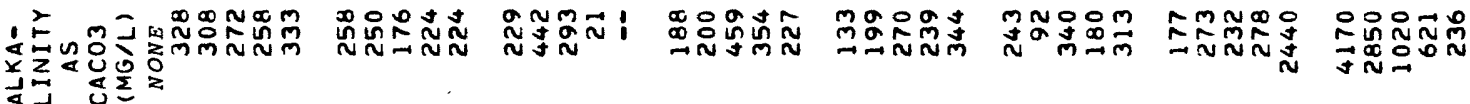

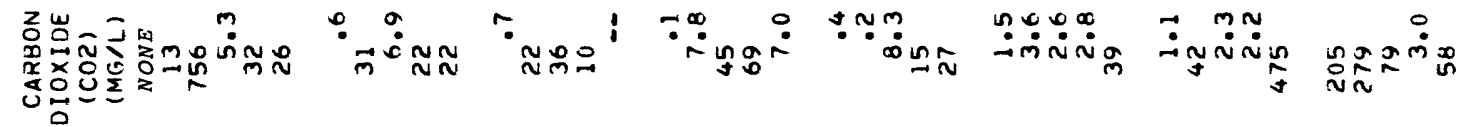

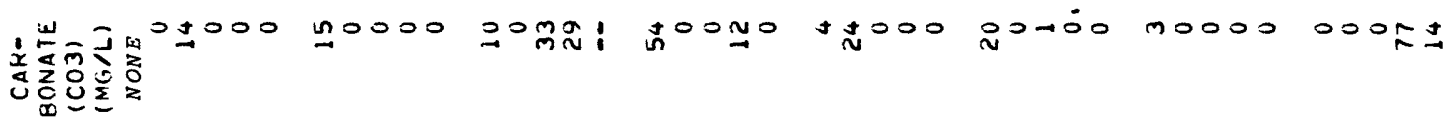

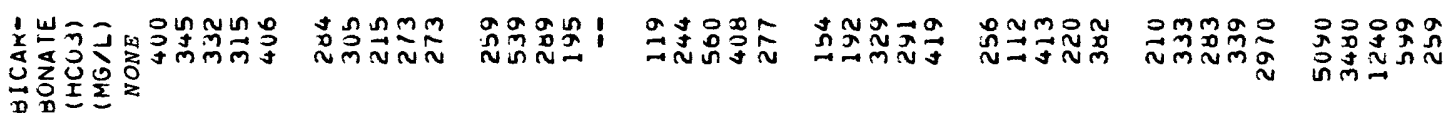

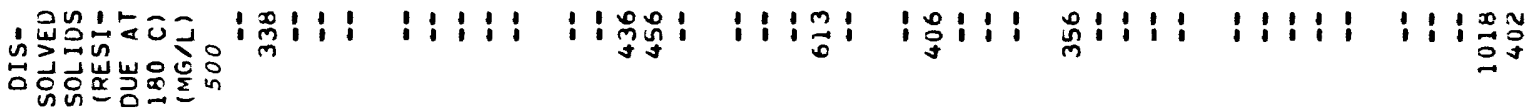

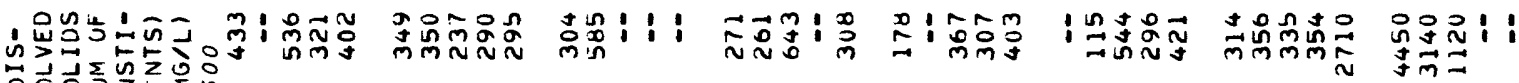

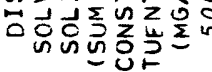

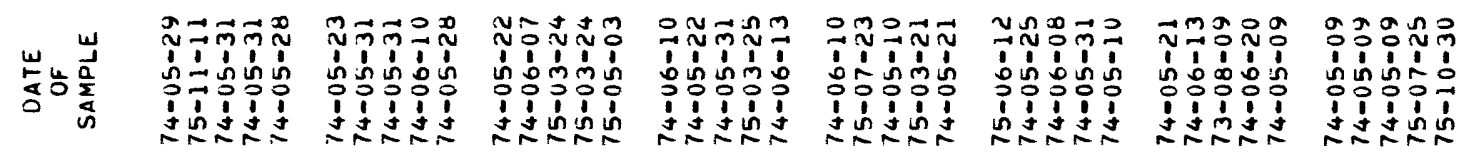




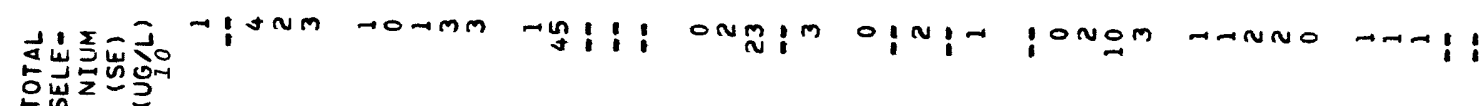

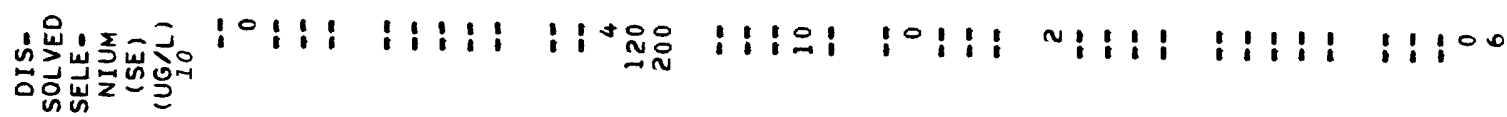

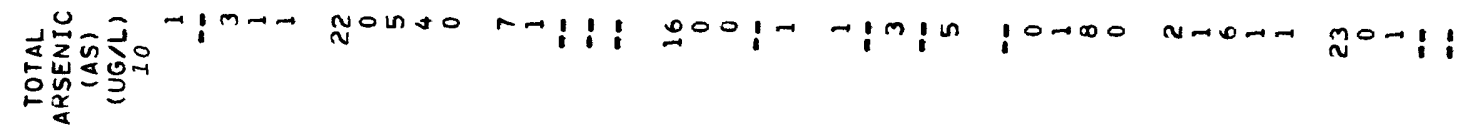

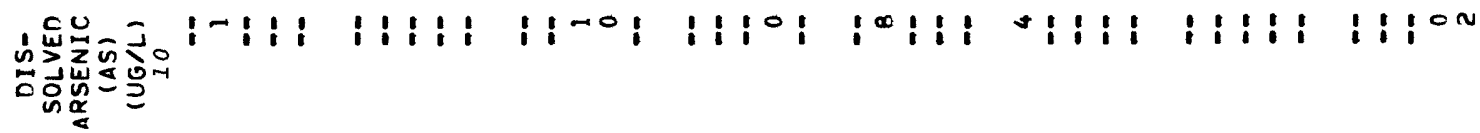

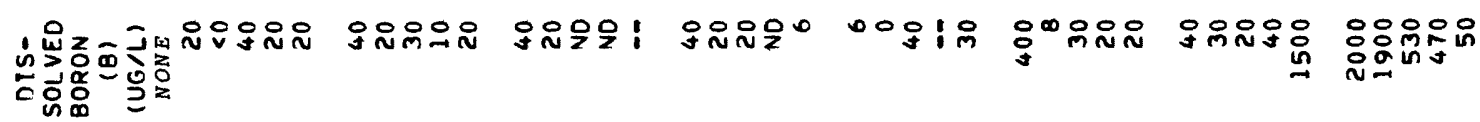

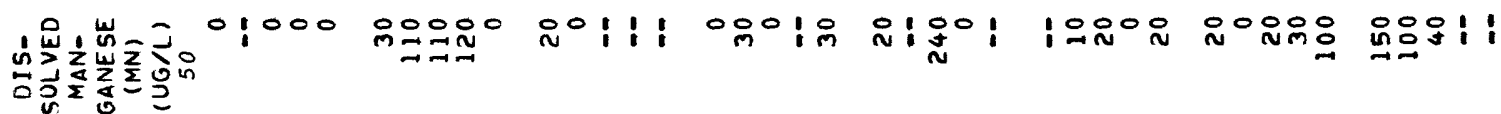

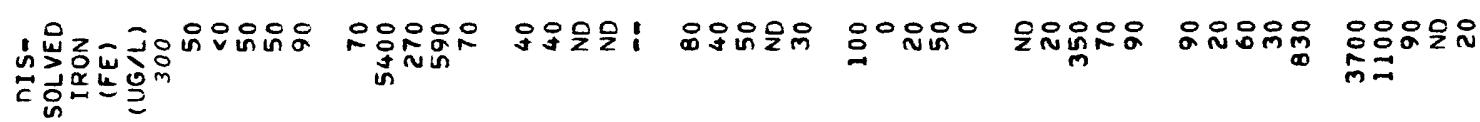

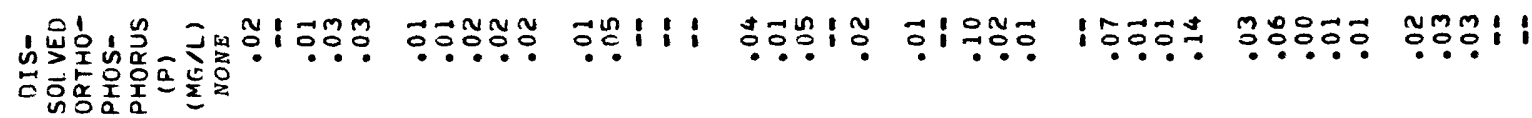

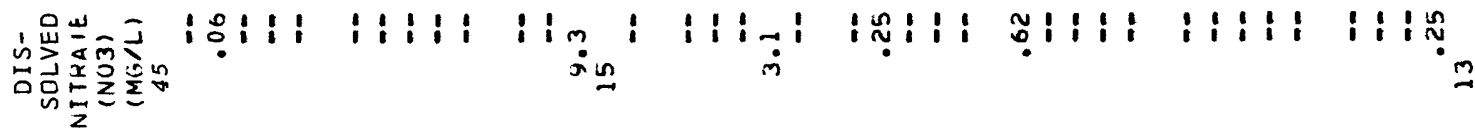

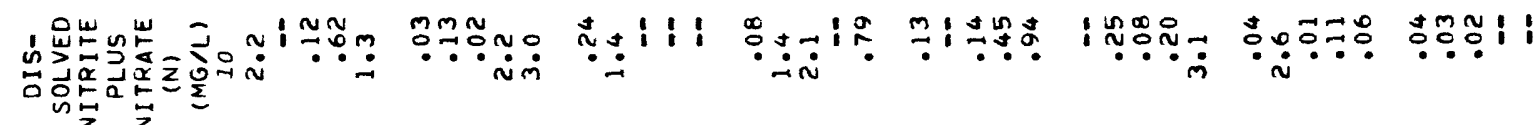
.

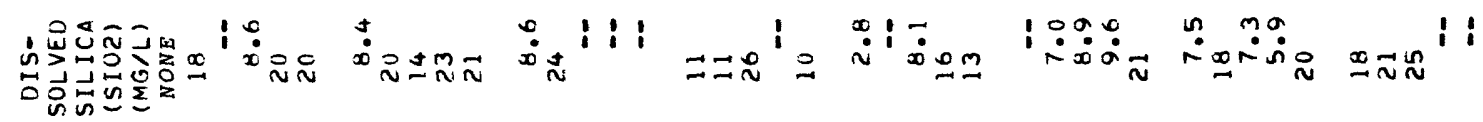

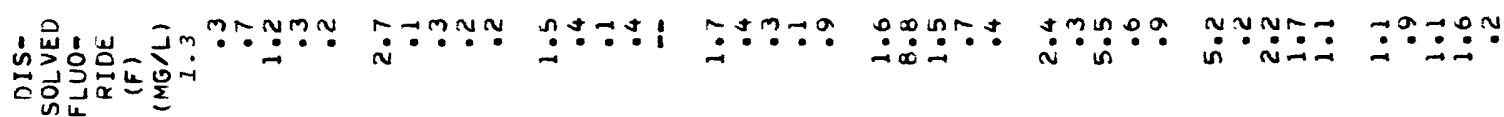

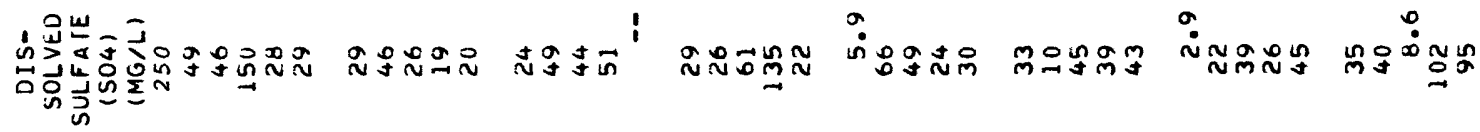

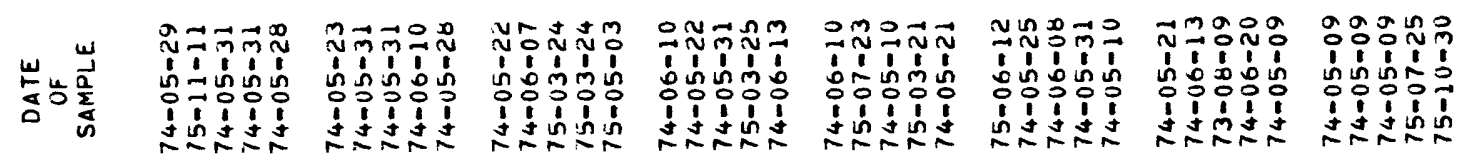




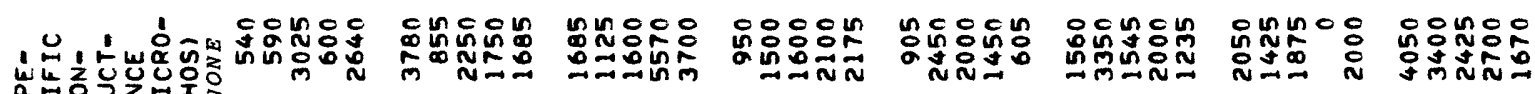

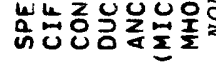

I

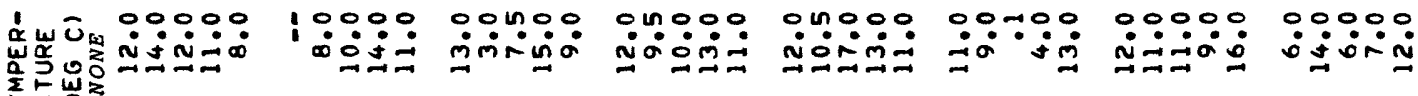

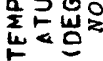

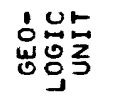

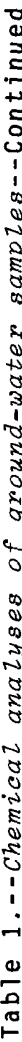

崖台崖

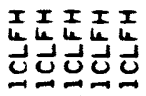
$\bar{\pi} \pi \pi \bar{n}$

우우ำำ

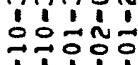

穴可可的

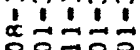

等

ninges

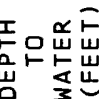

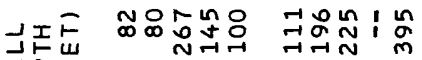

亗岲岃

$\stackrel{\infty}{\sim} \mid m^{*}+$

$\lim$ 츛

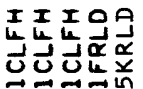

สลतส추

Bำบำ

i่า实

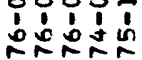

兌：先！！

1!禹! !

an:

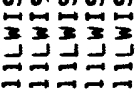

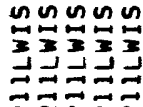

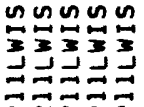

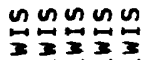

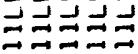

สaña

กำกิบี

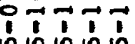

rantán

ลกล๊̃

กลกล

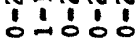

Tि7子T

옹ำก

00Omo

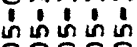

iopio

Tio

n⿺⿻一𠃋十

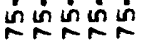

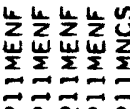

$\vec{\pi} \pi \approx \pi$

ํํำ-的品

วิํํㅇํำ

年

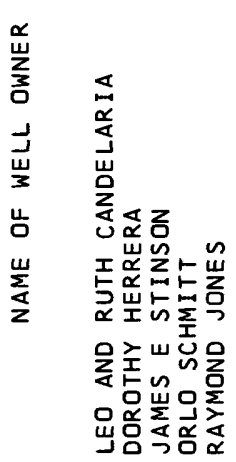

通

依

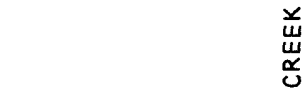

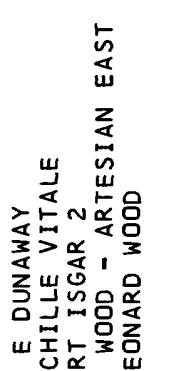

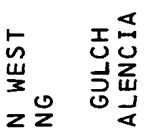

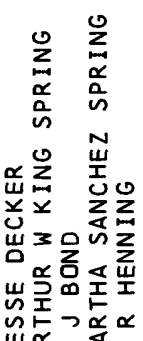

古

어누임

웅ㅇㅇㅇㅇ

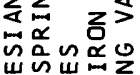

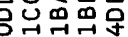

和造员

N거엄

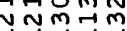

잉엉ㅇㅇ

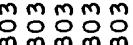

구 $\rightarrow$ 군

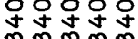

웅웅응

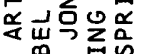

1 选的紫品

吕战的竞

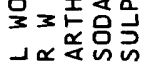

出选レ这口

包安造这电

品品战这

이윽응으

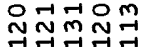

웅어윰이

mํํำ

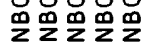

ธ్ㅐ에에

$-\mathfrak{m} N \tilde{N} N$

엉이임잉이

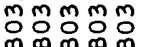

乙得盟

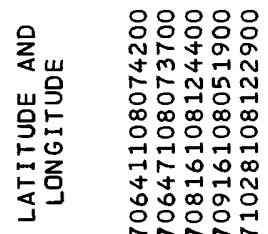

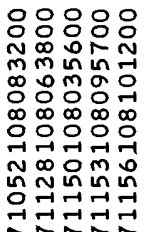

융유응

败

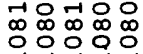

고ำกั

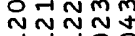

備解

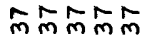

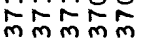

这交紊总

NNNNN

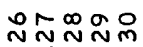

m $\tilde{m} m$ mm

응ㅇ

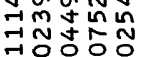

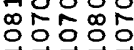

NNNNกำ

옹ํำ

minmm

ํำm

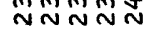

岃

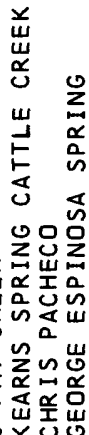$$
\text { (1) }
$$

出

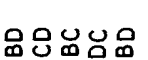

so

TNㅜN

잉유우

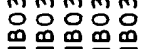

4au

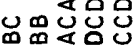

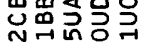

N $\tilde{N} 7 \exists]$

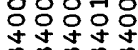

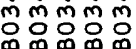

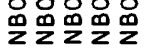

m呈 呈

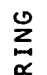

总

구음

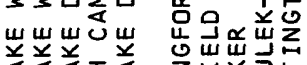

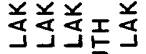

뜬한맘

路品品

过过出

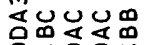

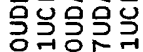

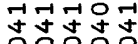

응ㅇㅇㅇㅇㅇ

mํํํํํํㅁ

乙畀得品

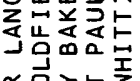

岕口乞要

的素口

面路品

诰罗

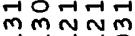

궁덩ㅎㅇㅇㅇㅇ

음음음

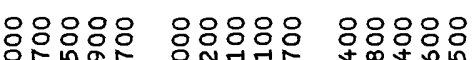

ㅇ:ㅇ

능ㅇㅇㅇㅇ음

둥도옹

윙용

응응응

응ㅇㅇㅇㅇㅡ

N

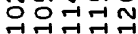

mmmm

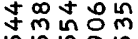

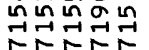

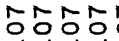

经去尔

NNNN

minmon

Nin士

$\rightarrow-75$

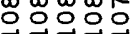

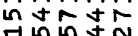

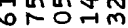

mmmmón

TNMten

우요웅

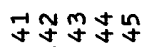

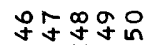

กิกกำ

NNNÑo 


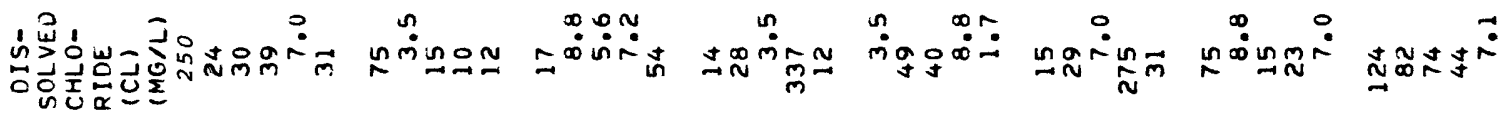

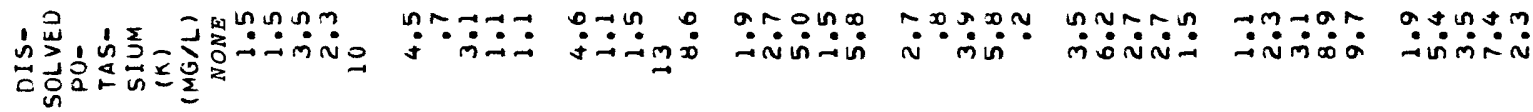

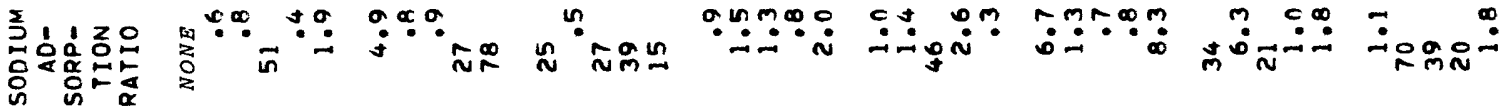

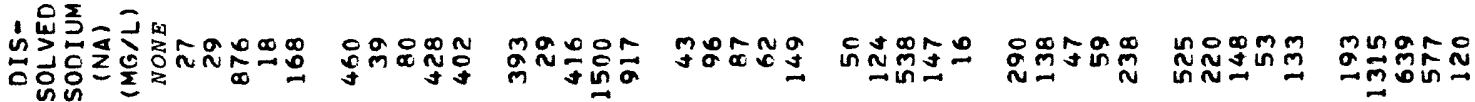

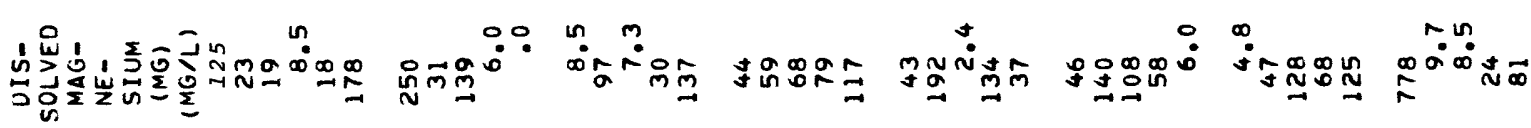

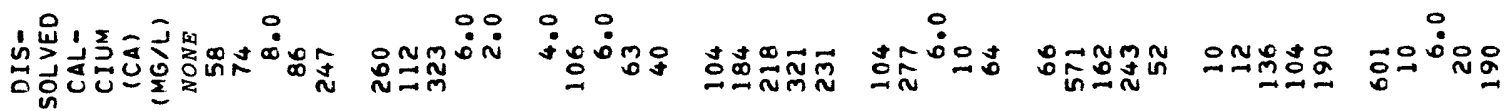

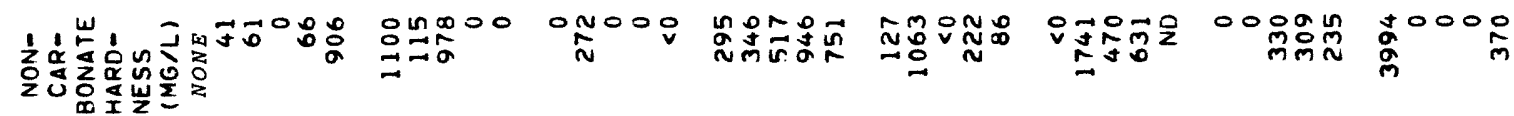

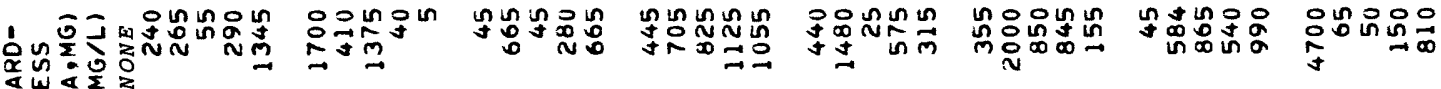

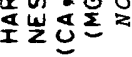

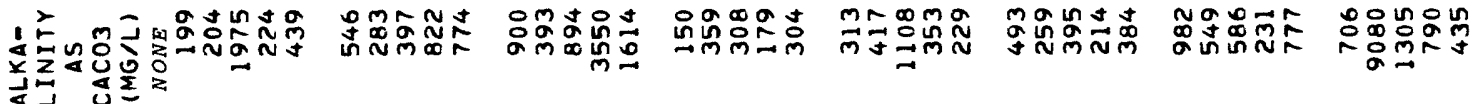

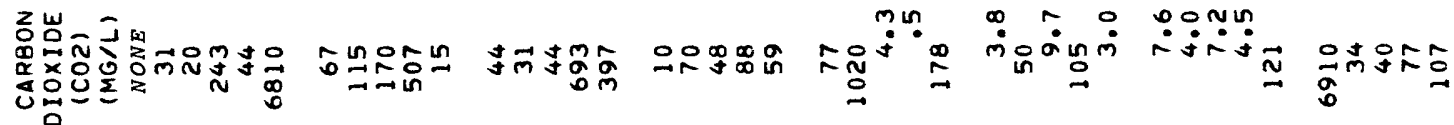

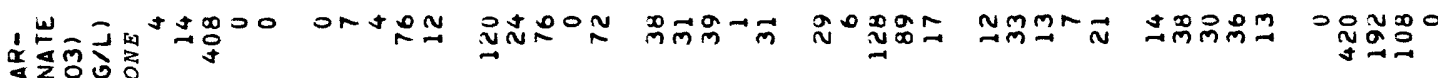

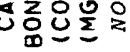

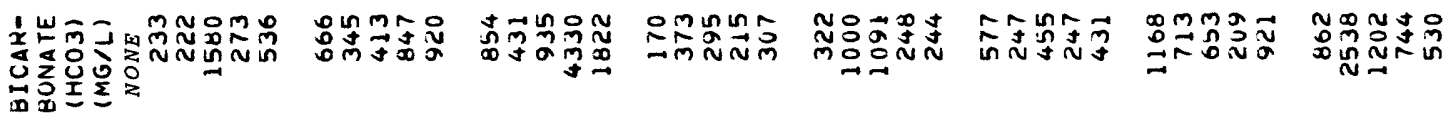

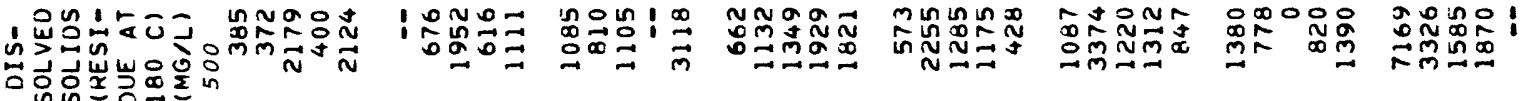

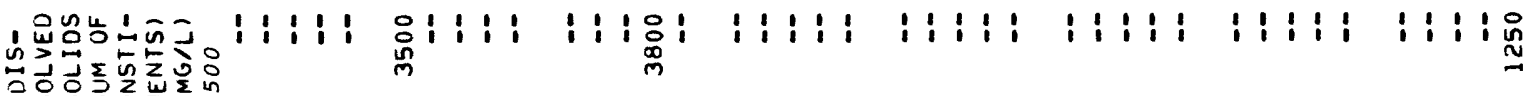

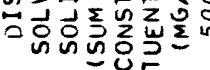

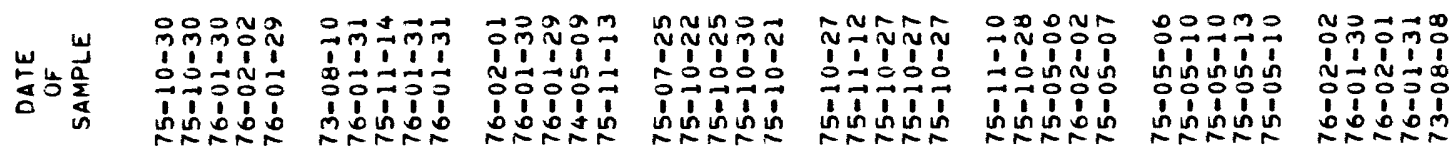




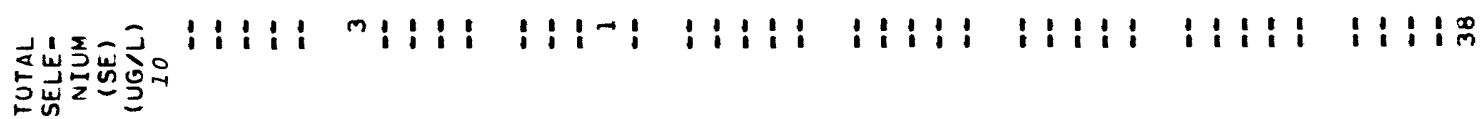

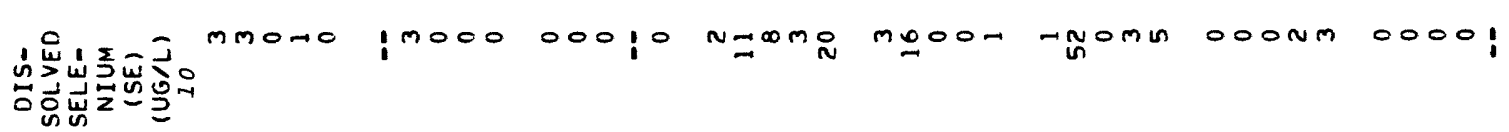

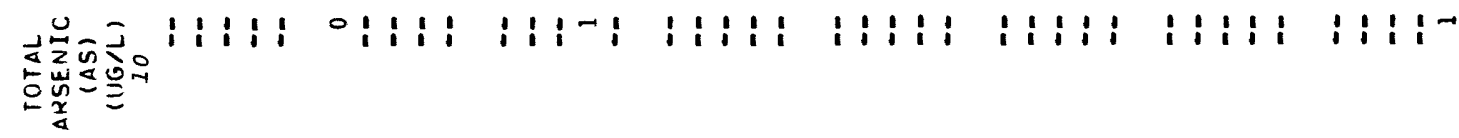

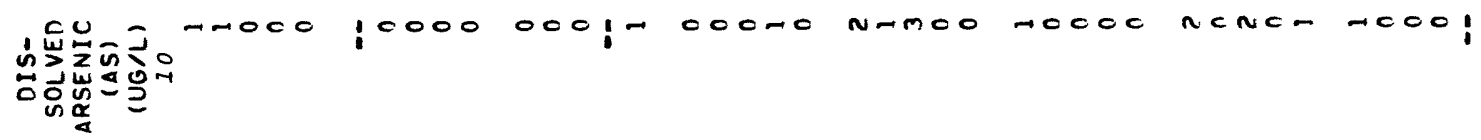

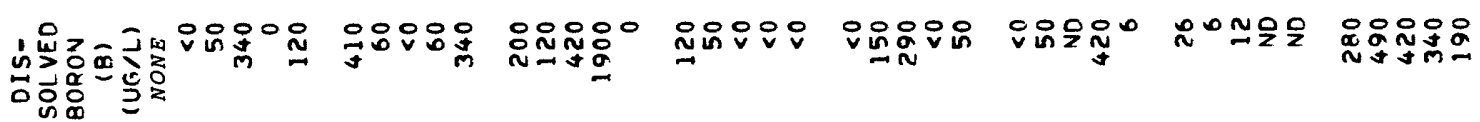

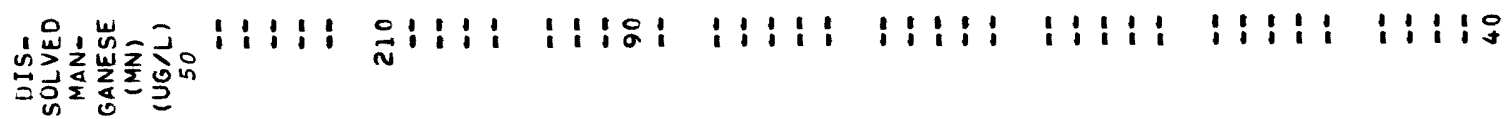

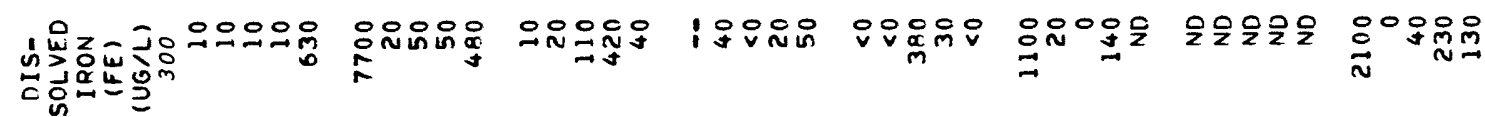

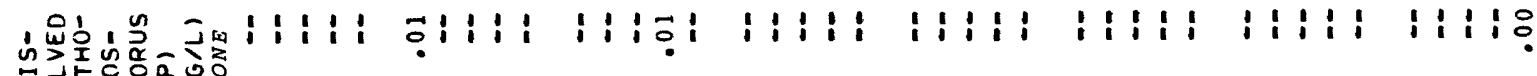

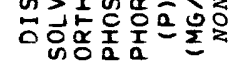

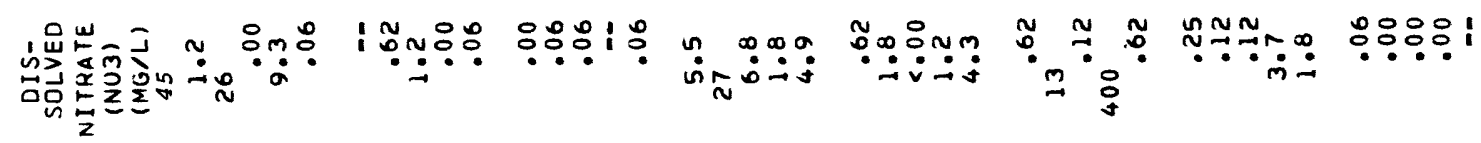

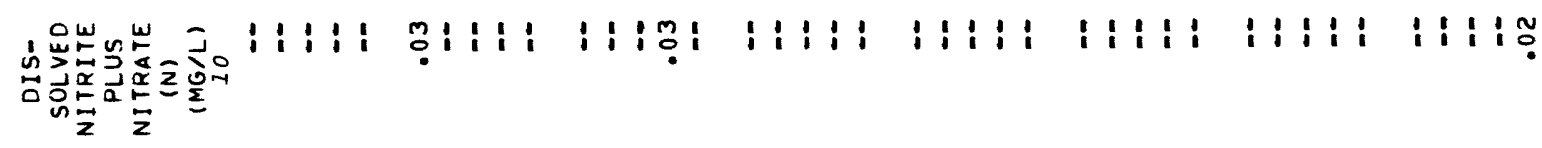

$\underset{\sim}{\stackrel{0}{\circ}}$

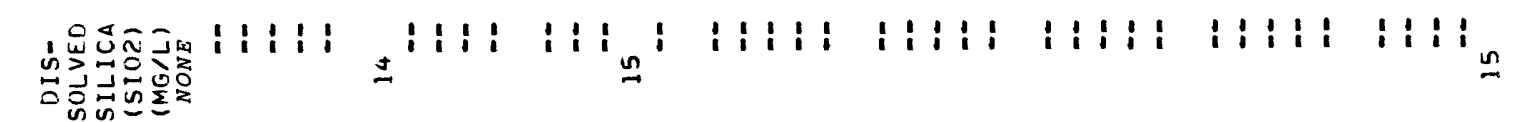

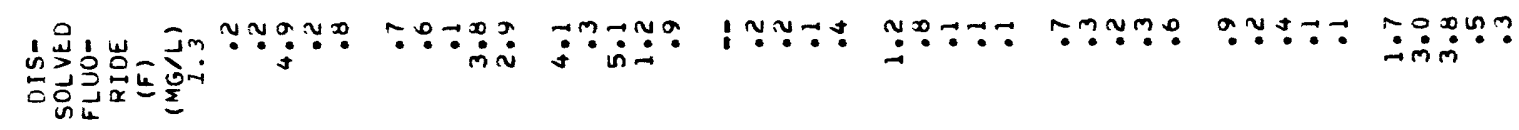

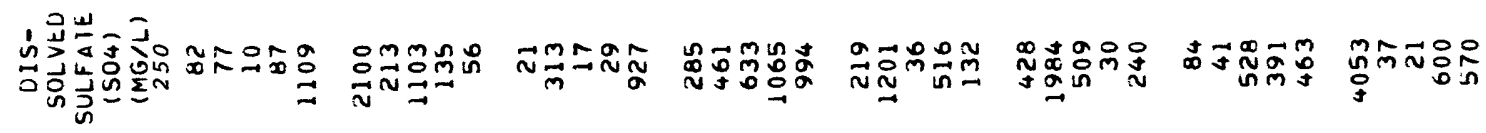

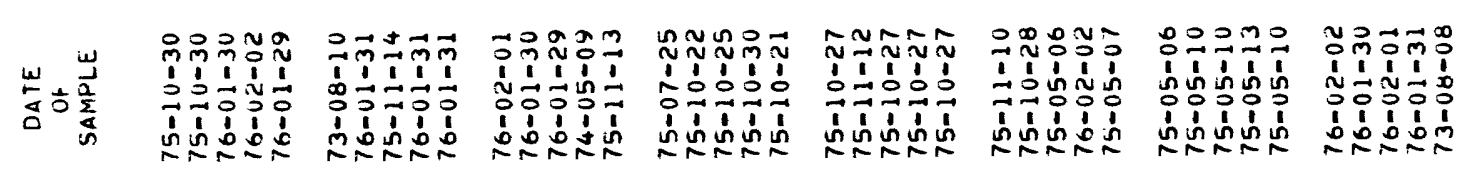




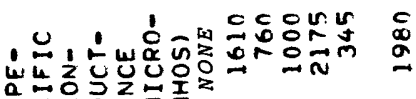

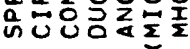

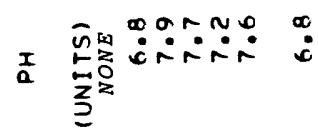

duำ

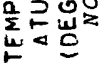

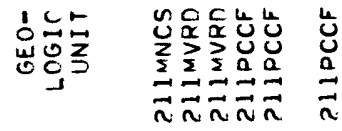

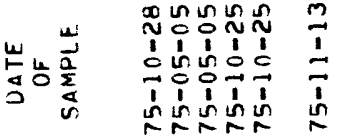

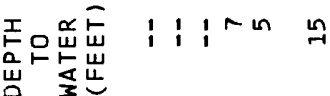

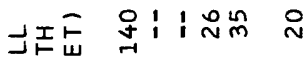

똟쓴

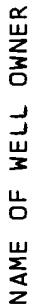

$\sum_{\substack{2 \\ 0}}^{2}$

必艺

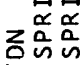

tou罗

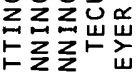

到㟧岗

웅원곤

象贺文

ㅇํㅇํํ워

z

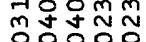

ㅇㅇㅇ응

mํํํํํํํํำ

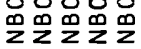

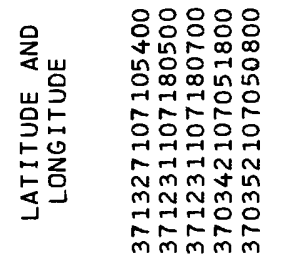

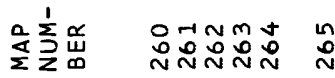

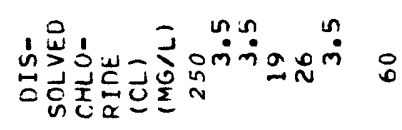

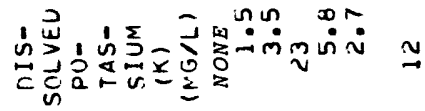

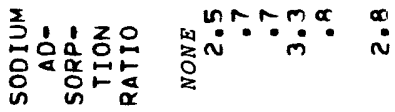

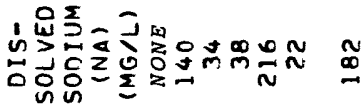

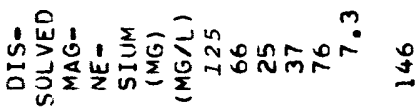

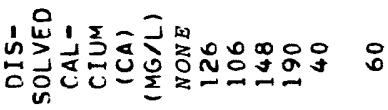

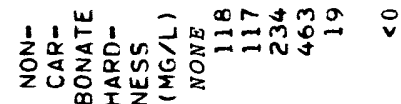

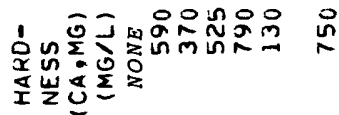

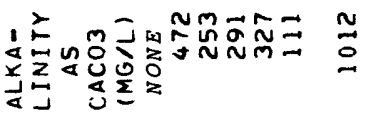

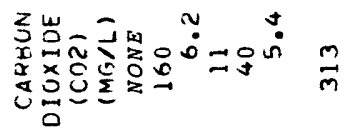

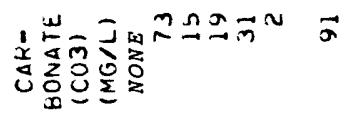

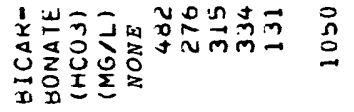

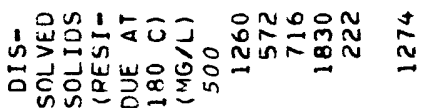

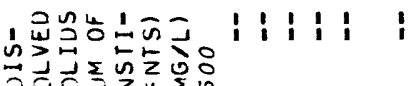

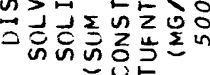

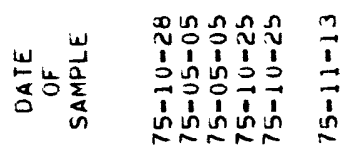

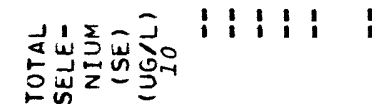

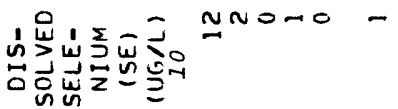

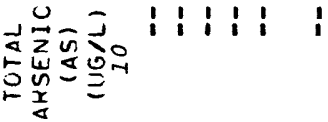

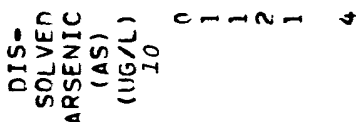

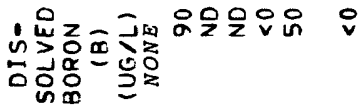

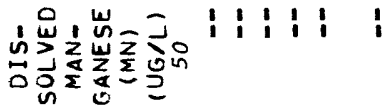

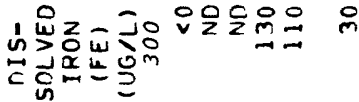

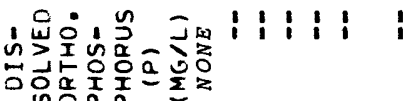

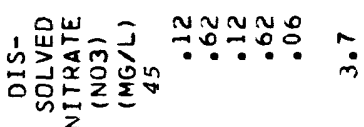

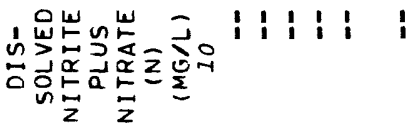

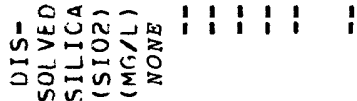

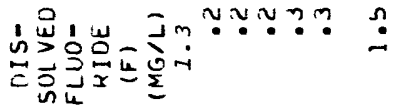

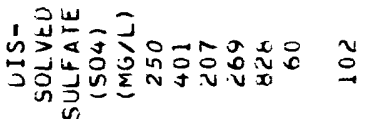

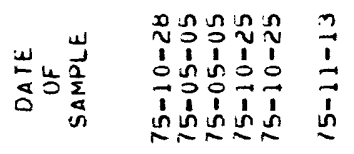




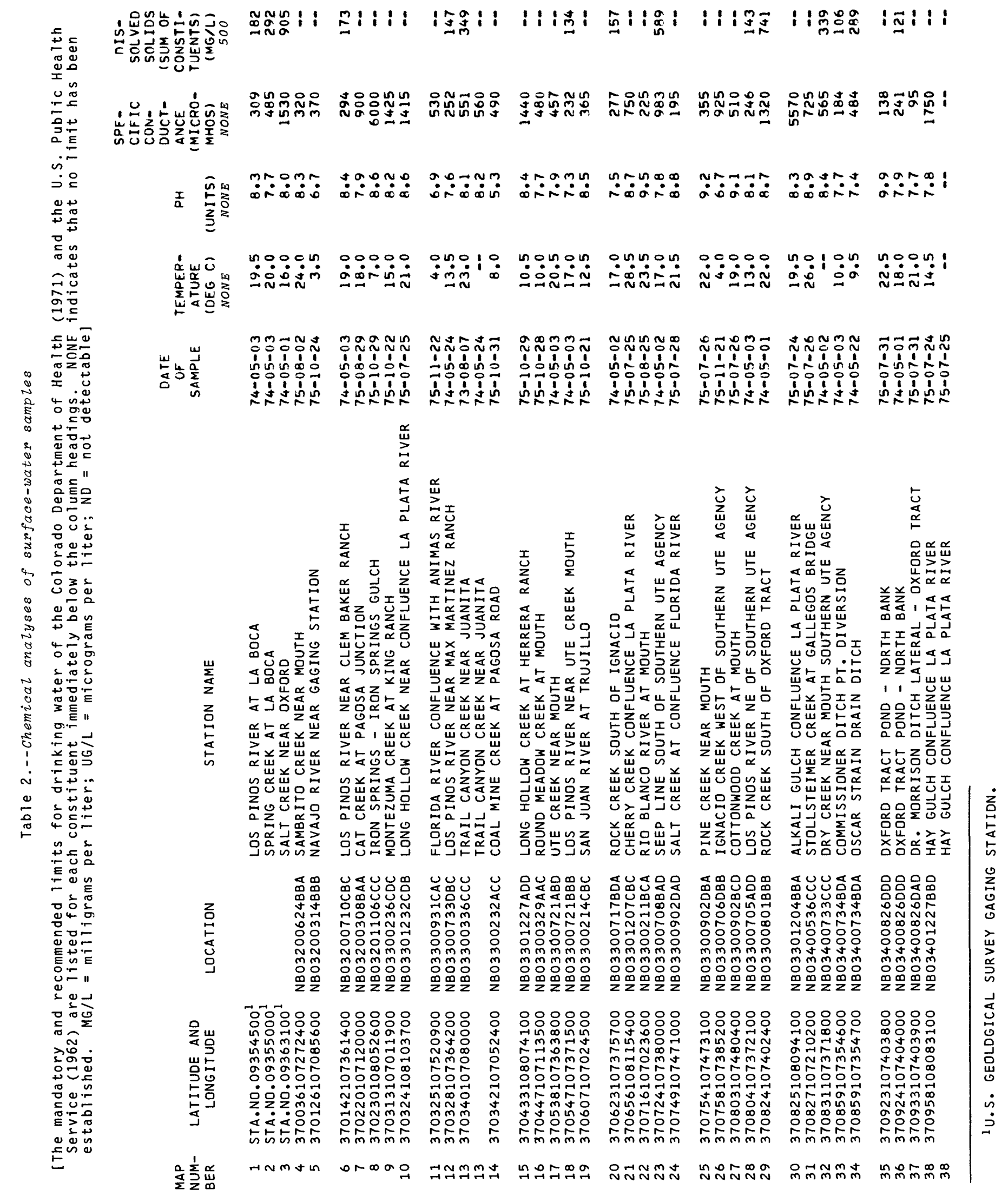




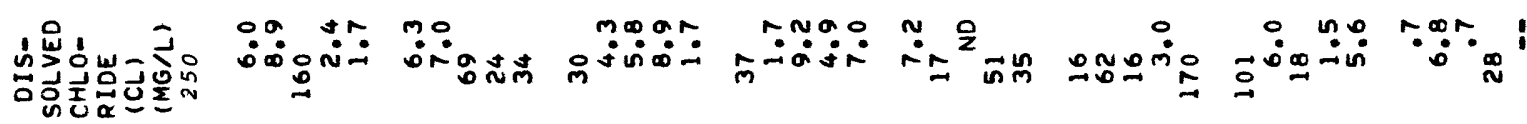

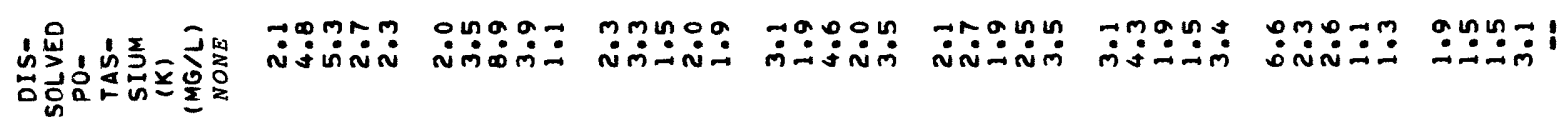

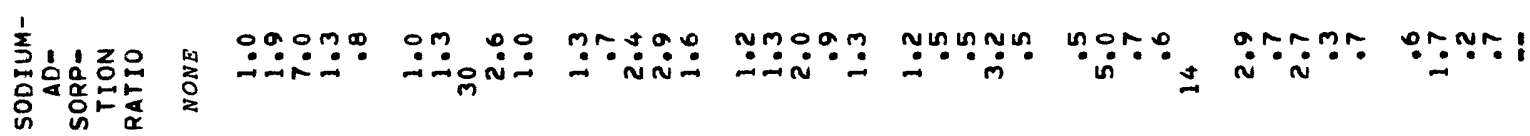

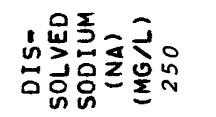

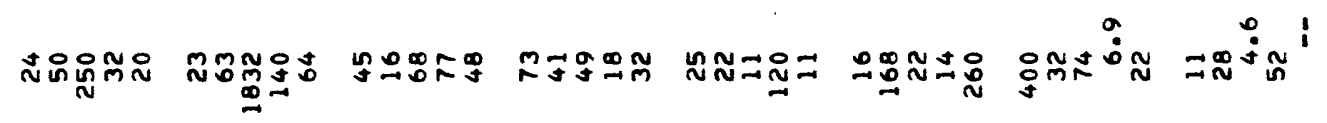

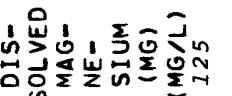

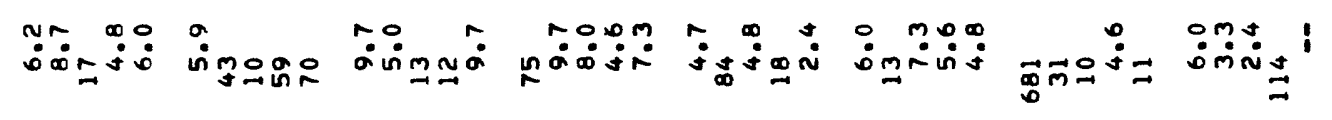

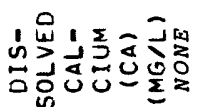

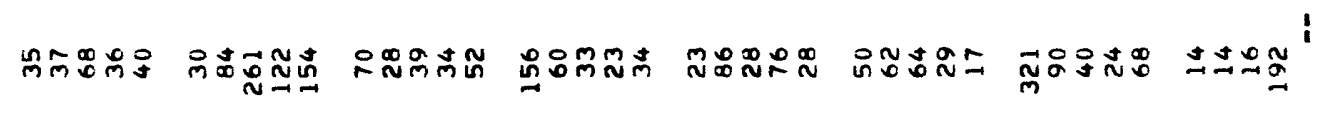

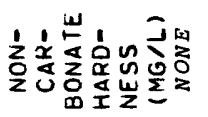

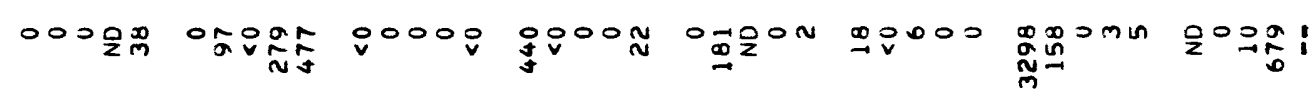

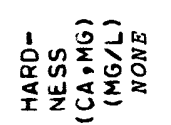

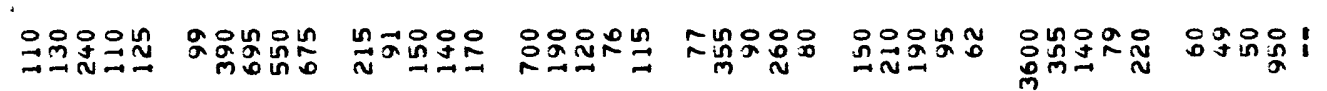

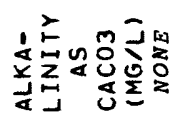

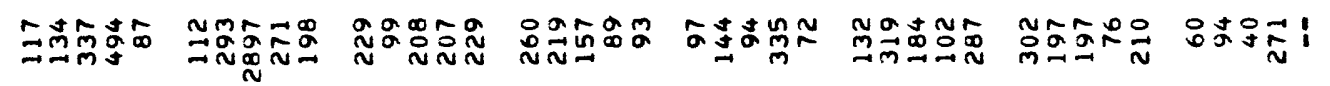

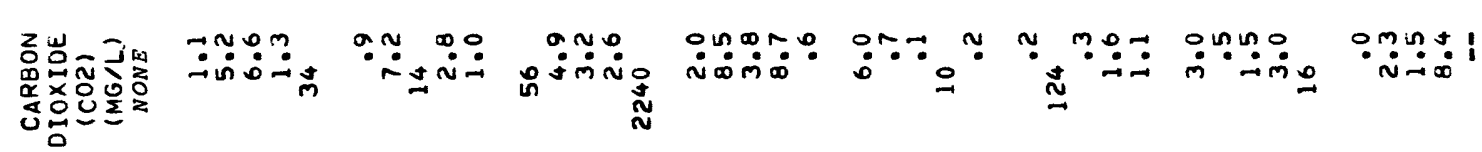

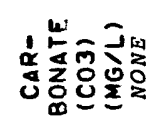

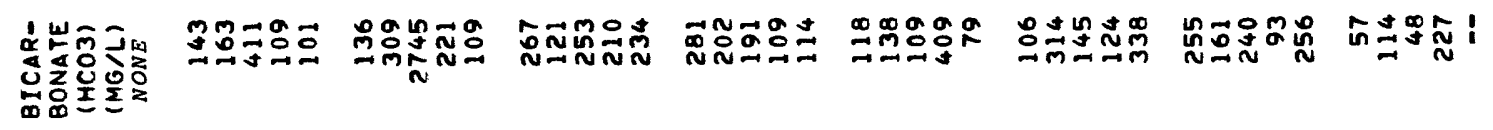

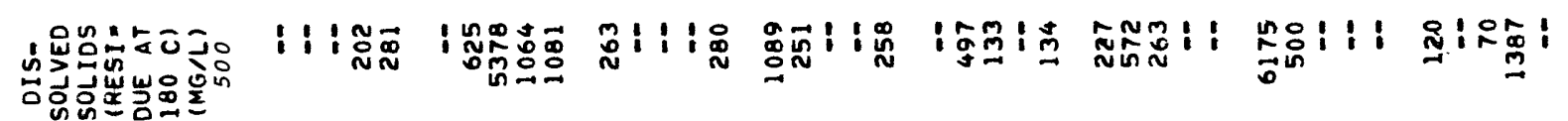

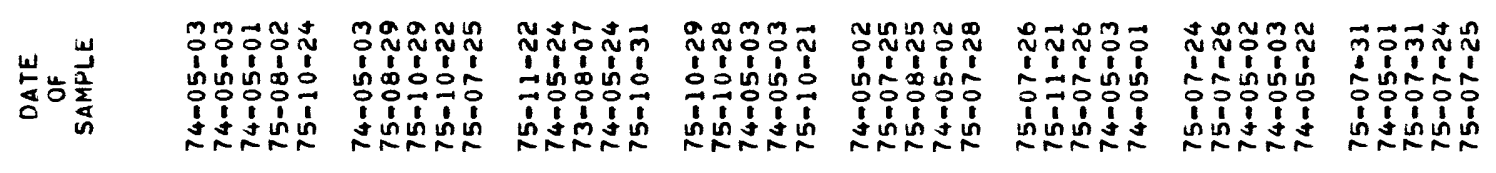




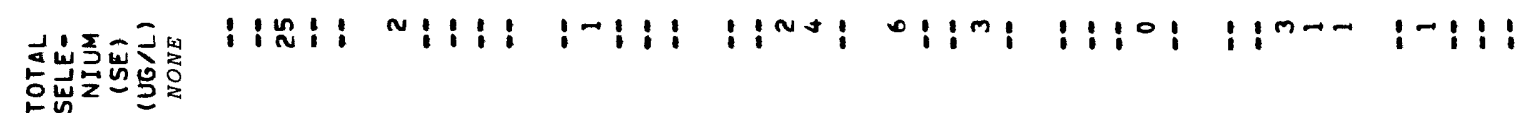

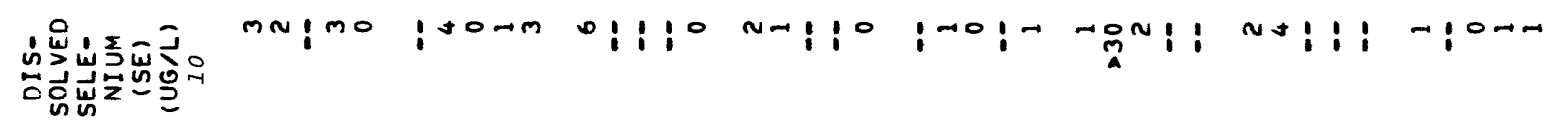

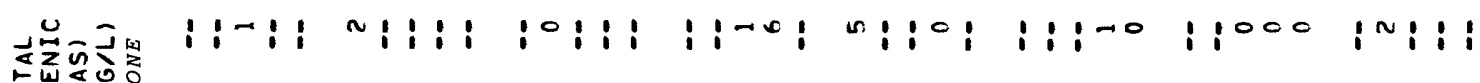

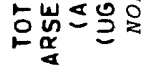

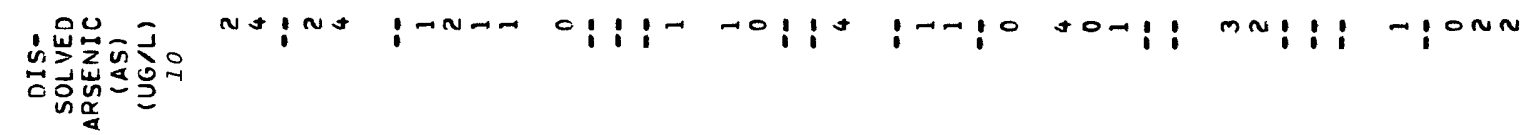

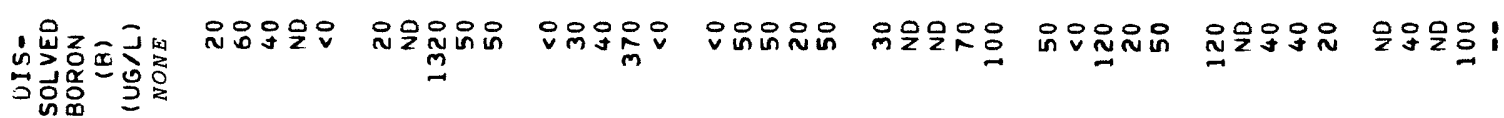

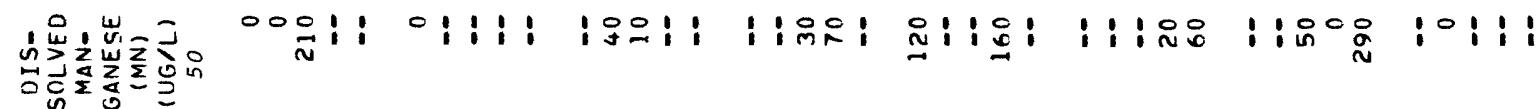

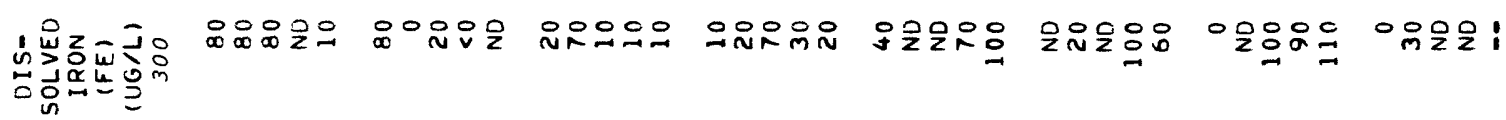

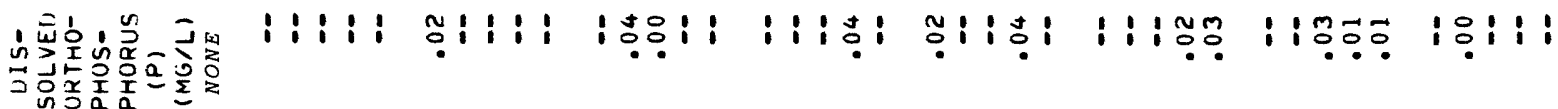

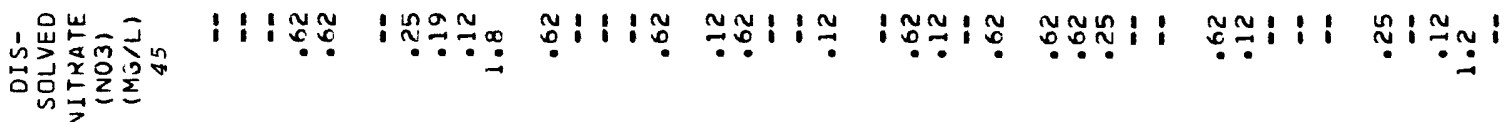

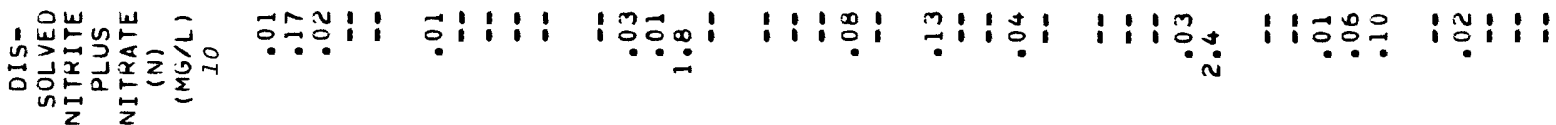

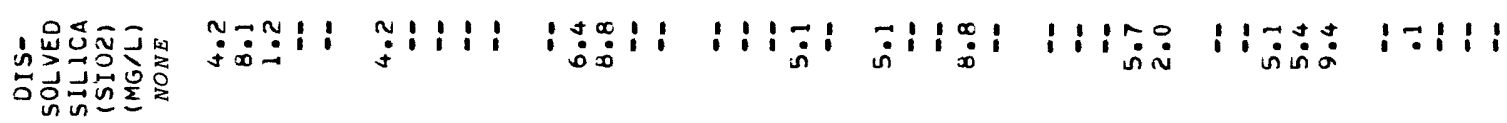

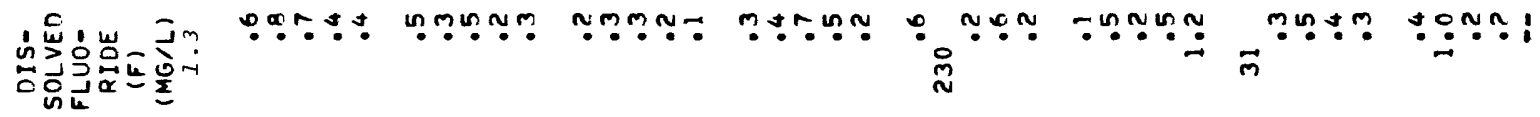

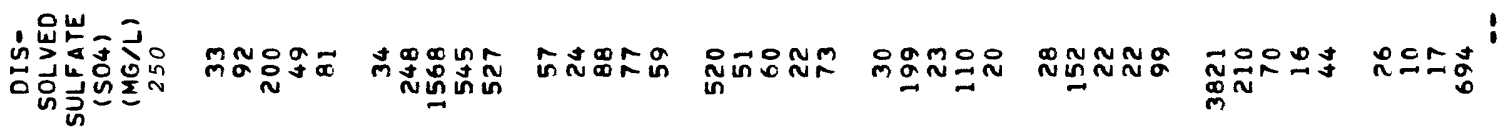

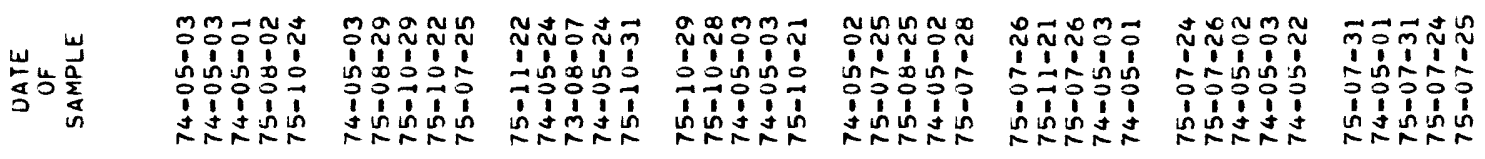




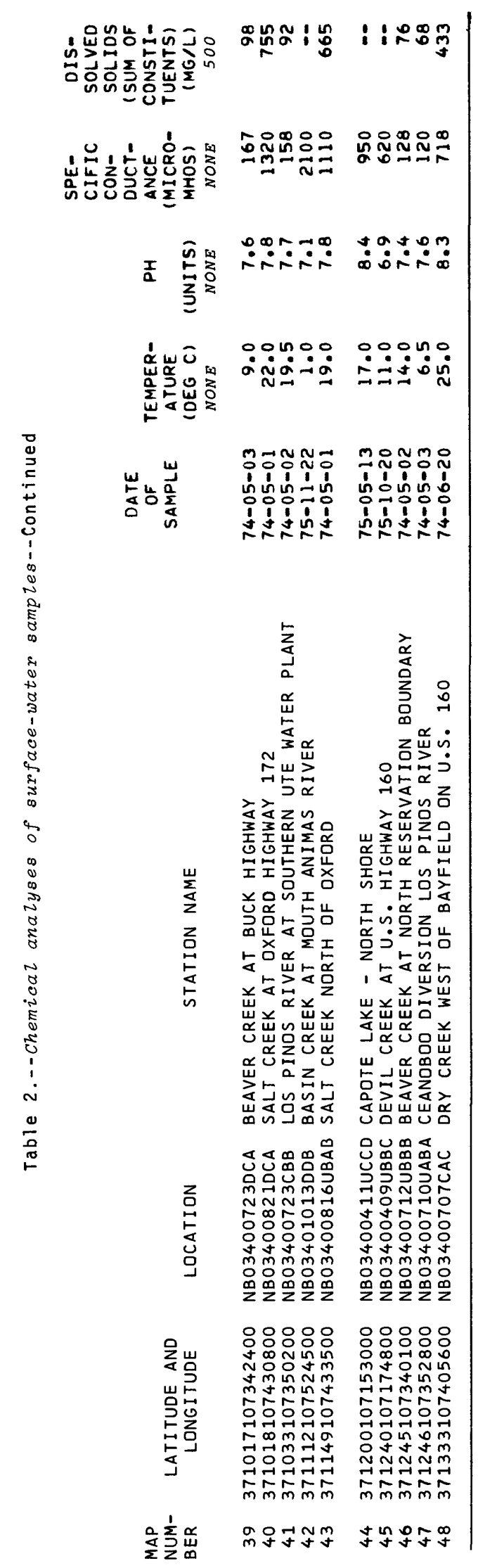




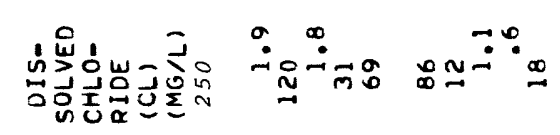

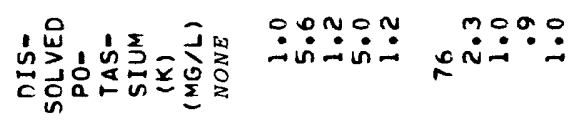

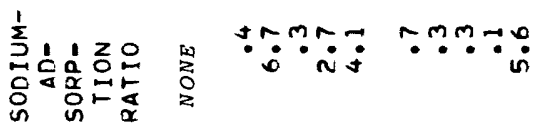

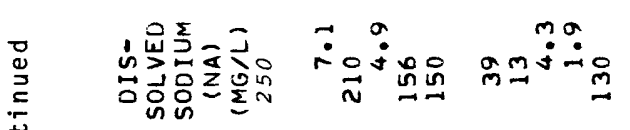

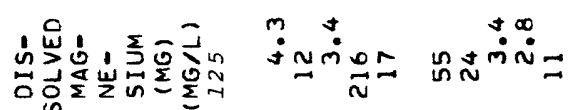

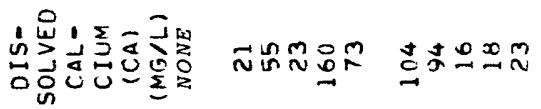

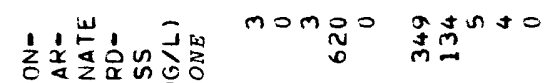

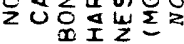

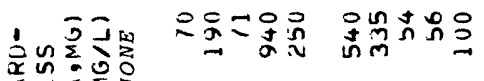

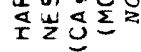

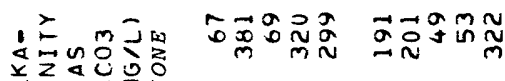

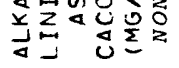

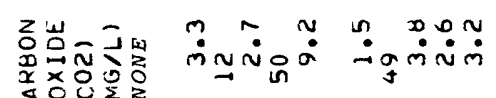

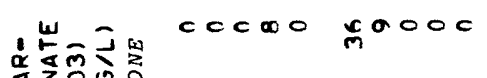

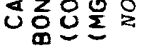

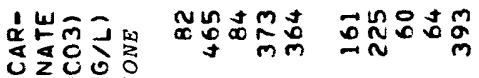

$$
\begin{aligned}
& \text { 路全交 }
\end{aligned}
$$

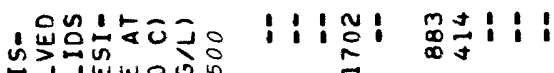

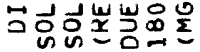

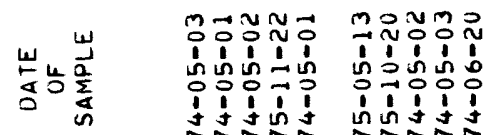




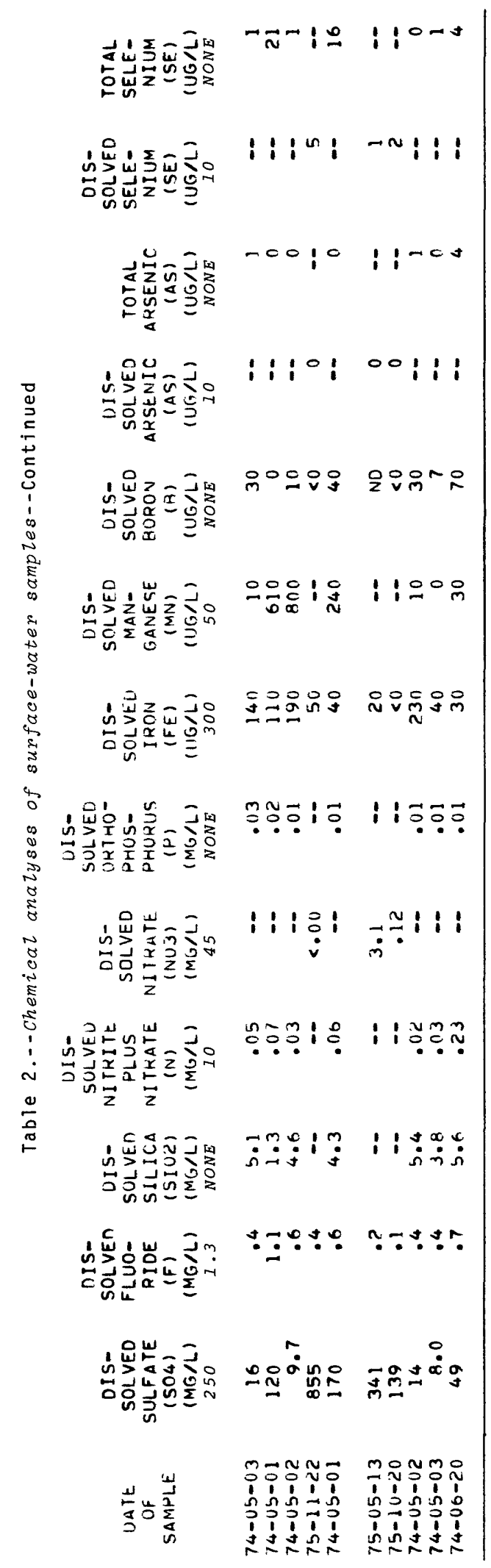

